National Toxicology Program

NTP DEVELOPMENTAL AND

REPRODUCTIVE TOXICITY

TECHNICAL REPORT ON THE

PRENATAL DEVELOPMENT

STUDIES OF

DIMETHYLAMINOETHANOL

BITARTRATE

(CASRN 5988-51-2) IN

SPRAGUE DAWLEY

(HSD:Sprague DaWley ${ }^{\circledR}$ SD $^{\circledR}$ )

Rats (Gavage Studies)

NTP DART 04

JUNE 2020 


\title{
NTP Developmental and Reproductive Toxicity Technical Report on the Prenatal Development Studies of Dimethylaminoethanol Bitartrate (CASRN 5988-51-2) in Sprague Dawley (Hsd:Sprague Dawley ${ }^{\circledR}$ SD $^{\circledR}$ ) Rats (Gavage Studies)
}

DART Report 04

June 2020

\author{
National Toxicology Program \\ Public Health Service \\ U.S. Department of Health and Human Services
}

ISSN: 2690-2052

Research Triangle Park, North Carolina, USA 


\section{Foreword}

The National Toxicology Program (NTP), established in 1978, is an interagency program within the Public Health Service of the U.S. Department of Health and Human Services. Its activities are executed through a partnership of the National Institute for Occupational Safety and Health (part of the Centers for Disease Control and Prevention), the Food and Drug Administration (primarily at the National Center for Toxicological Research), and the National Institute of Environmental Health Sciences (part of the National Institutes of Health), where the program is administratively located. NTP offers a unique venue for the testing, research, and analysis of agents of concern to identify toxic and biological effects, provide information that strengthens the science base, and inform decisions by health regulatory and research agencies to safeguard public health. NTP also works to develop and apply new and improved methods and approaches that advance toxicology and better assess health effects from environmental exposures.

The NTP Technical Report series for developmental and reproductive toxicity studies began in 2019. The studies described in this NTP Technical Report series (i.e., the NTP DART Report series) are designed and conducted to characterize and evaluate the developmental or reproductive toxicity of selected substances in laboratory animals. Substances (e.g., chemicals, physical agents, and mixtures) selected for NTP reproductive and developmental studies are chosen primarily on the basis of human exposure, level of commercial production, and chemical structure. The interpretive conclusions presented in NTP DART Reports are based only on the results of these NTP studies, and extrapolation of these results to other species, including characterization of hazards and risks to humans, requires analyses beyond the intent of these reports. Selection for study per se is not an indicator of a substance's developmental or reproductive toxicity potential.

NTP conducts its studies in compliance with its laboratory health and safety guidelines and the Food and Drug Administration Good Laboratory Practice Regulations and meets or exceeds all applicable federal, state, and local health and safety regulations. Animal care and use are in accordance with the Public Health Service Policy on Humane Care and Use of Laboratory Animals. Studies are subjected to retrospective quality assurance audits before they are presented for public review. Draft reports undergo external peer review before they are finalized and published.

The NTP DART Reports are available free of charge on the NTP website and cataloged in PubMed, a free resource developed and maintained by the National Library of Medicine (part of the National Institutes of Health). Data for these studies are included in NTP's Chemical Effects in Biological Systems database.

For questions about the reports and studies, please email NTP or call 984-287-3211. 


\section{Table of Contents}

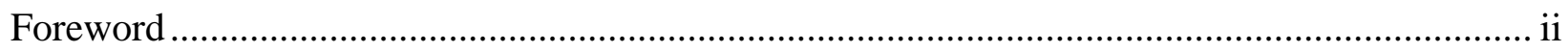

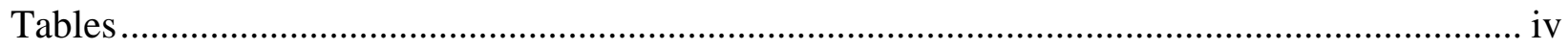

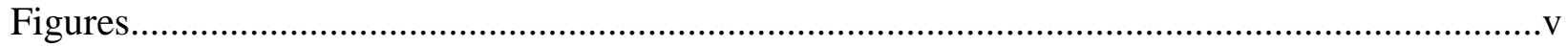

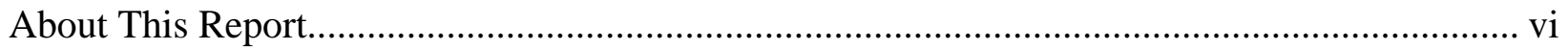

Explanation of Levels of Evidence for Developmental Toxicity ................................................. ix

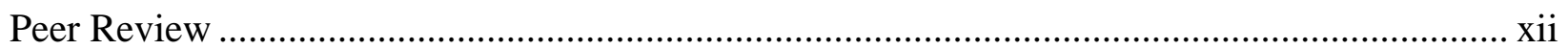

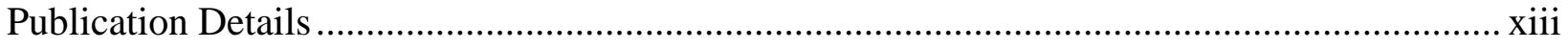

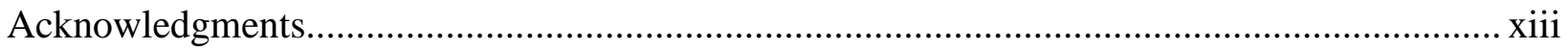

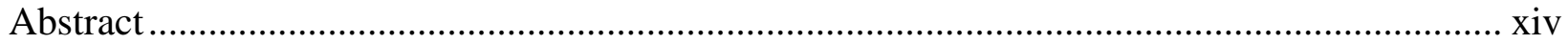

Dose Range-finding Prenatal Developmental Toxicity Study .............................................. xiv

Prenatal Developmental Toxicity Study ........................................................................... xiv

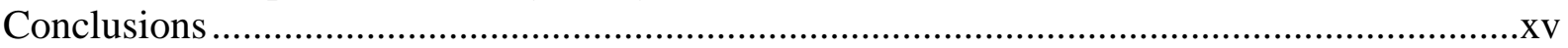

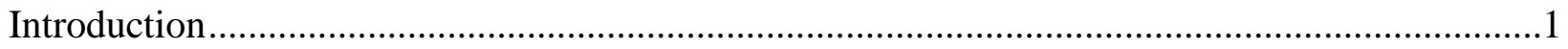

Chemical and Physical Properties.........................................................................................

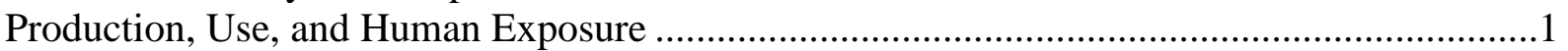

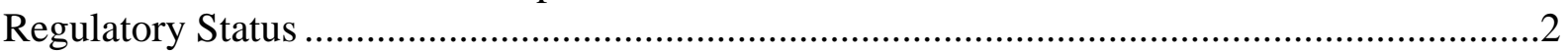

Absorption, Distribution, Metabolism, and Excretion .................................................................

Experimental Animals ..............................................................................................

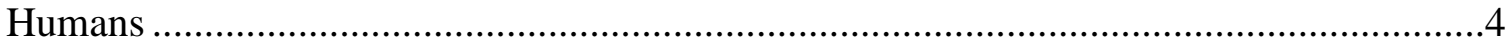

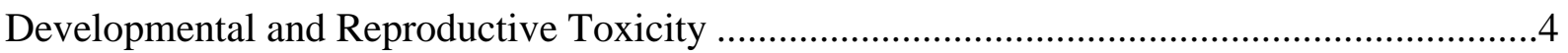

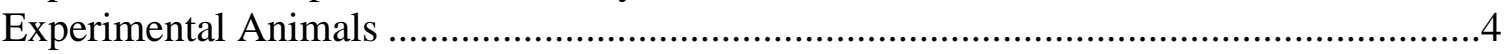

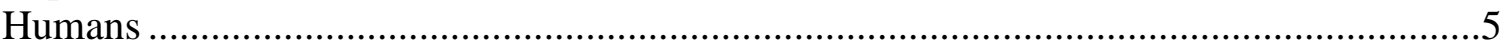

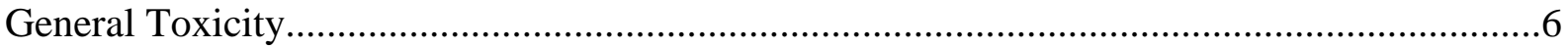

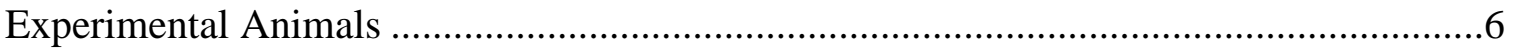

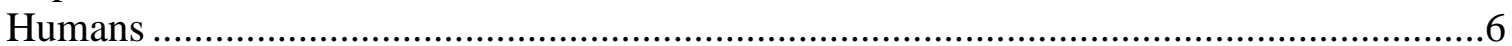

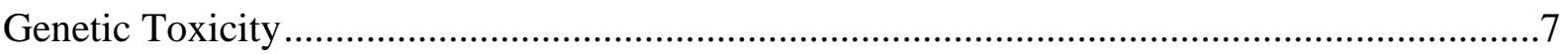

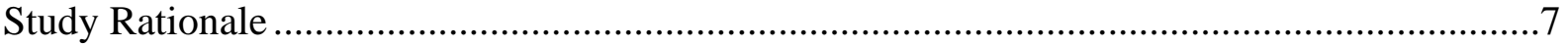

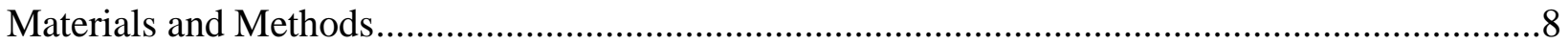

Overview of Prenatal Developmental Toxicity Study Designs ..................................................

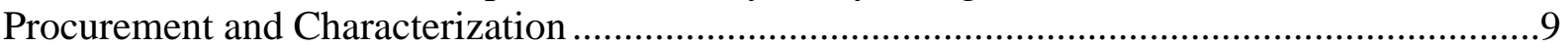

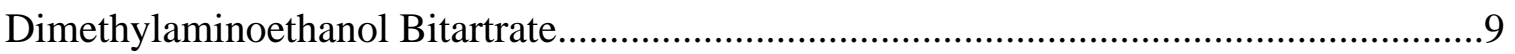

Sterile Water for Irrigation...........................................................................................10

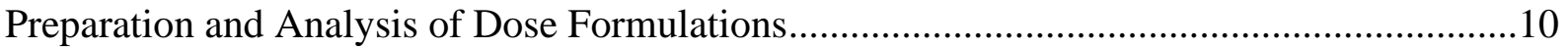

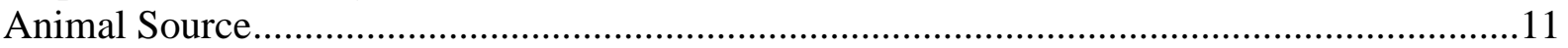

Animal Health Surveillance ..................................................................................................

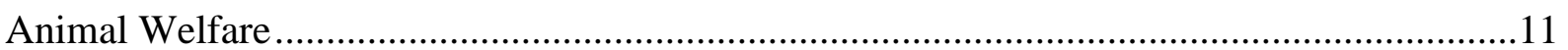

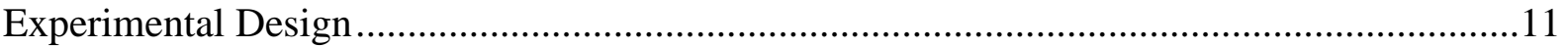

Dose Range-finding Study ...........................................................................................12

Prenatal Developmental Toxicity Study …………….....................................................12

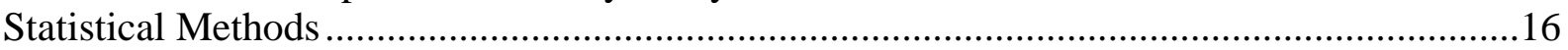




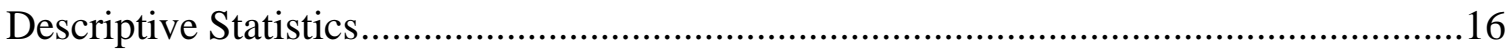

Analysis of Maternal Parameters and Uterine Contents .....................................................16

Analysis of Incidences of Gross Pathology and Morphology Findings ............................17

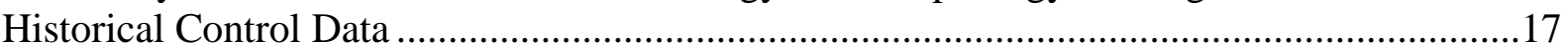

Quality Assurance Methods .....................................................................................................

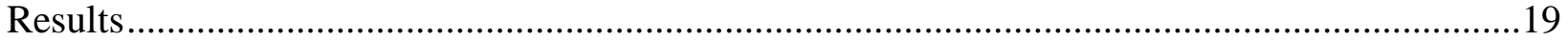

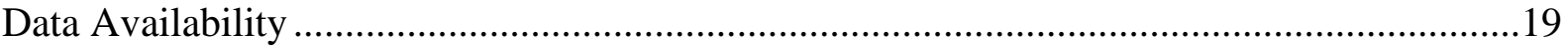

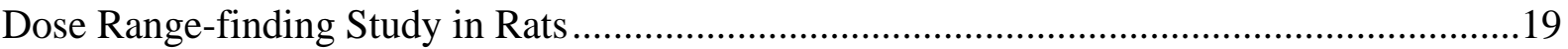

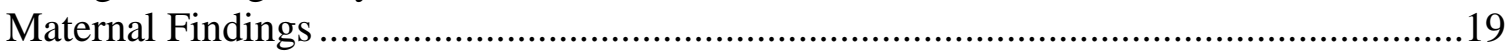

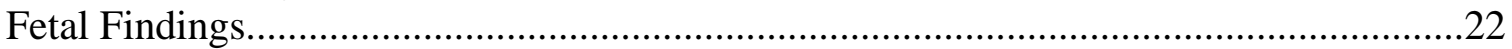

Dose Selection Rationale for the Prenatal Developmental Toxicity Study in Rats...........22

Prenatal Developmental Toxicity Study in Rats ....................................................................23

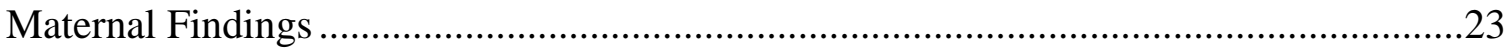

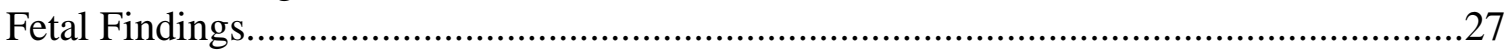

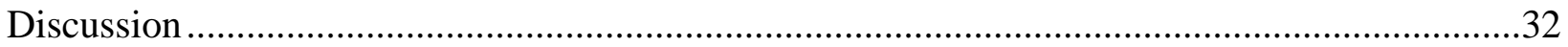

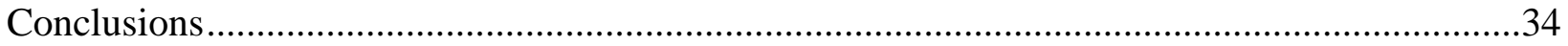

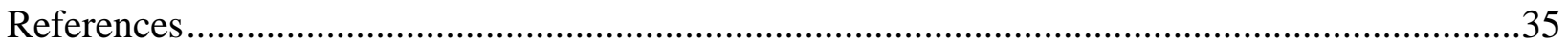

Appendix A. Chemical Characterization and Dose Formulation Studies.................................... A-1

Appendix B. Ingredients, Nutrient Composition, and Contaminant Levels in NIH-07 Rat

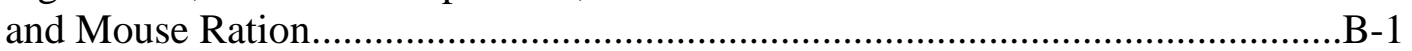

Appendix C. Summary of Peer Review Panel Comments........................................................

Appendix D. Supplemental Files ..........................................................................................

\section{Tables}

Summary of Exposure-related Findings in Rats in the Prenatal Developmental Toxicity

Gavage Study of Dimethylaminoethanol Bitartrate .......................................................... xvi

Table 1. Experimental Design and Materials and Methods in the Dose Range-finding and Prenatal Developmental Toxicity Gavage Studies of Dimethylaminoethanol

Bitartrate in Rats

Table 2. Maternal Disposition of Rats in the Dose Range-finding Gavage Study of Dimethylaminoethanol Bitartrate.............................................................................19

Table 3. Summary of Maternal Body Weight Gains of Rats in the Dose Range-finding Gavage Study of Dimethylaminoethanol Bitartrate........................................................20

Table 4. Summary of Maternal Feed Consumption of Rats in the Dose Range-finding Gavage Study of Dimethylaminoethanol Bitartrate.

Table 5. Summary of Maternal Feed Consumption of Rats in the Dose Range-finding Gavage Study of Dimethylaminoethanol Bitartrate

Table 6. Maternal Disposition of Rats in the Prenatal Developmental Toxicity Gavage Study of Dimethylaminoethanol Bitartrate

Table 7. Summary of Maternal Body Weight Gains of Rats in the Prenatal Developmental Toxicity Gavage Study of Dimethylaminoethanol Bitartrate. 
Table 8. Summary of Maternal Feed Consumption of Rats in the Prenatal Developmental Toxicity Study of Dimethylaminoethanol Bitartrate ……………………………..........25

Table 9. Summary of Maternal Liver Weights of Rats in the Prenatal Developmental

Toxicity Study of Dimethylaminoethanol Bitartrate ………………………………........25

Table 10. Summary of Uterine Content Data of Rats in the Prenatal Developmental Toxicity Study of Dimethylaminoethanol Bitartrate .....................................................26

Table 11. Summary of Selected Fetal External Findings in the Prenatal Developmental Toxicity Study of Dimethylaminoethanol Bitartrate .......................................................27

Table 12. Summary of Selected Fetal Visceral Findings in the Prenatal Developmental Toxicity Study of Dimethylaminoethanol Bitartrate .....................................................28

Table 13. Summary of Selected Fetal Skeletal Findings in the Prenatal Developmental Toxicity Study of Dimethylaminoethanol Bitartrate

\section{Figures}

Figure 1. Dimethylaminoethanol Bitartrate (CASRN: 5988-51-2; Chemical Formula:

$\mathrm{C}_{4} \mathrm{H}_{11} \mathrm{NO} \cdot \mathrm{C}_{4} \mathrm{H}_{6} \mathrm{O}_{6}$; Molecular Weight: 239.23)

Figure 2. Design of a Dose Range-finding and Prenatal Developmental Toxicity Study in Rats

Figure 3. Maternal Growth Curves for Pregnant Rats Administered

Dimethylaminoethanol Bitartrate by Gavage in the Dose Range-finding Study

Figure 4. Maternal Growth Curves for Pregnant Rats Administered Dimethylaminoethanol Bitartrate by Gavage in the Prenatal Developmental Toxicity Study 


\section{About This Report}

National Toxicology Program ${ }^{1}$

${ }^{1}$ Division of the National Toxicology Program, National Institute of Environmental Health

Sciences, Research Triangle Park, North Carolina, USA

\section{Collaborators}

K.A. Shipkowski, V.L. Sutherland, L.J. Betz, J. Blake, C.R. Blystone, S.D. Cooper, H.C. Cunny, R.A. Fernando, J.M. Fostel, P.M. Foster, V. Robinson, S.F. Harris, C.D. Hébert, M.J. Hooth, A.P. King-Herbert, G.E. Kissling, J.D. Krause, C.G. Leach, B.S. McIntyre, E. Mylchreest, K.R. Ryan, K.R. Shockley, M.V. Smith, A.H. Stokes, M.K. Vallant, S. Waidyanatha, N.J. Walker, A.T.D. Watson

Division of the National Toxicology Program, National Institute of Environmental Health Sciences, Research Triangle Park, North Carolina, USA

Evaluated and interpreted results and reported findings

K.A. Shipkowski, Ph.D., Co-study Scientist

V.L. Sutherland, Ph.D., Co-study Scientist

C.R. Blystone, Ph.D.

H.C. Cunny, Ph.D.

J.M. Fostel, Ph.D.

P.M. Foster, Ph.D. (Retired)

V. Robinson, M.A.

M.J. Hooth, Ph.D.

A.P. King-Herbert, D.V.M.

G.E. Kissling, Ph.D. (Retired)

B.S. McIntyre, Ph.D.

K.R. Ryan, Ph.D.

K.R. Shockley, Ph.D.

M.K. Vallant, M.S., MT (Retired)

S. Waidyanatha, Ph.D.

N.J. Walker, Ph.D.

A.T.D. Watson, Ph.D.

Southern Research, Birmingham, Alabama, USA

Conducted studies and evaluated findings

C.D. Hébert, Ph.D., Principal Investigator

E. Mylchreest, Ph.D., Study Director

A.H. Stokes, Ph.D., Study Director

Social \& Scientific Systems, Inc., Research Triangle Park, North Carolina, USA

Provided statistical analyses

M.V. Smith, Ph.D., Principal Investigator

L.J. Betz, M.S.

S.F. Harris, B.S.

J.D. Krause, Ph.D. 
C.G. Leach, M.S.

RTI International, Research Triangle Park, North Carolina, USA

Conducted pre-test chemistry activities and dose formulations

R.A. Fernando, Ph.D.

S.D. Cooper, B.S.

J. Blake, B.S.

\section{Contributors}

Division of the National Toxicology Program, National Institute of Environmental Health

Sciences, Research Triangle Park, North Carolina, USA

Provided oversight of report audit and preparation

G.K. Roberts, Ph.D.

Provided oversight of external peer review

E. A. Maull, Ph.D.

M.S. Wolfe, Ph.D.

Vistronix, Research Triangle Park, North Carolina, USA

Prepared data for report

P. Brown, B.S.

H. Gong, M.S.

C. Myers, M.S.

N. Sayers, B.S.

M. Shaw, B.S.

R. Whittlesey, M.S.

CSS Corporation, Research Triangle Park, North Carolina, USA

Prepared quality assessment audits

S. Brecher, Ph.D., Principal Investigator

S. Iyer, B.S.

V.S. Tharakan, D.V.M.

Biotechnical Services, Inc., Little Rock, Arkansas, USA

Prepared draft report

S.R. Gunnels, M.A., Principal Investigator

B.F. Hall, M.S.

L.M. Harper, B.S.

E.S Rathman, M.S.

D.C. Serbus, Ph.D. 


\section{ICF, Durham, North Carolina, USA}

Provided contract oversight, edited and formatted report, and supported peer review D.F. Burch, M.E.M., Contract Manager

S.E. Blaine, B.A.

T.W. Cromer, M.P.S.

L.M. Green, M.P.H.

T. Hamilton, M.S.

P.A. Hartman, M.E.M.

C.R. Lieb, B.S.

M.E. McVey, Ph.D.

B.C. Riley, B.S. 


\section{Explanation of Levels of Evidence for Developmental Toxicity}

The National Toxicology Program (NTP) describes the results of individual studies of chemical agents and other test articles and notes the strength of the evidence for conclusions regarding each study. Generally, each study is confined to a single laboratory animal species, although in some instances, multiple species may be investigated under the purview of a single study report. Negative results, in which the study animals do not exhibit evidence of developmental toxicity, do not necessarily imply that a test article is not a developmental toxicant, but only that the test article is not a developmental toxicant under the specific conditions of the study. Positive results demonstrating that a test article causes developmental toxicity in laboratory animals under the conditions of the study are assumed to be relevant to humans, unless data are available that demonstrate otherwise. In addition, such positive effects should be assumed to be primary effects, unless there is clear evidence that they are secondary consequences of excessive maternal toxicity. Given that developmental events are intertwined in the reproductive process, effects on developmental toxicity may be detected in reproductive studies. Evaluation of such developmental effects should be based on the NTP Criteria for Levels of Evidence for Developmental Toxicity.

It is critical to recognize that the "levels of evidence" statements described herein describe only developmental hazard. The actual determination of risk to humans requires exposure data that are not considered in these summary statements.

Five categories of evidence of developmental toxicity are used to summarize the strength of the evidence observed in each experiment: two categories for positive results (clear evidence and some evidence); one category for uncertain findings (equivocal evidence); one category for no observable effects (no evidence); and one category for experiments that cannot be evaluated because of major design or performance flaws (inadequate study). Application of these criteria requires professional judgment by individuals with ample experience and an understanding of the animal models and study designs employed. For each study, conclusion statements are made using one of the following five categories to describe the findings. These categories refer to the strength of the evidence of the experimental results and not to potency or mechanism.

\section{Levels of Evidence for Evaluating Developmental System Toxicity}

- Clear evidence of developmental toxicity is demonstrated by data that indicate a dose-related effect on one or more of its four elements (embryo-fetal death, structural malformations, growth retardation, or functional deficits) that is not secondary to overt maternal toxicity.

- Some evidence of developmental toxicity is demonstrated by dose-related effects on one or more of its four elements (embryo-fetal death, structural malformations, growth retardation, or functional deficits), but where there are greater uncertainties or weaker relationships with regard to dose, severity, magnitude, incidence, persistence, and/or decreased concordance among affected endpoints.

- Equivocal evidence of developmental toxicity is demonstrated by marginal or discordant effects on developmental parameters that may or may not be related to the test article. 
- No evidence of developmental toxicity is demonstrated by data from a study with appropriate experimental design and conduct that are interpreted as showing no biologically relevant effects on developmental parameters that are related to the test article.

- Inadequate study of developmental toxicity is demonstrated by a study that, because of major design or performance flaws, cannot be used to determine the occurrence of developmental toxicity.

When a conclusion statement for a particular study is selected, consideration must be given to key factors that would support the selection of an individual category of evidence. Such consideration should allow for incorporation of scientific experience and current understanding of developmental toxicity studies in laboratory animals, particularly with respect to interrelationships between endpoints, impact of the change on development, relative sensitivity of endpoints, normal background incidence, and specificity of the effect. For those evaluations that may be on the borderline between two adjacent levels, some factors to consider in selecting the level of evidence of developmental toxicity are given below:

- Increases in severity and/or prevalence (more individuals and/or more affected litters) as a function of dose generally strengthen the level of evidence, keeping in mind that the specific manifestation may be different with increasing dose. For example, malformations may be observed at a lower dose level, but higher doses may produce embryo-fetal death.

- Effects seen in many litters may provide stronger evidence than effects confined to one or a few litters, even if the incidence within those litters is high.

- Because of the complex relationship between maternal physiology and development, evidence for developmental toxicity may be greater for a selective effect on the embryo-fetus or pup.

- Concordant effects (syndromic) may strengthen the evidence of developmental toxicity. Single endpoint changes by themselves may be weaker indicators of effect than concordant effects on multiple endpoints related by a common process or mechanism.

- In order to be assigned a level of “clear evidence” the endpoint(s) evaluated should normally show a statistical increase in the deficit, or syndrome, on a litter basis.

- In general, the more animals affected, the stronger the evidence; however, effects in a small number of animals across multiple, related endpoints should not be discounted, even in the absence of statistical significance for the individual endpoint(s). In addition, rare malformations with low incidence, when interpreted in the context of historical controls, may be biologically important.

- Consistency of effects across generations in a multigenerational study may strengthen the level of evidence. However, if effects are observed in the $\mathrm{F}_{1}$ generation but not in the $F_{2}$ generation (or the effects occur at a lesser frequency in the $F_{2}$ generation), this may be due to survivor selection for resistance to the effect (i.e., if the effect is incompatible with successful reproduction, then the affected individuals will not produce offspring). 
- Transient changes (e.g., pup weight decrements, reduced ossification in fetuses) by themselves may be weaker indicators of an effect than persistent changes.

- Uncertainty about the occurrence of developmental toxicity in one study may be lessened by effects (even if not identical) that are observed in a second species.

- Insights from supportive studies (e.g., toxicokinetics, ADME, computational models, structure-activity relationships) and developmental findings from other in vivo animal studies (NTP or otherwise) should be drawn upon when interpreting the biological plausibility of an effect.

- New assays and techniques need to be appropriately characterized to build confidence in their utility: their usefulness as indicators of effect is increased if they can be associated with changes in traditional endpoints.

For more information visit: http://ntp.niehs.nih.gov/go/10003. 


\section{Peer Review}

An external ad hoc panel was convened at the National Institute of Environmental Health Sciences, Research Triangle Park, NC on July 31, 2019, to peer review the draft NTP Developmental and Reproductive Toxicity Technical Report on the Prenatal Development Studies of Dimethylaminoethanol Bitartrate (CASRN 5988-51-2) in Sprague Dawley (Hsd:Sprague Dawley ${ }^{\circledR} S D^{\circledR}$ ) Rats (Gavage Studies). The public could view the proceedings via webcast and there was opportunity for presentation of oral public comment. The selection of panel members and conduct of the peer review were in accordance with Federal policies and regulations. The panel was charged to:

1. Review and evaluate the scientific and technical elements of each study and its presentation.

2. Determine whether each study's experimental design, conduct, and findings support the NTP's conclusion regarding the prenatal developmental toxicity of the substance tested.

NTP carefully considered the panel's recommendations in finalizing the technical report. The peer review report is provided in Appendix D. Other meeting materials are available on the NTP website (https://ntp.niehs.nih.gov/go/meeting).

\section{Peer Reviewers}

George Daston, Ph.D., Chairperson

The Procter and Gamble Company

Cincinnati, Ohio, USA

\section{Cheryl Broussard, Ph.D.}

Centers for Disease Control and Prevention

Atlanta, Georgia, USA

Alan Hoberman, Ph.D.

Charles River Laboratories Preclinical Services

Horsham, Pennsylvania, USA

Linda Roberts, Ph.D.

NapaTox Consulting LLC

San Francisco, California, USA

Mary Alice Smith, Ph.D.

University of Georgia

Athens, Georgia, USA

Kimberley Treinen, Ph.D.

Sunovion Pharmaceuticals, Inc.

Marlborough, Massachusetts, USA 


\section{Publication Details}

Publisher: National Toxicology Program

Publishing Location: Research Triangle Park, NC

ISSN: 2690-2052

DOI: https://doi.org/10.22427/NTP-DART-04

Report Series: NTP Developmental and Reproductive Toxicity Report Series

Report Series Number: 04

Official citation: National Toxicology Program (NTP). 2020. NTP developmental and reproductive toxicity technical report on the prenatal development studies of dimethylaminoethanol bitartrate (CASRN 5988-51-2) in Sprague Dawley (Hsd:Sprague Dawley ${ }^{\circledR}$ $\mathrm{SD}^{\circledR}$ ) rats (gavage studies). Research Triangle Park, NC: National Toxicology Program. DART Report 04.

\section{Acknowledgments}

This work was supported by the Intramural Research Program (ES103316, ES103318, and ES103319) at the National Institute of Environmental Health Sciences, National Institutes of Health and performed for the National Toxicology Program, Public Health Service, U.S. Department of Health and Human Services under contracts HHSN273201800006C, HHSN273201600020C, HHSN273201300010C, HHSN273201400004C, HHSN273201300009C, HHSN316201200054W, and HHSN273201300004C. 


\section{Abstract}

Dimethylaminoethanol is a close structural analog of choline, an essential nutrient. Dietary supplements containing dimethylaminoethanol bitartrate, a salt of dimethylaminoethanol, are marketed to improve memory and general cognitive function due to the ability of dimethylaminoethanol to increase levels of acetylcholine in the brain. Human exposure to dimethylaminoethanol may also occur through occupational and industrial routes (e.g., spray painting, beverage can lacquering). Dimethylaminoethanol was nominated by the National Institute of Environmental Health Sciences (NIEHS) for toxicological characterization due to concerns for widespread human exposure through its use in industrial and consumer products. Because of the limited literature indicating that dimethylaminoethanol could be a teratogen and reproductive toxicant and because of the possibility for widespread exposure to the salt form of dimethylaminoethanol (dimethylaminoethanol bitartrate) as a dietary supplement in women of childbearing age, the National Toxicology Program (NTP) conducted prenatal developmental toxicology studies in Sprague Dawley (Hsd:Sprague Dawley ${ }^{\circledR} \mathrm{SD}^{\circledR}$ ) rats. In these studies, timemated female rats received dimethylaminoethanol bitartrate in sterile water by gavage from implantation on gestation day (GD) 6 to the day before expected parturition (GD 20). To identify dose levels that would appropriately challenge the model system, dimethylaminoethanol bitartrate-related maternal and fetal toxicity were examined in the dose range-finding study followed by the prenatal developmental toxicity study.

\section{Dose Range-finding Prenatal Developmental Toxicity Study}

Groups of 10 time-mated female rats were administered 0, 250, 500, or 1,000 mg

dimethylaminoethanol bitartrate/kg body weight per day (mg/kg/day) in sterile water by gavage from GD 6 to GD 20. Vehicle control ( $0 \mathrm{mg} / \mathrm{kg})$ animals received sterile water.

There were no indications of maternal or fetal toxicity in the dose range-finding study. All animals survived to study termination. There were no dose-related effects on maternal body weights, body weight gains, body weights corrected for live litter size, or feed consumption. The number of pregnant females, mean number of corpora lutea, dead fetuses, early and late resorptions, and fetal sex ratio were similar across all treatment groups. There was a significant positive trend in the mean number of live female fetuses per litter relative to dose. There were no exposure-related fetal findings.

\section{Prenatal Developmental Toxicity Study}

As no maternal toxicity was observed in the dose range-finding study, groups of 25 time-mated female rats were administered $0,250,500$, or $1,000 \mathrm{mg} / \mathrm{kg} /$ day in sterile water by gavage from GD 6 to GD 20. Vehicle control (0 mg/kg) animals received sterile water. In this study, dimethylaminoethanol bitartrate was well tolerated and there were no significant effects on mortality, maternal body weights, body weight gains, body weights corrected for litter size, or feed consumption during gestation. In the $1,000 \mathrm{mg} / \mathrm{kg} /$ day group, one dam was euthanized moribund (GD 21) and one was found dead (GD 10); however, those deaths were not considered dose-related. Clinical observations were limited to single or sporadic incidences with the exception of brown or red vaginal discharge, which was observed between GD 14 and GD 21 in $10 / 20,3 / 20,4 / 20$, and 10/24 dams in the $0,250,500$, and $1,000 \mathrm{mg} / \mathrm{kg} /$ day groups, respectively. There were no notable placental or other maternal gross observations at necropsy except for a significant, but not biologically relevant, positive trend in mean absolute liver weight. 
The number of pregnant females, mean number of corpora lutea, implantations, litter size, live fetuses per litter, and fetal sex ratio were similar across all treatment groups.

External and visceral malformations were limited to common background findings and singular or sporadic incidences. There were no observed incidences of fetal head, specifically brain, abnormalities. Skeletal malformations and variations occurred predominantly in the ribs. A significant increase in the incidence of absent innominate artery (a variation) and total, short thoracolumbar ribs (a variation) was observed in the $1,000 \mathrm{mg} / \mathrm{kg}$ group, along with a significant positive trend. Additionally, there was a significant increase in the number of supernumerary sites, or ossification sites, in the skull in $1,000 \mathrm{mg} / \mathrm{kg}$ fetuses as well as a significant positive trend across all exposed groups. These effects might be reversible (supernumerary ribs) or of uncertain biological significance (supernumerary sites in the skull); however, in the absence of maternal toxicity or effects on fetal body weight, the increased incidences of extra ossification sites in two separate locations, each occurring through two different skeletal developmental pathways, suggest that these effects could be related to dimethylaminoethanol bitartrate exposure.

\section{Conclusions}

Under the conditions of the prenatal study, there was equivocal evidence ${ }^{\dagger}$ of developmental toxicity of dimethylaminoethanol bitartrate in Sprague Dawley (Hsd:Sprague Dawley ${ }^{\circledR} \mathrm{SD}^{\circledR}$ ) rats attributable to increased incidences of absent innominate artery, short thoracolumbar ribs, and supernumerary sites in the skull in the absence of overt maternal toxicity.

Synonyms: 2-Dimethylaminoethanol bitartrate; 2-dimethylaminoethanol tartrate; dimethylethanolamine bitartrate; $N, N$-dimethylethanolamine- tartaric acid salt; ethanol, 2-(dimethylamino)-, [R(R*, $\left.\left.\mathrm{R}^{*}\right)\right]$-2,3-dihydroxybutanedioate; ethanol, 2-(dimethylamino)-, tartrate

${ }^{\dagger}$ See Explanation of Levels of Evidence for Developmental Toxicity. 
Summary of Exposure-related Findings in Rats in the Prenatal Developmental Toxicity Gavage Study of Dimethylaminoethanol Bitartrate

\begin{tabular}{|c|c|c|c|c|}
\hline & 0 mg/kg & $250 \mathrm{mg} / \mathrm{kg}$ & $500 \mathrm{mg} / \mathrm{kg}$ & $1,000 \mathrm{mg} / \mathrm{kg}$ \\
\hline \multicolumn{5}{|l|}{ Maternal Parameters } \\
\hline Animals on Study & 25 & 25 & 25 & 25 \\
\hline Number Pregnant & 20 & 20 & 20 & 24 \\
\hline Number Found Dead & 0 & 0 & 0 & 1 \\
\hline Number Euthanized Moribund & 0 & 0 & 0 & 1 \\
\hline Number Euthanized - Early Delivery & 1 & 0 & 0 & 1 \\
\hline Clinical Observations & None & None & None & None \\
\hline \multicolumn{5}{|l|}{ Body Weight and Feed Consumption ${ }^{\mathrm{a}}$} \\
\hline Terminal Body Weight & $359.6 \pm 8.8$ & $375.2 \pm 5.3$ & $380.3 \pm 5.1$ & $367.1 \pm 6.5$ \\
\hline Body Weight Change GD 6 to 21 & $120.5 \pm 7.5$ & $135.2 \pm 4.7$ & $140.0 \pm 4.2^{*}$ & $127.7 \pm 5.8$ \\
\hline Feed Consumption GD 6 to 21 & $21.2 \pm 0.4$ & $21.6 \pm 0.4$ & $22.0 \pm 0.3$ & $21.5 \pm 0.4$ \\
\hline Necropsy Observations & None & None & None & None \\
\hline \multicolumn{5}{|l|}{ Developmental/Fetal Parameters } \\
\hline Number of Litters Examined & 19 & 20 & 20 & 22 \\
\hline Number of Live Fetuses Evaluated & 209 & 265 & 260 & 249 \\
\hline Number of Live Fetuses per Litter ${ }^{b}$ & $11.00 \pm 1.12$ & $13.25 \pm 0.60$ & $13.00 \pm 0.56$ & $11.32 \pm 1.07$ \\
\hline Number of Early Resorptions ${ }^{\mathrm{c}}$ & 9 & 10 & 10 & 14 \\
\hline Number of Late Resorptions ${ }^{c}$ & 0 & 0 & 0 & 0 \\
\hline Number of Dead Fetuses ${ }^{c}$ & 0 & 0 & 0 & 11 \\
\hline Number with Whole Litter Resorptions & 0 & 0 & 0 & 0 \\
\hline Percent Postimplantation Loss ${ }^{\mathrm{b}}$ & $5.05 \pm 1.57$ & $3.80 \pm 1.53$ & $3.45 \pm 1.10$ & $11.17 \pm 5.56$ \\
\hline Fetal Body Weight per Litter ${ }^{a}$ & $5.38 \pm 0.15$ & $5.26 \pm 0.05$ & $5.33 \pm 0.06$ & $5.22 \pm 0.09$ \\
\hline Male Fetal Weight per Litter ${ }^{\mathrm{a}}$ & $5.44 \pm 0.16(18)$ & $5.37 \pm 0.05(19)$ & $5.50 \pm 0.06(20)$ & $5.51 \pm 0.09(20)$ \\
\hline Female Fetal Weight per Litter ${ }^{\mathrm{a}}$ & $5.15 \pm 0.12(18)$ & $5.14 \pm 0.06(20)$ & $5.18 \pm 0.07(20)$ & $5.21 \pm 0.08(20)$ \\
\hline Gravid Uterine Weight ${ }^{\mathrm{a}}$ & $80.18 \pm 7.36$ & $95.85 \pm 3.93$ & $96.17 \pm 3.82$ & $85.25 \pm 6.38$ \\
\hline External Findings & None & None & None & None \\
\hline \multicolumn{5}{|l|}{ Visceral Findings $^{d}$} \\
\hline \multicolumn{5}{|l|}{ Arteries } \\
\hline \multicolumn{5}{|l|}{ Innominate artery, absent - [V] } \\
\hline Fetuses & $3(1.44)^{* * \# \#}$ & $4(1.51)$ & $6(2.31)$ & $12(4.62)^{* \#}$ \\
\hline Litters & $3(15.79)^{*}$ & $4(20.00)$ & $4(20.00)$ & $10(45.45)^{*}$ \\
\hline \multicolumn{5}{|l|}{ Skeletal Findings ${ }^{d}$} \\
\hline \multicolumn{5}{|l|}{ Supernumerary Rib } \\
\hline Thoracolumbar short, total - [V] & & & & \\
\hline
\end{tabular}


Dimethylaminoethanol Bitartrate, NTP DART 04

\begin{tabular}{lcccc}
\hline & $\mathbf{0 ~} \mathbf{~ m g} / \mathbf{k g}$ & $\mathbf{2 5 0} \mathbf{~ m g} / \mathbf{k g}$ & $\mathbf{5 0 0} \mathbf{~} \mathbf{g} / \mathbf{k g}$ & $\mathbf{1 , 0 0 0} \mathbf{~ m g} / \mathbf{k g}$ \\
\hline Fetuses & $56(26.79)^{* * \# \#}$ & $56(21.21)$ & $59(22.69)$ & $100(38.46)^{* * \#}$ \\
Litters & $17(89.47)$ & $18(90.00)$ & $18(90.00)$ & $19(86.36)$
\end{tabular}

Skull

General, supernumerary site - [V]

$\begin{array}{lcccc}\text { Fetuses } & 1(1.0)^{* * \#} & 3(2.34) & 2(1.59) & 13(10.16)^{* * \#} \\ \text { Litters } & 1(5.56)^{* *} & 3(15.00) & 2(10.00) & 10(50.00)^{* *}\end{array}$

Level of Evidence of Developmental Toxicity: Equivocal Evidence

*Statistically significant ( $\mathrm{p} \leq 0.05$ ) trend (denoted in vehicle control column) or pairwise comparison (denoted in dose group column); ** $\leq 0.01$.

\#Statistically significant $(\mathrm{p} \leq 0.05)$ trend (denoted in vehicle control column) or pairwise comparison (denoted in dose group column) in litter-based analysis of fetuses; ${ }^{\# \#} \mathrm{p} \leq 0.01$

$\mathrm{GD}$ = gestation day; [V] = variation .

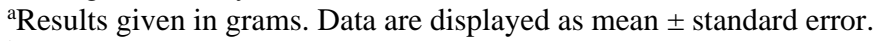

bData are displayed as mean \pm standard error.

c No statistical analyses were performed on number of early resorptions, number of late resorptions, or number of dead fetuses.

${ }^{\mathrm{d} U p p e r ~ r o w ~ d e n o t e s ~ n u m b e r ~ o f ~ a f f e c t e d ~ f e t u s e s ~(\%) ~ a n d ~ l o w e r ~ r o w ~ t h e ~ n u m b e r ~ o f ~ a f f e c t e d ~ l i t t e r s ~(\%) . ~}$ 


\section{Introduction}<smiles>CN(C)CCO</smiles>

Figure 1. Dimethylaminoethanol Bitartrate (CASRN: 5988-51-2; Chemical Formula: $\mathrm{C}_{4} \mathrm{H}_{11} \mathrm{NO} \bullet$ $\mathrm{C}_{4} \mathrm{H}_{6} \mathrm{O}_{6}$; Molecular Weight: 239.23)

Synonyms: 2-Dimethylaminoethanol bitartrate; 2-dimethylaminoethanol tartrate; dimethylethanolamine bitartrate; $N, N$ dimethylethanolamine- tartaric acid salt; ethanol, 2-(dimethylamino)-, [R(R*, $\left.\left.\mathrm{R}^{*}\right)\right]-2,3-$ dihydroxybutanedioate; ethanol, 2(dimethylamino)-, tartrate.

\section{Chemical and Physical Properties}

Dimethylaminoethanol bitartrate, a salt of dimethylaminoethanol, is produced from dimethylaminoethanol and tartaric acid. Dimethylaminoethanol bitartrate is a white powder with a molecular weight of $239.23 \mathrm{~g} / \mathrm{mol}$ and a melting point range of $109^{\circ}-113^{\circ} \mathrm{C}$; it is also soluble in water. $1 ; 2$

There is limited information available on the bitartrate form, but dimethylaminoethanol, the free base, is a colorless liquid with a molecular weight of $89.136 \mathrm{~g} / \mathrm{mol}$, a melting point of $-65^{\circ} \mathrm{C}$, and a boiling point of $134.1^{\circ} \mathrm{C}{ }^{3}$ Dimethylaminoethanol has a density of $0.8866 \mathrm{~g} / \mathrm{cm}^{3}$ (at $20^{\circ} \mathrm{C}$ ), a $\log$ Kow (octanol:water partition coefficient) of -0.55 (at $23^{\circ} \mathrm{C}$ ), and a vapor pressure of $21 \mathrm{~mm} \mathrm{Hg}$ torr (at $20^{\circ} \mathrm{C}$ ). It has also been reported to have an amine or fishy odor. Dimethylaminoethanol is moderately flammable. ${ }^{3}$

\section{Production, Use, and Human Exposure}

A production volume of 100 to 250 million pounds was reported for dimethylaminoethanol in 2015 that was based on information submitted under the 2016 Toxic Substances Control Act Inventory Update Rule. ${ }^{4}$ Dimethylaminoethanol was also included in the 2004 Organisation for Economic Co-operation and Development (OECD) List of High Production Volume Chemicals, ${ }^{5}$ which included chemicals produced at more than 1,000 tons per year. The U.S. Environmental Protection Agency (EPA) Chemical Data Reporting (CDR) database ${ }^{6}$ listed eight United Statesbased industries producing dimethylaminoethanol; two of those companies reported annual production of 38,000 and 79,000 pounds dimethylaminoethanol. ${ }^{6}$

Dimethylaminoethanol is used in a variety of industrial and consumer applications, including as a catalyst in the curing of epoxy resins and polyurethanes, as an inhibitor of corrosion, and as an amino resin stabilizer. Dimethylaminoethanol is also used as a chemical intermediate in the synthesis of antihistamines, local anesthetics, dyes, textiles, and emulsifiers/solubilizers in waterbased paints. ${ }^{3}$ In accordance with the OECD Screening Information Data Set, it is estimated that $50 \%$ of dimethylaminoethanol produced is used in the manufacturing of flocculants for wastewater treatment; $20 \%$ in the manufacturing of flexible and rigid polyurethane foams and 
lacquers; $20 \%$ in the manufacturing of water-based paints and surface coatings; and $10 \%$ to produce ion exchange resins, pharmaceuticals, and corrosion inhibitors. ${ }^{7}$

Occupational exposure to dimethylaminoethanol is believed to primarily involve workers in the spray painting and beverage can lacquering industries. There is some concern for the release of dimethylaminoethanol into the environment from these industrial sources. ${ }^{8}$

Nonoccupational exposure to dimethylaminoethanol can occur through the consumption of squid, sardines, and other fatty fish. ${ }^{9}$ Dimethylaminoethanol can also be released from sealants, architectural coatings, furniture and cabinet coatings, polyurethane foam cushions, and carpets in homes, buildings, and vehicles; ${ }^{10 ; 11}$ however, the primary concern for nonoccupational exposure is through pharmaceuticals and dietary supplements.

Dimethylaminoethanol is a close structural analog of choline ( $N, N, N$-trimethylaminoethanol), an essential nutrient. Dimethylaminoethanol supplies the brain with choline, where it is acetylated by choline acetylase to form acetylcholine. ${ }^{10}$ Dimethylaminoethanol salts (e.g., $p$ acetamidobenzoate) have been used to treat central nervous system disorders in humans, specifically those considered to be associated with decreased cholinergic neuron function. ${ }^{12}$ Dimethylaminoethanol salts have also been used to manage learning and behavioral problems, Huntington's chorea, chronic fatigue, and neurasthenia. ${ }^{3 ; 10 ; 13}$ The prescription drug Deaner ${ }^{\circledR}$ (deanol $p$-acetamidobenzoate) was used in the United States for more than 20 years to treat learning and behavioral problems in children, but was withdrawn from the market in 1983 due to better alternatives becoming available. The dimethylaminoethanol chemical structure is also part of many different pharmaceutical formulations, including a variety of antihistamines, antiemetics, local anesthetics, and tamoxifen. ${ }^{9}$

A number of dietary supplements on the market contain dimethylaminoethanol, most commonly in the form of dimethylaminoethanol bitartrate, and these supplements are purported to improve memory and general cognitive function. The recommended dosage for these supplements varies between products, with recommended adult doses ranging from 100 to $500 \mathrm{mg}$ dimethylaminoethanol/day. One dimethylaminoethanol bitartrate supplement currently on the market contains $351 \mathrm{mg}$ dimethylaminoethanol bitartrate, which corresponds to approximately $130 \mathrm{mg}$ dimethylaminoethanol. ${ }^{14}$ Dietary supplements containing dimethylaminoethanol are also marketed to treat symptoms of attention deficit hyperactivity disorder (ADHD) in children and on average contain $100 \mathrm{mg}$ dimethylaminoethanol (as dimethylaminoethanol bitartrate). ${ }^{15 ;} 16$

\section{Regulatory Status}

No regulatory limits for dimethylaminoethanol exposure have been established by NIOSH or EPA. Individual industrial companies have established workplace exposure limits for dimethylaminoethanol; for example, DuPont has an 8-hour time-weighted average of $2 \mathrm{ppm}$ for dimethylaminoethanol. ${ }^{9}$ Federal regulations currently applicable to dimethylaminoethanol include the following: 40 CFR Part 60 [Subpart YYY-Standards of Performance for Volatile Organic Compounds (VOC) Emissions from Synthetic Organic Chemical Manufacturing Industry (SOCMI) Wastewater], which regulates the emission of volatile organic compounds (VOCs) from wastewater; 40 CFR § 63.100ff (Subpart F-National Emission Standards for Organic Hazardous Air Pollutants from the Synthetic Organic Chemical Manufacturing Industry), which regulates air pollution emitted by chemical manufacturers that produce 
dimethylaminoethanol (or mixtures containing dimethylaminoethanol); 21 CFR § 173.20 [Secondary Direct Food Additives Permitted in Food for Human Consumption (Subpart APolymer Substances and Polymer Adjuvants for Food Treatment)], which regulates membranes used for food packaging that were produced by reactions with dimethylaminoethanol; and 21 CFR § 175.300 (Indirect Food Additives: Adhesives and Components of Coatings), which states that dimethylaminoethanol, when used in coating emulsions, can be used as an adjuvant at no more than $2 \%$ (by weight).

\section{Absorption, Distribution, Metabolism, and Excretion}

\section{Experimental Animals}

Data on absorption, distribution, metabolism, and excretion of dimethylaminoethanol bitartrate could not be located in the literature, and data for dimethylaminoethanol or other dimethylaminoethanol salts or esters in the literature are limited. Briefly, in male Wistar rats, following an intravenous dose of $11 \mathrm{mg} / \mathrm{kg}(120 \mathrm{mmol} / \mathrm{kg})\left[{ }^{14} \mathrm{C}\right]$ dimethylaminoethanol or $30 \mathrm{mg} / \mathrm{kg}(120 \mathrm{mmol} / \mathrm{kg}$ ) cyprodenate, $0.16 \%$ and $0.2 \%$, respectively, of the administered dose were measured in the plasma 6 minutes after dosing. ${ }^{17}$ Only $33 \%$ of the administered dose was eliminated in urine by 24 hours. The $N$-oxide of dimethylaminoethanol was the primary urinary metabolite in rodents, constituting $13.5 \%$ of the dose eliminated in urine within 24 hours. In another study in rats, following an intravenous dose of $30 \mathrm{mg} / \mathrm{kg}(0.13 \mathrm{mmol} / \mathrm{kg})$

$\left[{ }^{14} \mathrm{C}\right]$ cyprodenate maleate, the cyclohexylpropionic acid ester of dimethylaminoethanol, approximately $2.41 \%, 1.30 \%$, and $0.20 \%$ of the dose was found in the liver, brain, and plasma, respectively, 5 minutes after dosing. In male mice, 10 minutes after an intraperitoneal dose of $300 \mathrm{mg} / \mathrm{kg}$ (3.30 mmol/kg) dimethylaminoethanol, approximately $280 \mathrm{nmol}$ dimethylaminoethanol/g plasma was detected. ${ }^{18}$ Daily oral exposures (duration not provided) of chinchilla rabbits to dimethylaminoethanol as deanol acetamidobenzoate $(0.48 \mu \mathrm{g}, 1.8 \mathrm{nmol})$ or dimethylaminoethanol (10.4 $\mu \mathrm{g}, 4.5 \mathrm{nmol})$, resulted in plasma concentrations of 6 to $7 \mu \mathrm{M}$ (1.6 to $1.9 \mu \mathrm{g} / \mathrm{mL})$ deanol acetamidobenzoate or 12 to $18 \mu \mathrm{M}(1.1$ to $1.6 \mu \mathrm{g} / \mathrm{mL})$

dimethylaminoethanol. The chemical could not be detected in the plasma 36 hours after the end of the treatment period. Concentrations in the cerebrospinal fluid were similar to measurements in the plasma. ${ }^{19}$

NTP investigated the absorption, distribution, metabolism, and excretion of dimethylaminoethanol in male and female Wistar Han rats and B6C3F1/N mice. ${ }^{20}$ Within 24 hours following gavage administration of 10,50 , or $500 \mathrm{mg} / \mathrm{kg}$ in rats, $57-62 \%$ of the administered dose was excreted in urine, $4-5 \%$ was expired as $\mathrm{CO}_{2}$, and $<1 \%$ was recovered in feces and as volatile organic compounds demonstrating that dimethylaminoethanol was well absorbed and rapidly excreted. A significant amount of the administered dose was retained in tissues with $34 \%, 30 \%$, and $24 \%$ of the 10,50 , and $500 \mathrm{mg} / \mathrm{kg}$ doses, respectively, recovered 24 hours after administration. Following a single oral dose of $500 \mathrm{mg} / \mathrm{kg}$ in rats, $\left[{ }^{14} \mathrm{C}\right]$ dimethylaminoethanol-derived radioactivity was highest 2 hours after administration and declined over time with $84 \%, 24 \%, 15 \%$, and $13 \%$ recovered at 2, 24, 72, and 168 hours, respectively. Of the tissues examined, liver, kidney, lung, and thyroid gland contained the highest concentrations; tissue-to-blood ratio was higher than 1.0 in all examined tissues. Excretion in mice was somewhat different than in rats, with increasing dose (10, 50, and $500 \mathrm{mg} / \mathrm{kg}$ ), the administered dose recovered at 24 hours in urine increased $(16 \%, 18 \%$, and 
$43 \%)$, expired as $\mathrm{CO}_{2}$ decreased (22\%, 16\%, and 13\%), and that remaining in tissues decreased. The tissues with the highest levels of radioactivity were the liver, kidney, thyroid gland, lung, spleen, adipose, and uterus.

Urinary products identified following gavage administration of dimethylaminoethanol were the $\mathrm{N}$-oxide metabolite and unmetabolized parent compound; the amounts of each depended on the dose, sex, and species. $N, N$-dimethylglycine was identified as a minor metabolite; dimethylamine and $N, N$-dimethylnitrosamine were not detected. As the dose increased, the concentration of parent compound generally increased compared with that of the $\mathrm{N}$-oxide, except in male rats, suggesting saturation of metabolism. In male rats, the $N$-oxide metabolite was not detected at the low dose; however, at the higher doses, male rats produced more $\mathrm{N}$-oxide than male mice and female rats and mice. ${ }^{20}$

Following administration of $500 \mathrm{mg} / \mathrm{kg}$ dimethylaminoethanol in male Wistar Han rats, serum choline levels were moderately elevated within 12 hours of administration. ${ }^{20}$ To understand the effects of choline disposition by dimethylaminoethanol, male and female rats were given three consecutive daily gavage doses of 100 or $500 \mathrm{mg} / \mathrm{kg}$ dimethylaminoethanol prior to administration of a single dose of $100 \mathrm{mg} / \mathrm{kg}\left[{ }^{14} \mathrm{C}\right]$ choline. Only modest effects on choline disposition occurred. In an investigation by Schlenk ${ }^{21}$ following intracerebral injection of $\left[{ }^{14} \mathrm{C}\right]$ dimethylaminoethanol in rats, brain levels of phosphatidylethanolamine were found to increase over the 7-hour observation period and were 10- to 40-fold higher than levels of phosphodimethylethanolamine. Analysis of brain tissue from mice administered $\left[{ }^{14} \mathrm{C}\right]$ dimethylaminoethanol or $p$-chlorophenoxyacetate, a dimethylaminoethanol derivative, indicated the presence of phosphoryl-dimethylaminoethanol and phosphatidyldimethylaminoethanol; phosphatidyl-dimethylaminoethanol is believed to be the end-metabolite of dimethylaminoethanol. ${ }^{22}$ Mice administered dimethylaminoethanol had increased concentrations and rate of turnover of free choline in the blood and kidneys. ${ }^{9}$ Jope and Jenden ${ }^{23}$ reported increased choline concentrations in the plasma and brain of rats treated with dimethylaminoethanol. The extent to which dimethylaminoethanol is methylated and substituted into acetylcholine is not well understood; however, it has been suggested that once it crosses the blood-brain barrier, dimethylaminoethanol is methylated to form choline and subsequently incorporated into acetylcholine. ${ }^{9}$ Dimethylaminoethanol is reported to undergo metabolism via the phospholipid cycle, resulting in the production of phosphoryldimethylethanolamine and glycerophosphatidylcholine. ${ }^{17}$

\section{Humans}

In a study using human volunteers, 33\% of an injected dose of $1 \mathrm{~g}$ (10 mmol) dimethylaminoethanol was excreted unchanged. ${ }^{24}$ The investigators proposed that the remaining compound could have been demethylated to ethanolamine and used in normal metabolic pathways.

\section{Developmental and Reproductive Toxicity}

\section{Experimental Animals}

Choline is an essential nutrient; however, mammals are limited in their ability to synthesize choline and, therefore, much of it is acquired through dietary sources. Choline is required for 
many biological processes, in particular nervous system development, and choline deficiency has been associated with the development of neural tube defects (NTDs). ${ }^{25 ;}{ }^{26}$ As dimethylaminoethanol is a structural analog of choline, there is potential for dimethylaminoethanol to disrupt choline uptake and metabolism and thereby interfere with biological processes such as development.

Pregnant Sprague Dawley rats fed a choline-deficient diet supplemented with $1 \% \mathrm{~N}$ methylaminoethanol or $1 \%$ dimethylaminoethanol $(10,000 \mathrm{mg} / \mathrm{kg}$ feed) from gestational day (GD) 6 to postnatal day (PND) 14 had significantly reduced offspring survival compared to pregnant rats supplied standard lab chow. ${ }^{27}$ Despite no effects on pregnancy progression, litter size, or pup body weight, only 18/253 pups from exposed dams survived to at least PND 3, whereas pups from control dams survived to at least PND 15. Pups from dams fed the dimethylaminoethanol-supplemented diet had increased levels of glycogen and fatty infiltration in their livers; dimethylaminoethanol $(72.2 \pm 12.7 \mathrm{nmol} / \mathrm{g})$ was measured in the brains of these pups as well. Choline and acetylcholine levels were increased (53\% and 36\%, respectively) in the brains of pups from dams fed the dimethylaminoethanol-supplemented diet relative to dams fed the choline-deficient diet.

Exposure to dimethylaminoethanol via inhalation for 90 days did not induce any histopathologic changes in the gonads of rats. ${ }^{9}$

Inhalation exposure to dimethylaminoethanol (10, 30, or $100 \mathrm{ppm})$ induced maternal toxicity in pregnant Fischer 344 rats, as indicated by decreases in body weight (30 and 100 ppm) and ocular effects (30 and $100 \mathrm{ppm}$ ). ${ }^{28}$ Reported gestational effects included significant decreases in the number of viable implants per litter, the percentage of live fetuses per litter, and litter size (all evident at the lowest concentration tested, $10 \mathrm{ppm}$ ), as well as a significant decrease in the percentage of male fetuses in rats exposed to $30 \mathrm{ppm}$ dimethylaminoethanol.

Skeletal alterations were observed in the fetuses of pregnant Fischer 344 rats exposed to 10 to $100 \mathrm{ppm}$ dimethylaminoethanol via inhalation from GD 6 to GD $15 .{ }^{29}$ Recorded skeletal variations were sporadic and included increased incidences of split cervical centra 1, 2, 3, and/or 4 , and bilobed thoracic centrum 1 . Decreased incidences of poorly ossified cervical centrum 6 , bilobed thoracic centrum 9, bilobed sternebra 5, and unossified proximal phalanges of the forelimb were also reported. A no-observed-adverse-effect level (NOAEL) of $100 \mathrm{ppm}$ or greater was estimated for embryo-fetal toxicity and teratogenicity, whereas a NOAEL of $10 \mathrm{ppm}$ was estimated for maternal toxicity.

Exposure of neurulating mouse embryos (collected at GD 9) to dimethylaminoethanol (0, 250, 375,500 , or $750 \mu \mathrm{M}$ ) in vitro for 26 hours altered choline uptake and metabolism, resulting in significant dose-dependent increases in the incidence and severity of malformations. ${ }^{25}$; 26 The malformations included NTDs, craniofacial hypoplasia, caudal dysgenesis, and abnormal circulation. The average amount of embryonic protein was decreased in embryos exposed to $375 \mu \mathrm{M}$ dimethylaminoethanol or higher.

\section{Humans}

There are no studies in the literature on the developmental or reproductive toxicity of dimethylaminoethanol in humans. Decreases in choline are associated with NTDs in humans; 
however, the data are somewhat inconsistent. ${ }^{30-32}$ Dimethylaminoethanol is not recommended for use during pregnancy or lactation. ${ }^{9 ;} 13$

\section{General Toxicity}

\section{Experimental Animals}

Reported oral LD 50 (lethal dose for $50 \%$ of exposed animals) values for rats range from 2,000 to $6,000 \mathrm{mg} / \mathrm{kg}$ (22.44 to $67.31 \mathrm{mmol} / \mathrm{kg}$ ) dimethylaminoethanol. ${ }^{24 ; 33}$

Rats orally exposed to $890,1,250$, or $1,800 \mathrm{mg} / \mathrm{kg} /$ day dimethylaminoethanol for 14 days exhibited signs of toxicity early in the dosing period at the mid and high doses. ${ }^{34}$ Signs of toxicity included sluggishness, discharge around the eyes and nose, kyphosis, and prostration; however, these abated by days 2 to 5 in surviving animals. Observations at necropsy included red, mottled lungs, dark fluid in the stomach and intestine, and reddened stomach.

Exposure to dimethylaminoethanol via inhalation has been demonstrated to induce toxicity and mortality in rats. Exposure concentration-related mortality was observed in rats exposed to 1,668, 2,408, or 3,311 ppm dimethylaminoethanol for 4 hours and observed for 14 days. ${ }^{35}$ Rats from all exposure groups showed signs of toxicity including lacrimation, nasal discharge, respiratory difficulties, decreased motor activity, and weight loss.

Exposure of F344 rats to 98, 288, or 586 ppm dimethylaminoethanol via inhalation, 6 hours/day over 11 days (nine exposures total), caused 100\% mortality at $586 \mathrm{ppm}$ and some mortality at 288 ppm. ${ }^{35}$ Histologic lesions in the 288 and 98 ppm groups were observed primarily in the upper respiratory tract and in the eyes (288 ppm only). In a related study, F344 rats exposed to 8, 24, or 76 ppm dimethylaminoethanol via inhalation for 6 hours/day, 5 days/week for 13 weeks were observed with corneal opacity and alterations in nasal tissue at 24 and $76 \mathrm{ppm} .{ }^{35}$

Dimethylaminoethanol did not induce genotoxicity when evaluated in the Salmonella typhimurium assay, Drosophila melanogaster sex-linked recessive lethal assay, sister chromatid exchange assays, or hypoxanthine-guanine phosphoribosyl transferase forward gene mutation tests. ${ }^{9 ;}$ 36-40 There were no significant increases in micronucleated erythrocytes in Swiss-Webster mice exposed to 270 to $860 \mathrm{mg} / \mathrm{kg}$ dimethylaminoethanol. ${ }^{40}$

\section{Humans}

No serious side effects were reported in humans treated orally with up to 1,200 mg dimethylaminoethanol/day (13.46 mmol/day). ${ }^{41}$

Oral administration of 10 to $20 \mathrm{mg}$ ( 0.042 to $0.084 \mathrm{mmol})$ dimethylaminoethanol tartrate to humans caused mild mental stimulation. ${ }^{24}$ Doses of $20 \mathrm{mg} /$ day $(0.084 \mathrm{mmol})$ gradually increased muscle tone and the frequency of convulsions in more susceptible individuals. Larger doses (unspecified) induced insomnia, muscle tenseness, and sporadic muscle twitches.

Humans treated with dimethylaminoethanol to relieve tardive dyskinesia exhibited severe cholinergic side effects, including nasal and oral secretion, dyspnea, and respiratory failure. ${ }^{42 ;} 43$ A meta-analysis of randomized controlled trials of dimethylaminoethanol indicated that not only was it no more effective at treating tardive dyskinesia than placebo, but treatment with 
dimethylaminoethanol was also associated with a significantly increased risk of adverse outcomes. ${ }^{44 ;} 45$

\section{Genetic Toxicity}

No studies on the genetic toxicity of dimethylaminoethanol were found in the published literature.

\section{Study Rationale}

Dimethylaminoethanol was nominated by the National Institute of Environmental Health Sciences (NIEHS) for toxicological characterization due to the potential for widespread human exposure through its use in industrial and consumer products. Dimethylaminoethanol is structurally similar to choline, an essential nutrient, and might affect choline uptake and synthesis in the body. Given the limited literature indicating that dimethylaminoethanol may be a teratogen and reproductive toxicant, and given the possibility for widespread exposure to the salt form of dimethylaminoethanol (dimethylaminoethanol bitartrate) as a dietary supplement in women of childbearing age, NTP conducted prenatal developmental toxicity studies to assess the effects of oral dimethylaminoethanol bitartrate administration in pregnant rats and on fetal development. 


\section{Materials and Methods}

\section{Overview of Prenatal Developmental Toxicity Study Designs}

Prenatal developmental toxicity studies are conducted to ascertain if in utero exposure to a test agent results in embryo-fetal death, structural malformations/variations, growth retardation, or functional deficits that are not secondary to overt maternal toxicity. Overt maternal toxicity has been shown to impact normal embryo-fetal growth and development (e.g., excessively lower maternal body weight gains and lower fetal weights, increased maternal stress in mice, and cleft palate). ${ }^{46-48}$ The presence of maternal toxicity, however, should not negate a priori an apparent fetal response. Rather, given the maternal/embryo-fetal interrelationship, maternal responses should be considered when interpreting fetal findings. Pregnant animals should be administered the highest feasible dose levels of test agent (or the limit dose) to achieve maximal dam and fetal exposure and sufficiently challenge the test system to identify potential developmental hazards. ${ }^{49}$

The conduct of a dose range-finding study helps determine dose selection when the potential for test agent-induced maternal toxicity is unknown, can provide preliminary information on embryo-fetal outcomes (e.g., postimplantation loss, changes in fetal weight, external defects), and informs the prenatal developmental toxicity study design. In the prenatal developmental toxicity study, fetal examination is expanded to include examination of the fetal viscera, head (soft tissue and skeletal components), and the skeleton for osseous and cartilaginous defects. Abnormalities are categorized in one of two groups: (1) malformations that are permanent structural changes that could adversely affect survival, development, or function; and (2) variations that are a divergence beyond the usual range of structural constitution but might not adversely affect survival or health,47 consistent with that described by Makris et al. ${ }^{50}$ The general study design for the dose range-finding and prenatal developmental toxicity studies in the rat is presented in Figure 2. 


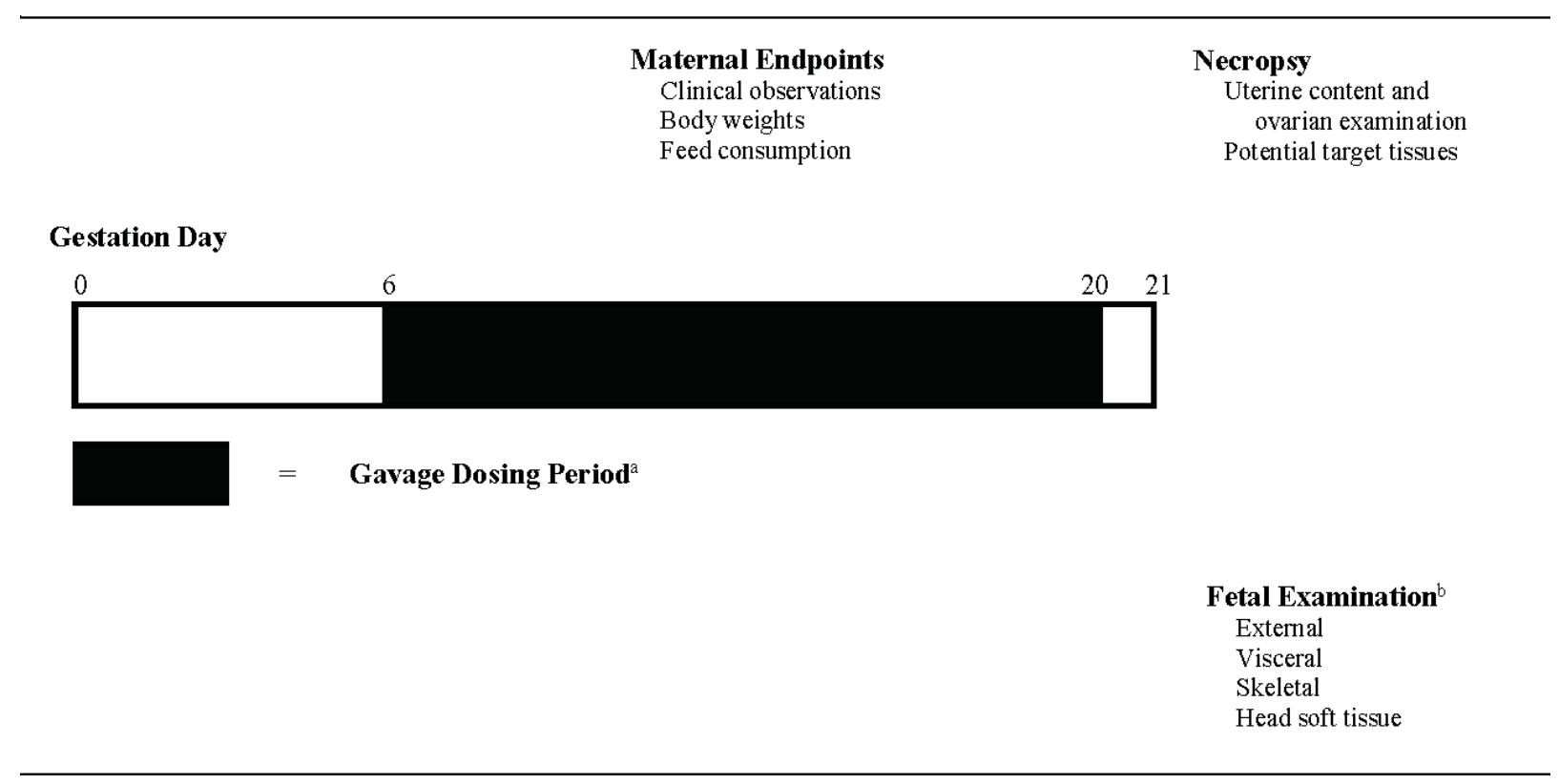

Figure 2. Design of a Dose Range-finding and Prenatal Developmental Toxicity Study in Rats

${ }^{a}$ Animals are exposed once daily from gestation day (GD) 6 to GD 20 and necropsied on GD 21.

${ }^{b}$ All fetuses are examined externally (including inspection of the oral cavity). Fetuses in the prenatal developmental toxicity study are also examined for visceral and skeletal effects with approximately $50 \%$ of the heads examined for soft tissue alterations.

\section{Procurement and Characterization}

\section{Dimethylaminoethanol Bitartrate}

Dimethylaminoethanol bitartrate (DMAE) was obtained from Bayville Chemical Supply Company, Inc. (Deer Park, NY) in one lot (159AK) that was used in the dose range-finding and prenatal developmental toxicity studies (Appendix A). Identity, purity, and stability analyses were conducted by the analytical chemistry laboratory at RTI International (Research Triangle Park, NC) for the study laboratory at Southern Research (Birmingham, AL). Lot 159AK of the chemical, a white crystalline powder, was identified as dimethylaminoethanol bitartrate using Fourier transform infrared (FTIR) and proton and carbon-13 nuclear magnetic resonance spectroscopy. The exact mass for dimethylaminoethanol and tartaric acid was determined using ultra high-performance liquid chromatography (UHPLC) coupled with time-of-flight mass spectrometry (TOF-MS) detection. In addition, the melting point of the bulk chemical was determined.

The moisture content of lot 159AK was measured by a desorption type Karl Fischer analysis and by thermogravimetric analysis (TGA); these procedures were conducted by Robertson Microlit Laboratory (Ledgewood, NJ). The purity of lot 159AK was determined by Galbraith Laboratories, Inc. (Knoxville, TN) using elemental analyses and by the analytical chemistry laboratory. RTI initially used UHPLC/TOF-MS with a hydrophilic interaction liquid chromatography (HILIC) gradient in the positive mode for dimethylaminoethanol and in the negative mode for tartaric acid; they subsequently used gas chromatography (GC) with MS detection. RTI assayed the bulk chemical for volatile organic impurities using two GC systems with flame ionization detection (FID). 
The Karl Fischer analysis indicated approximately 12\% water, and TGA results indicated an estimated maximum water content not greater than $3.5 \%$, as calculated from the mass lost in the temperature range matching the boiling point of water. Elemental analyses for carbon, hydrogen, nitrogen, and oxygen were consistent with the structural composition of dimethylaminoethanol bitartrate and theoretical values. UHPLC/TOF-MS indicated one major peak in chromatograms accounting for greater than $99.9 \%$ of the total peak area relative to either the dimethylaminoethanol or tartaric acid peaks. GC/MS indicated one major peak accounting for $100 \%$ of the total peak area; the spectrum was consistent with a library reference spectrum. ${ }^{51} \mathrm{~A}$ residual solvent screening assay using GC/FID by a second system tentatively identified the presence of ethanol at $0.325 \%(\mathrm{w} / \mathrm{w})$. The overall purity of lot 159AK was determined to be $96 \%$ or greater.

Stability studies of lot 159AK were conducted using the same HILIC gradient UHPLC/TOF-MS system used for the bulk chemical purity assessment. Results indicated that both dimethylaminoethanol and the counterion tartaric acid were stable in the bulk chemical for at least 14 days when stored in amber glass vials sealed with Teflon ${ }^{\circledR}$-lined caps at temperatures up to $60^{\circ} \mathrm{C}$. To ensure stability, the bulk chemical was stored at room temperature in sealed amber glass bottles. Reanalyses of the bulk chemical were performed prior to the dose range-finding study and after the prenatal developmental toxicity study using FTIR spectroscopy (dose rangefinding study only) and GC/FID by a fourth system—no degradation of the bulk chemical was detected.

\section{Sterile Water for Irrigation}

The sterile water vehicle was obtained from Baxter Healthcare Corporation (Cleveland, MS) in two lots (G105999 and G110783). Lot G10599 was used in the dose range-finding study, and lot G110783 was used in the prenatal developmental toxicity study.

\section{Preparation and Analysis of Dose Formulations}

The dose formulations were prepared once for each study by mixing dimethylaminoethanol bitartrate with sterile water to give the required concentrations (Appendix $\mathrm{D}^{52}$ ). The dose formulations were stored at room temperature in sealed amber glass bottles for up to 42 days.

The analytical chemistry laboratory used GC/FID to evaluate syringeability of a $300 \mathrm{mg} / \mathrm{mL}$ formulation using a 22-gauge gavage needle and stability of a $10 \mathrm{mg} / \mathrm{mL}$ formulation. Syringeability was confirmed, and stability was confirmed for at least 42 days for dimethylaminoethanol formulations stored in sealed clear glass bottles both refrigerated and up to room temperature and for 3 hours under simulated animal room conditions.

Additional stability studies of formulations of dimethylaminoethanol bitartrate in sterile water were performed to monitor the relative stability of the tartaric acid counterion and the $\mathrm{pH}$ of the formulations. Two formulations ( 25.0 and $22.5 \mathrm{mg} / \mathrm{mL}$ ) of dimethylaminoethanol bitartrate in sterile water were prepared for direct comparison to standards of tartaric acid at concentrations equivalent to those present in the formulations. After dilution into the range of a validated analytical method, a $300 \mathrm{mg} / \mathrm{mL}$ formulation was also analyzed using HPLC. Formulations were determined to have a stable tartaric acid concentration for at least 42 days. The $\mathrm{pH}$ of the formulations across the concentration range 2.5 to $300 \mathrm{mg} / \mathrm{mL}$ was between 3.4 and 3.6; the 
$10 \mathrm{mg} / \mathrm{mL}$ formulation suggests that the $\mathrm{pH}$ did not change over the period of 42 days when stored either refrigerated or at room temperatures.

Periodic analyses of the dose formulations of dimethylaminoethanol bitartrate were conducted by the analytical chemistry laboratory using GC/FID. During the dose range-finding study, the dose formulations were analyzed once; all three of the dose formulations were within $10 \%$ of the target concentrations. Animal room samples of these dose formulations were also analyzed, and all three were within $10 \%$ of the target concentrations. During the prenatal developmental toxicity study, the dose formulations were analyzed once; all three dose formulations analyzed were used and all three animal room samples were within $10 \%$ of the target concentrations.

\section{Animal Source}

Female Sprague Dawley (Hsd:Sprague Dawley ${ }^{\circledR} \mathrm{SD}^{\circledR}$ ) rats were obtained from Envigo (formerly Harlan Laboratories, Inc., Indianapolis, IN) for use in the dose range-finding and prenatal developmental toxicity studies (Table 1 ). Sexually mature (12 to 13 weeks old) females were time-mated overnight at the vendor and were received on gestation day (GD) 1 or 2 for both the dose range-finding and prenatal developmental toxicity studies. GD 0 was defined as the day positive evidence of mating was observed.

\section{Animal Health Surveillance}

Disease screening was not conducted; however, rats were obtained from a commercial colony free of the following rat pathogens: Sendai virus, pneumonia virus of mice, sialodacryoadenitis virus, Kilham rat virus, Toolan’s H1 virus, rat minute virus, reovirus, rat theilovirus, lymphocytic choriomeningitis virus, hanta virus, mouse adenovirus, rat parvovirus, Mycoplasma pulmonis, and Pneumocystis carinii.

\section{Animal Welfare}

Animal care and use were in accordance with the Public Health Service Policy on Humane Care and Use of Animals. All animal studies were conducted in an animal facility accredited by AAALAC International. Studies were approved by the Southern Research Animal Care and Use Committee and conducted in accordance with all relevant National Institutes of Health (NIH) and National Toxicology Program (NTP) animal care and use policies and applicable federal, state, and local regulations and guidelines.

\section{Experimental Design}

In both dimethylaminoethanol bitartrate studies, time-mated rats were housed individually, provided NIH-07 feed and water ad libitum, and observed at least twice daily for viability (morning and afternoon). Clinical observations were recorded on GD 3 (prenatal developmental toxicity study only), and on GD 6 through GD 21 until removal, typically twice daily (at the time of dose administration and cage side postdose). Dams in the dose range-finding study were weighed daily from GD 3 through GD 21, and those in the prenatal developmental toxicity study were weighed on the day of arrival, on GD 3, and daily from GD 6 through GD 21. Feed consumption was recorded for GD 6 to 9, GD 9 to 12, GD 12 to 15, GD 15 to 18, and GD 18 to 21. Details of the study design-including animal source and identification, diet, water, husbandry, environmental conditions, euthanasia, necropsy, and fetal evaluations - are 
summarized in Table 1. Information on feed composition and contaminants are provided in Appendix B.

On GD 21, rats were weighed, euthanized with $\mathrm{CO}_{2}$ inhalation, and examined for gross lesions of the thoracic and abdominal cavities. The liver and gravid uterus were excised and weighed (liver for the prenatal developmental toxicity study only), and any placental findings were recorded. The numbers of uterine implantation sites and corpora lutea visible on the surface of each ovary were recorded. Uterine contents were examined for pregnancy status, and the number and location of all live and dead fetuses (a live fetus is defined as one that responds to stimuli; a dead fetus is defined as a term fetus that does not respond to stimuli and is not markedly autolyzed) and resorptions were recorded. Resorptions were classified as early or late. Early resorptions included a conceptus characterized by a grossly necrotic mass that had no recognizable fetal form or presence of nidation sites ("pregnant by stain”). Late resorptions were characterized by grossly necrotic but recognizable fetal forms with placental remains visible. ${ }^{53 ; 54}$ Postimplantation loss was calculated as the number of dead plus resorbed conceptuses divided by the total number of implantations (multiplied by 100). For each uterus with no macroscopic evidence of implantation, the uterus was stained with $10 \%(\mathrm{v} / \mathrm{v})$ ammonium sulfide to visualize any possible early implantation sites. ${ }^{55}$

Adult females that were euthanized moribund, delivered early, or found dead received a gross necropsy that included an examination of the thoracic and abdominal viscera for evidence of dosing trauma or toxicity. The uterus of each female was examined and stained, if necessary, to determine pregnancy status. Dams were not retained for further examination.

\section{Dose Range-finding Study}

Time-mated rats were individually identified by tail marking and randomized by GD 3 body weight stratification into four groups (vehicle control, low, mid, or high) using Southern Research’s Instem $^{\mathrm{TM}}$ Provantis $^{\circledR}$ (version 8) electronic data collection system.

Groups of 10 time-mated female rats were administered 0 (vehicle control), 250, 500, or $1,000 \mathrm{mg}$ dimethylaminoethanol bitartrate/kg body weight per day (mg/kg/day) calculated from the most recent body weight, in sterile water by gavage from GD 6 to GD 20. Vehicle control animals received sterile water alone; the dosing volume was $5 \mathrm{~mL} / \mathrm{kg}$ body weight.

A high dose of $1,000 \mathrm{mg} / \mathrm{kg}$ dimethylaminoethanol bitartrate was selected for the dose rangefinding study because $1,000 \mathrm{mg} / \mathrm{kg}$ is the limit dose recommended by the Organisation for Economic Co-operation and Development (OECD) for prenatal developmental toxicity studies. ${ }^{49}$

On GD 21, fetuses were removed from the uterus, individually weighed (live fetuses only), and examined externally for alterations, including inspection of the oral cavity for cleft palate. Live fetuses were euthanized by decapitation or with intraperitoneal injection of a commercially available solution containing sodium pentobarbital followed by bilateral pneumothorax and/or decapitation. Fetuses were not retained following completion of the external examination.

\section{Prenatal Developmental Toxicity Study}

On receipt (GD 1 or 2), time-mated rats were individually identified by tail marking and randomized by GD 3 body weight stratification into four groups (vehicle control, low, mid, or 
high) using Southern Research’s Instem ${ }^{\mathrm{TM}}$ Provantis ${ }^{\circledR}$ (version 8) electronic data collection system. Dams were received in three groups, at least 2 days apart, to allow for a staggered study start.

Groups of 25 time-mated female rats were administered 0 (vehicle control), 250, 500, or $1,000 \mathrm{mg}$ dimethylaminoethanol bitartrate/kg/day (based on the most recent body weight) in sterile water by gavage from GD 6 to GD 20. Vehicle control animals received sterile water alone; the dosing volume was $5 \mathrm{~mL} / \mathrm{kg}$ body weight.

On GD 21, fetuses were removed from the uterus, and live fetuses individually weighed. The uteri of animals that did not appear pregnant were examined for nidations (implantation sites) by staining with $0.5 \%$ ammonium sulfide. ${ }^{55 ; 56}$ All fetuses were examined externally for alterations, including inspection of the oral cavity for cleft palate. Live fetuses were subsequently euthanized by intraperitoneal injection of sodium pentobarbital. Fetal sex was confirmed by inspection of gonads in situ. All fetuses were examined for soft tissue alterations under a stereomicroscope. ${ }^{57}$; 58 The heads were removed from approximately half of the fetuses in each litter, fixed in Bouin's solution, and subsequently examined by free-hand sectioning. ${ }^{59}$ This technique precludes skeletal evaluations of the skull; therefore, remaining heads and all fetuses were eviscerated, fixed in ethanol, macerated in potassium hydroxide, stained with alcian blue and alizarin red, and examined for subsequent cartilage and osseous alterations. ${ }^{56 ; 60}$ External, visceral, and skeletal fetal alterations were recorded as developmental variations or malformations.

Table 1. Experimental Design and Materials and Methods in the Dose Range-finding and Prenatal Developmental Toxicity Gavage Studies of Dimethylaminoethanol Bitartrate in Rats

\begin{tabular}{|c|c|}
\hline Dose Range-finding Study & Prenatal Developmental Toxicity Study \\
\hline \multicolumn{2}{|l|}{ Study Laboratory } \\
\hline Southern Research (Birmingham, AL) & Southern Research (Birmingham, AL) \\
\hline \multicolumn{2}{|l|}{ Strain and Species } \\
\hline Sprague Dawley (Hsd:Sprague Dawley ${ }^{\circledR} \mathrm{SD}^{\circledR}$ ) rats & Sprague Dawley (Hsd:Sprague Dawley ${ }^{\circledR} \mathrm{SD}^{\circledR}$ ) rats \\
\hline \multicolumn{2}{|l|}{ Animal Source } \\
\hline $\begin{array}{l}\text { Envigo (formerly Harlan Laboratories, Inc.) } \\
\text { (Indianapolis, IN) }\end{array}$ & $\begin{array}{l}\text { Envigo (formerly Harlan Laboratories, Inc.) } \\
\text { (Indianapolis, IN) }\end{array}$ \\
\hline \multicolumn{2}{|l|}{ Day of Arrival } \\
\hline February 5, 2014 (GD 2) & $\begin{array}{l}\text { April 9, } 2014 \text { (GD } 1 \text { or } 2) \\
\text { April 11, } 2014 \text { (GD } 1 \text { or 2) } \\
\text { April 16, } 2014 \text { (GD } 1 \text { or 2) }\end{array}$ \\
\hline \multicolumn{2}{|l|}{ Average Age on Arrival } \\
\hline 12 weeks & 12 to 13 weeks \\
\hline \multicolumn{2}{|l|}{ Weight Range at Randomization } \\
\hline $224.8-262.3 \mathrm{~g}$ & 207.5 to 260.6 g on GD 3 \\
\hline \multicolumn{2}{|l|}{ Calendar Day of First Dose and Last Dose } \\
\hline $\begin{array}{l}\text { GD } 6 \text { (February 9, 2014) and GD } 20 \text { (February 24, } \\
\text { 2014) }\end{array}$ & $\begin{array}{l}\text { GD } 6 \text { (April 13, 14, 15, 16, or 20, 2014) and GD } 20 \\
\text { (April 27, 28, 29, 30, or May 4, 2014) }\end{array}$ \\
\hline
\end{tabular}




\section{Duration of Dosing}

GD 6 to 20, once daily

GD 6 to 20, once daily

\section{Size of Study Groups}

10 time-mated females

25 time-mated females

\section{Method of Randomization and Identification}

Time-mated animals were uniquely identified on day of receipt by indelible ink tail marking and assigned to one of four exposure groups by stratified randomization of GD 3 body weights using Instem Provantis ${ }^{\circledR}$ (version 8) electronic data collection system.

Each animal was assigned a unique animal number in Provantis. This number was linked to the respective tattoo, and all data collected during the study was associated with the Provantis animal number.

\section{Animals per Cage}

Diet

Irradiated NIH-07 0.5-inch pellet Certified Rodent Diet (Zeigler Brothers, Inc., Gardners, PA), available ad libitum

Same as dose range-finding study

\section{Water}

Tap water (Birmingham Water Works Co., Birmingham, Same as dose range-finding study AL, municipal supply) via automatic watering system, available ad libitum

\section{Cages}

Solid bottom polycarbonate cages (Lab Products, Inc., Seaford, DE), changed weekly

Same as dose range-finding study

\section{Bedding}

Certified irradiated Sani-Chips ${ }^{\circledR}$ hardwood cage bedding Same as dose range-finding study (P.J. Murphy Forest Products Corporation, Montville, NJ), changed weekly

\section{Cage Filters}

Reemay ${ }^{\circledR}$ spun-bonded polyester (Andico, Birmingham, Same as dose range-finding study AL), changed every 2 weeks

\section{Racks}

Stainless steel (Lab Products, Inc., Seaford, DE), changed every 2 weeks

Same as dose range-finding study

\section{Animal Room Environment}

Temperature: $72^{\circ} \mathrm{F} \pm 3^{\circ} \mathrm{F}$

Relative humidity: $50 \% \pm 15 \%$

Room fluorescent light: 12 hours/day

Room air changes: at least 10/hour
Same as dose range-finding study

Doses 


\begin{tabular}{l} 
Dose Range-finding Study \\
\hline 0, 250, 500 , or $1,000 \mathrm{mg} / \mathrm{kg}$ in sterile water (dosing \\
volume $5 \mathrm{~mL} / \mathrm{kg}$ ) \\
Type and Frequency of Observation of Dams
\end{tabular}

Observed for viability twice daily (cageside) from GD 3 through GD 20 Clinical observations (out of cage) were performed at least once during the pre-study period and at least once daily while on study (1 to 3 hours postdose).

Animals were weighed daily beginning on GD 3. Feed consumption was recorded at 3-day intervals from GD 6 through GD 21.

\section{Primary Method of Euthanasia}

$100 \% \mathrm{CO}_{2}$ (adults) or intraperitoneal injection of a solution containing sodium pentobarbital followed by bilateral pneumothorax and/or decapitation (fetuses)

\section{Necropsy and Postmortem Evaluation of Females}

On GD 21, terminal body weights and gravid uterine weights were recorded, and the uterine contents examined. The number of corpora lutea on each ovary was recorded. The number and location of all fetuses (live or dead) and resorptions (early or late) and the total number of implantation sites were recorded; if no macroscopic evidence of pregnancy, the uterus was stained with a $10 \%$ aqueous solution of ammonium sulfide to visualize potential evidence of implantation sites. There were no early removals.

\section{Fetal Evaluation}

Live fetuses were counted, sexed, weighed, and examined for external morphological abnormalities that included inspection of the oral cavity for cleft palate.

\section{Prenatal Developmental Toxicity Study}

$0,250,500$, or $1,000 \mathrm{mg} / \mathrm{kg}$ in sterile water (dosing volume $5 \mathrm{~mL} / \mathrm{kg}$ )

Observed for viability twice daily (cageside) from GD 3 through GD 20. Clinical observations (out of cage) were performed at least once during the pre-study period and at least once daily while on study (1 to 3 hours postdose).

Animals were weighed on the day of arrival, on GD 3, and on GD 6 through GD 21. Feed consumption was recorded at 3-day intervals from GD 6 through GD 21.

$100 \% \mathrm{CO}_{2}$ (adults) or decapitation or intraperitoneal injection of a solution containing sodium pentobarbital followed by bilateral pneumothorax and/or decapitation (fetuses)

On GD 21, terminal body, liver, and gravid uterine weights were recorded. Uterine contents were examined. The number of corpora lutea on each ovary was recorded. The number and location of all fetuses (live or dead) and resorptions (early or late) and the total number of implantation sites were recorded; if no macroscopic evidence of pregnancy, the uterus was stained with a $10 \%$ aqueous solution of ammonium sulfide to visualize potential evidence of implantation sites.

For animals removed early, gross necropsy including an examination of the thoracic and abdominal viscera was performed. The uterus of each female was examined to determine pregnancy status, or, if no evidence of pregnancy, stained to visualize possible early implantation sites.

Live fetuses were counted, sexed, weighed, and examined for external morphological abnormalities including inspection of the oral cavity for cleft palate. Placental morphology was also evaluated.

Live fetuses were euthanized and then examined for visceral morphological abnormalities by fresh dissection. The sex of each fetus was confirmed by internal examination. The heads from approximately one half of the fetuses in each litter were fixed, sectioned, and examined. All fetuses were eviscerated, fixed, stained, and examined for visceral and skeletal developmental variations, malformations, or other morphological findings.

GD = gestation day. 


\section{Statistical Methods}

In both the dose range-finding study and the main study, statistical analyses were performed on data from pregnant females that survived until the end of the study and were examined on GD 21 and from live fetuses. Statistical analyses were performed using SAS 9.3 (SAS Institute, Cary, NC).

\section{Descriptive Statistics}

Maternal Parameters: Maternal body weights were measured daily starting at GD 3 and reported as means. Terminal maternal body weights at GD 21 were adjusted for gravid uterine weight by subtracting the gravid uterine weight from the dam's body weight. Body weight gains were calculated over each 3-day interval and from GD 6 to GD 21. Daily feed consumption was averaged over each 3-day interval and from GD 6 to GD 21. These continuous variables, in addition to gravid uterine weights, other organ weights, hematology, and clinical chemistry were summarized with means and standard errors.

Placental and Fetal Parameters: Data on uterine contents are reported as means and standard errors of counts per dam/litter (corpora lutea, implants, resorptions, dead fetuses) and as total numbers of occurrences (resorptions, dead fetuses). Data from females that were not pregnant or that did not survive to the end of the study were not included. Postimplantation loss is calculated as a percentage of the number of implants per dam. Fetal findings are reported as means and standard errors of counts per litter (numbers of live fetuses, male fetuses, and female fetuses), means and standard errors of litter means (fetal weight, male fetal weight, and female fetal weight), and total numbers of occurrences (total number of live fetuses). In addition, several calculated variables are reported, including the percentage of live male fetuses per litter.

Incidences of morphological findings from the gross, external, visceral, skeletal, and head examinations of pathology of placentae and fetuses are presented as number and percentage of affected fetuses and as number and percentage of affected litters.

\section{Analysis of Maternal Parameters and Uterine Contents}

Maternal organ and body weight data, which historically have approximately normal distributions, were analyzed with the parametric multiple comparison procedures of Dunnett ${ }^{61}$ and Williams. ${ }^{62 ;} 63$ Non-normally distributed variables, such as feed consumption and uterine content endpoints, were analyzed using the nonparametric multiple comparison methods of Shirley ${ }^{64}$ (as modified by Williams ${ }^{65}$ ) and Dunn. ${ }^{66}$ For normally distributed and non-normally distributed variables, the Jonckheere test ${ }^{67}$ was used to assess the significance of dose-related trends at $\mathrm{p}<0.01$ to determine whether a monotonic trend-sensitive test (the Williams or Shirley test) was more appropriate than a test that does not assume a monotonic dose-related trend (the Dunnett or Dunn test). Prior to statistical analysis, extreme values identified by the outlier test of Dixon and Massey ${ }^{68}$ were examined by NTP personnel, and implausible values were eliminated from the analysis.

Fetal body weights were analyzed using mixed-effects linear models, with litter as a random effect to account for potential within-litter correlations. To test for a linear trend, the numerical values of dose were used, and the fit to a linear model was evaluated. For pairwise comparisons 
with the control group, a second mixed-effects model used dose as a categorical variable, followed by the Dunnett ${ }^{61}$ and $\mathrm{Hsu}^{69}$ multiple comparisons tests.

\section{Analysis of Incidences of Gross Pathology and Morphology Findings}

Incidences of gross findings, malformations, and variations in the fetuses were summarized and analyzed as the number of litters affected and as the number of fetuses affected. Incidences of gross findings, malformations, and numbers of litters affected were analyzed using the CochranArmitage trend test ${ }^{70}$ and Fisher's exact test. ${ }^{71}$ The numbers of fetuses affected were analyzed using mixed-effects logistic regression in which the litter was a random effect to account for potential litter effects..$^{7-74}$ For each fetal finding, an initial mixed-effects logistic regression model used the numerical value of dose to assess the significance of a dose-related trend; a subsequent logistic regression model incorporated dose as a categorical variable to compare each exposure group with the control group. To conduct the mixed-effects logistic regression analyses, at least one finding was required per exposure group, and the correlation matrix describing the relationship between litters was required to be "positive definite." If the mixedeffects logistic regression failed to converge or did not meet the specified criteria, two separate analyses were used to bracket the true p value. The Cochran-Armitage trend test and Fisher exact test were used with litter as the experimental unit to calculate the upper limit for the true $\mathrm{p}$ value and with fetus as the experimental unit to calculate the lower limit for the true p value.

\section{Historical Control Data}

The concurrent control group represents the most valid comparison to the treated groups and is the only control group analyzed statistically in NTP developmental and reproductive toxicity studies. However, historical control data are often helpful in interpreting potential exposurerelated effects, particularly for uncommon fetal findings that occur at very low incidence. For meaningful comparisons, the conditions for studies in the historical control database must be generally similar. Factors that could affect the background incidences of fetal findings at a variety of anatomical sites are diet, sex, strain/stock, route of exposure, study type, and laboratory that conducted the study. The NTP historical control database for teratology studies contains all fetal evaluations (e.g., teratology studies or modified one-generation studies) for each laboratory. In general, the historical control database for a given study includes studies using the same route of administration and study design. Historical control data for rats in this Developmental and Reproductive Toxicity Technical Report represent data from gavage studies conducted at Southern Research. The concurrent controls are included in the historical control data set. NTP historical controls are available online at https://ntp.niehs.nih.gov/go/historical_controls.

\section{Quality Assurance Methods}

The dose range-finding and prenatal developmental toxicity studies were conducted in compliance with Food and Drug Administration Good Laboratory Practice Regulations (21 CFR, Part 58). Records from these studies were submitted to the NTP Archives. The prenatal developmental toxicity study was audited retrospectively by an independent quality assessment contractor. Separate audits covered completeness and accuracy of the final study data tables for the dose range-finding and prenatal developmental toxicity studies and a draft of this NTP Developmental and Reproductive Toxicity Technical Report. Audit procedures and findings are 
presented in the reports and are on file at NIEHS. The audit findings were reviewed and assessed by NTP staff, and all comments were resolved or otherwise addressed during the preparation of this report. 


\section{Results}

\section{Data Availability}

NTP evaluated all study data. Data relevant for evaluating toxicological findings are presented here. All study data are available in the NTP Chemical Effects in Biological Systems (CEBS) database: http://dx.doi.org/10.22427/NTP-DATA-DART-04. ${ }^{52}$

\section{Dose Range-finding Study in Rats}

\section{Maternal Findings}

Viability and Clinical Observations

All dams survived to end of the study (Table 2). There were no treatment-related clinical observations (Appendix $\mathrm{D}^{52}$ ).

Table 2. Maternal Disposition of Rats in the Dose Range-finding Gavage Study of Dimethylaminoethanol Bitartrate

\begin{tabular}{lcccc}
\hline & $\mathbf{0 ~} \mathbf{~ m g} / \mathbf{k g}$ & $\mathbf{2 5 0} \mathbf{~} \mathbf{g} / \mathbf{k g}$ & $\mathbf{5 0 0} \mathbf{~} \mathbf{g} / \mathbf{k g}$ & $\mathbf{1 , 0 0 0} \mathbf{~ m g} / \mathbf{k g}$ \\
\hline Time-mated Females & 10 & 10 & 10 & 10 \\
Pregnant Females Examined (on GD 21) & 9 & 7 & 10 & 8 \\
Nonpregnant (on GD 21) & 1 & 3 & 0 & 2 \\
\hline
\end{tabular}

\section{Body Weights and Feed Consumption}

There were no dose-related effects on maternal body weight gain during gestation (Figure 3, Table 3; Appendix $\mathrm{D}^{52}$ ). One 1,000 mg/kg dam lost body weight between gestation day (GD) 15 and GD 18 (loss of 15.5 g) and between GD 18 and GD 21 (loss of 23.7 g), which coincided with decreased feed consumption by the same animal. This body weight decrease was not considered treatment related.

Mean feed consumption for the intervals or the overall dosing period was not affected by administration of dimethylaminoethanol bitartrate (Table 4). 


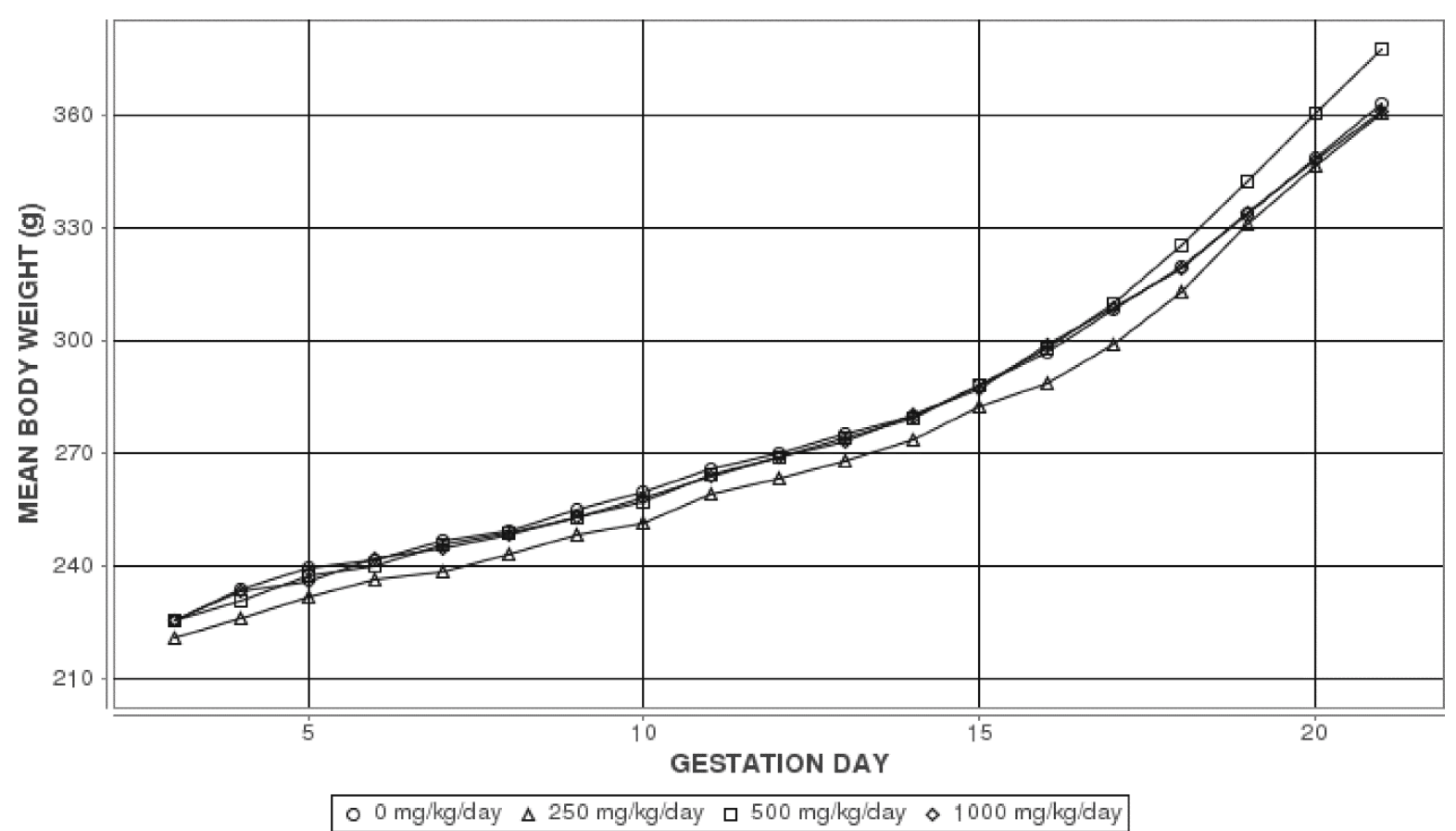

Figure 3. Maternal Growth Curves for Pregnant Rats Administered Dimethylaminoethanol Bitartrate by Gavage in the Dose Range-finding Study

Information for statistical significance in maternal weights is provided in Table 3 and Appendix D. ${ }^{52}$

Table 3. Summary of Maternal Body Weight Gains of Rats in the Dose Range-finding Gavage Study of Dimethylaminoethanol Bitartrate ${ }^{a}$

\begin{tabular}{|c|c|c|c|c|}
\hline $\begin{array}{l}\text { Gestation Day } \\
\text { Interval }\end{array}$ & $0 \mathrm{mg} / \mathrm{kg}$ & $250 \mathrm{mg} / \mathrm{kg}$ & $500 \mathrm{mg} / \mathrm{kg}$ & $1,000 \mathrm{mg} / \mathrm{kg}$ \\
\hline $6-21$ & $121.5 \pm 10.5(9)$ & $124.4 \pm 12.9(7)$ & $137.5 \pm 5.5(10)$ & $119.0 \pm 15.9$ (8) \\
\hline $3-6$ & $15.7 \pm 2.7(9)$ & $15.1 \pm 1.1(7)$ & $14.8 \pm 1.0(10)$ & $16.5 \pm 1.8(8)$ \\
\hline $6-9$ & $13.9 \pm 1.1(9)$ & $11.9 \pm 1.4(7)$ & $12.9 \pm 1.5(10)$ & $10.9 \pm 1.0(8)$ \\
\hline $9-12$ & $14.9 \pm 1.2(9)$ & $15.0 \pm 0.9(7)$ & $16.1 \pm 1.1(10)$ & $15.9 \pm 0.6(8)$ \\
\hline $12-15$ & $18.0 \pm 2.0(9)$ & $19.3 \pm 2.3(7)$ & $19.0 \pm 1.7(10)$ & $18.1 \pm 1.5(8)$ \\
\hline $15-18$ & $31.5 \pm 2.8(9)$ & $30.4 \pm 4.1(7)$ & $37.3 \pm 2.6(10)$ & $31.9 \pm 7.0(8)$ \\
\hline $18-21$ & $43.3 \pm 5.1(9)$ & $47.8 \pm 5.6(7)$ & $52.3 \pm 1.6(10)$ & $42.2 \pm 9.7(8)$ \\
\hline
\end{tabular}

Statistical analyses performed by the Jonckheere test (trend) and the Williams or Dunnett test (pairwise comparison) found no statistically significant trend or difference from the control group in a pairwise comparison.

aBody weight gains for pregnant animals are given in grams. Data are displayed as mean \pm standard error (n). 
Table 4. Summary of Maternal Feed Consumption of Rats in the Dose Range-finding Gavage Study of Dimethylaminoethanol Bitartrate ${ }^{\mathrm{a}}$

\begin{tabular}{ccccc}
\hline $\begin{array}{c}\text { Gestation Day } \\
\text { Interval }\end{array}$ & $\mathbf{0 ~} \mathbf{~ m g / k g}$ & $\mathbf{2 5 0} \mathbf{~ m g} / \mathbf{k g}$ & $\mathbf{5 0 0} \mathbf{~} \mathbf{g g} / \mathbf{k g}$ & $\mathbf{1 , 0 0 0} \mathbf{~} \mathbf{g} / \mathbf{k g}$ \\
\hline $6-21$ & $21.8 \pm 0.4(9)$ & $22.0 \pm 0.7(7)$ & $22.3 \pm 0.6(10)$ & $21.7 \pm 0.8(8)$ \\
$6-9^{\mathrm{b}}$ & $19.3 \pm 0.2(4)$ & $19.3 \pm 0.9(3)$ & $18.9 \pm 1.1(5)$ & $19.1 \pm 0.3(4)$ \\
$9-12$ & $21.6 \pm 0.5(9)$ & $21.2 \pm 0.8(7)$ & $22.0 \pm 0.5(10)$ & $21.9 \pm 0.7(8)$ \\
$12-15$ & $21.6 \pm 0.4(9)$ & $21.6 \pm 0.9(7)$ & $21.2 \pm 0.6(10)$ & $21.3 \pm 0.3(8)$ \\
$15-18$ & $23.4 \pm 0.5(9)$ & $23.2 \pm 0.8(7)$ & $24.3 \pm 0.8(10)$ & $24.0 \pm 1.0(8)$ \\
$18-21$ & $23.6 \pm 0.7(9)$ & $24.6 \pm 1.0(7)$ & $24.6 \pm 0.5(10)$ & $22.2 \pm 3.0(8)$ \\
\hline
\end{tabular}

Statistical analysis performed by the Jonckheere test (trend) and the Shirley or Dunn test (pairwise comparison) found no statistically significant trend or pairwise comparison to the control group.

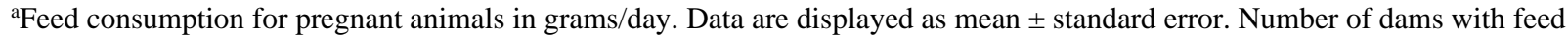
consumption measured is given in parentheses.

because of a technical error, feed consumption was not recorded for a number of dams on GD 9.

\section{Maternal and Litter Observations}

Gross observations at necropsy were limited to skin discoloration in one 1,000 $\mathrm{mg} / \mathrm{kg}$ rat and fluid in the uterus of one $250 \mathrm{mg} / \mathrm{kg}$ rat and one $1,000 \mathrm{mg} / \mathrm{kg}$ rat (Appendix $\mathrm{D}^{52}$ ). These observations were not considered related to chemical administration.

The number of pregnant animals, the mean number of corpora lutea, dead fetuses, early and late resorptions, and sex ratio were similar across all treatment groups (Table 5). There was a significant positive trend in the mean number of live female fetuses per litter relative to dose (Table 5). There was no effect of dose on mean fetal body weight per litter.

Table 5. Summary of Maternal Feed Consumption of Rats in the Dose Range-finding Gavage Study of Dimethylaminoethanol Bitartrate ${ }^{\mathrm{a}}$

\begin{tabular}{|c|c|c|c|c|}
\hline & $0 \mathrm{mg} / \mathrm{kg}$ & $250 \mathrm{mg} / \mathrm{kg}$ & $500 \mathrm{mg} / \mathrm{kg}$ & $1,000 \mathrm{mg} / \mathrm{kg}$ \\
\hline \multicolumn{5}{|l|}{ Pregnancy Summary } \\
\hline Mated females & 10 & 10 & 10 & 10 \\
\hline Pregnant females & 9 & 7 & 10 & 8 \\
\hline Pregnant females examined on GD $21^{\mathrm{a}}$ & 9 & 7 & 10 & 8 \\
\hline Corpora lutea per female ${ }^{\mathrm{b}}$ & $14.89 \pm 0.54(9)$ & $16.00 \pm 1.23(7)$ & $15.40 \pm 0.65(10)$ & $14.75 \pm 0.65(8)$ \\
\hline Implantations per female ${ }^{\mathrm{b}}$ & $11.33 \pm 1.38(9)$ & $11.86 \pm 1.90(7)$ & $13.10 \pm 0.71(10)$ & $14.00 \pm 0.65(8)$ \\
\hline Percent postimplantation loss ${ }^{\mathrm{b}}$ & $10.22 \pm 7.35(9)$ & $0.95 \pm 0.95(7)$ & $2.30 \pm 1.19(10)$ & $3.42 \pm 1.30(8)$ \\
\hline Total resorptions per litter ${ }^{\mathrm{b}}$ & $0.56 \pm 0.29(9)$ & $0.14 \pm 0.14(7)$ & $0.30 \pm 0.15(10)$ & $0.50 \pm 0.19(8)$ \\
\hline Early resorptions per litter ${ }^{\mathrm{b}}$ & $0.56 \pm 0.29(9)$ & $0.14 \pm 0.14(7)$ & $0.30 \pm 0.15(10)$ & $0.50 \pm 0.19(8)$ \\
\hline Late resorptions per litter ${ }^{\mathrm{b}}$ & $0.00 \pm 0.00(9)$ & $0.00 \pm 0.00(7)$ & $0.00 \pm 0.00(10)$ & $0.00 \pm 0.00(8)$ \\
\hline Dead fetuses per litter ${ }^{\mathrm{b}}$ & $0.00 \pm 0.00(9)$ & $0.00 \pm 0.00(7)$ & $0.00 \pm 0.00(10)$ & $0.00 \pm 0.00(8)$ \\
\hline Number of early resorptions ${ }^{c}$ & 5 & 1 & 3 & 4 \\
\hline Number of late resorptions & 0 & 0 & 0 & 0 \\
\hline Number of whole litter resorptions & 0 & 0 & 0 & 0 \\
\hline
\end{tabular}




\section{Dimethylaminoethanol Bitartrate, NTP DART 04}

\begin{tabular}{|c|c|c|c|c|}
\hline & 0 mg/kg & $250 \mathrm{mg} / \mathrm{kg}$ & $500 \mathrm{mg} / \mathrm{kg}$ & $1,000 \mathrm{mg} / \mathrm{kg}$ \\
\hline Number of dead fetuses & 0 & 0 & 0 & 0 \\
\hline \multicolumn{5}{|l|}{ Live Fetuses $^{\mathrm{b}}$} \\
\hline Number of live fetuses & 97 & 82 & 128 & 108 \\
\hline Live fetuses per litter & $10.78 \pm 1.55$ (9) & $11.71 \pm 1.86(7)$ & $12.80 \pm 0.71(10)$ & $13.50 \pm 0.60(8)$ \\
\hline Live male fetuses per litter & $5.56 \pm 1.09(9)$ & $7.00 \pm 1.31(7)$ & $7.10 \pm 0.80(10)$ & $6.38 \pm 0.65(8)$ \\
\hline Live female fetuses per litter & $5.22 \pm 0.88(9)^{*}$ & $4.71 \pm 1.02(7)$ & $5.70 \pm 0.83(10)$ & $7.13 \pm 0.30(8)$ \\
\hline Percent live male fetuses per litter & $44.84 \pm 8.15(9)$ & $64.57 \pm 8.10(7)$ & $55.99 \pm 5.40(10)$ & $46.54 \pm 2.99(8)$ \\
\hline \multicolumn{5}{|l|}{ Fetal Weight $(\mathrm{g})^{\mathrm{d}}$} \\
\hline Fetal body weight per litter & $5.39 \pm 0.05(9)$ & $5.39 \pm 0.17(7)$ & $5.40 \pm 0.05(10)$ & $5.08 \pm 0.40(8)$ \\
\hline Male fetal weight per litter & $5.53 \pm 0.07(8)$ & $5.45 \pm 0.16(7)$ & $5.52 \pm 0.06(10)$ & $5.21 \pm 0.41(8)$ \\
\hline Female fetal weight per litter & $5.26 \pm 0.09(9)$ & $5.18 \pm 0.15(6)$ & $5.25 \pm 0.05(10)$ & $4.97 \pm 0.39(8)$ \\
\hline \multicolumn{5}{|l|}{ Gravid Uterine Weight (g) } \\
\hline Gravid uterine weight & $80.57 \pm 10.81(9)$ & $84.13 \pm 14.08(7)$ & $94.56 \pm 4.66(10)$ & $93.54 \pm 5.54(8)$ \\
\hline Terminal body weight & $363.1 \pm 12.0(9)$ & $360.8 \pm 12.9(7)$ & $377.8 \pm 7.3(10)$ & $361.3 \pm 16.0(8)$ \\
\hline Adjusted body weight & $282.56 \pm 4.18(9)$ & $276.63 \pm 5.67(7)$ & $283.24 \pm 4.73(10)$ & $267.80 \pm 11.29(8)$ \\
\hline
\end{tabular}

Values are reported per litter as mean \pm standard error (n) and do not include nonpregnant animals or those that did not survive to the end of the study.

*Statistically significant $(\mathrm{p} \leq 0.05)$ trend (denoted in vehicle control column).

GD = gestation day.

aStatistical analysis performed by the Cochran-Armitage (trend) and Fisher exact (pairwise) tests.

bStatistical analysis of number per litter or female performed by the Jonckheere's (trend) and Shirley or Dunn (pairwise) tests.

cStatistical analysis not performed on number of early resorptions.

${ }^{\mathrm{d} S t a t i s t i c a l ~ a n a l y s i s ~ p e r f o r m e d ~ u s i n g ~ a ~ m i x e d-e f f e c t s ~ l i n e a r ~ m o d e l ~ w i t h ~ l i t t e r ~ a s ~ a ~ r a n d o m ~ e f f e c t ~(t r e n d ~ a n d ~ p a i r w i s e) . ~}$

'Statistical analysis performed by the Jonckheere (trend) and Williams or Dunnett (pairwise) tests;

adjusted body weight $=$ terminal body weight minus gravid uterine weight.

\section{Fetal Findings}

\section{External}

No external malformations or variations were observed in either the vehicle control or exposed groups (Appendix $\mathrm{D}^{52}$ ).

\section{Dose Selection Rationale for the Prenatal Developmental Toxicity Study in Rats}

No maternal toxicity was observed in the dose range-finding study up to the limit dose of $1,000 \mathrm{mg} / \mathrm{kg}$. Thus, dose concentrations of 250,500 , and $1,000 \mathrm{mg} / \mathrm{kg}$ dimethylaminoethanol bitartrate were chosen for the subsequent prenatal developmental toxicity gavage study. 


\section{Prenatal Developmental Toxicity Study in Rats}

\section{Maternal Findings}

\section{Viability and Clinical Observations}

One $1,000 \mathrm{mg} / \mathrm{kg} /$ day dam was euthanized moribund on GD 21 following observations of dehydration, coldness to touch, brown discoloration in both eyes, and hypoactivity, but it is unclear if this condition was related to treatment (Table 6). Offspring from this dam were examined and included in fetal assessments. A second 1,000 mg/kg dam was found dead on GD 10; however, this death was determined to be the result of a gavage accident given the breathing difficulties observed after dosing. One vehicle control dam and one 1,000 mg/kg dam delivered prior to scheduled C-section on GD 21, and were therefore euthanized on GD 19 and 20, respectively. All other dams survived to the end of the study.

Clinical observations were generally limited to single or sporadic incidences among groups except vaginal discharge (Appendix $\mathrm{D}^{52}$ ). Brown or red vaginal discharge was observed between GD 14 and GD 21 in 10, 3, 4, and 10 dams in the 0, 250, 500, and 1,000 mg/kg groups, respectively; however, given the lack of a dose-response trend, the observations of vaginal discharge were considered unrelated to chemical administration.

Table 6. Maternal Disposition of Rats in the Prenatal Developmental Toxicity Gavage Study of Dimethylaminoethanol Bitartrate

\begin{tabular}{lcccc}
\hline & $\mathbf{0 ~} \mathbf{~ g} / \mathbf{k g}$ & $\mathbf{2 5 0} \mathbf{~} \mathbf{g} / \mathbf{k g}$ & $\mathbf{5 0 0} \mathbf{~} \mathbf{g} / \mathbf{k g}$ & $\mathbf{1 , 0 0 0} \mathbf{~} \mathbf{g} / \mathbf{k g}$ \\
\hline Time-mated Females & 25 & 25 & 25 & 25 \\
Pregnant Females Examined (on GD 21) & 19 & 20 & 20 & 21 \\
Delivered Early & $1^{\mathrm{a}}$ & 0 & 0 & $1^{\mathrm{b}}$ \\
Euthanized Moribund & 0 & 0 & 0 & $1^{\mathrm{c}}$ \\
Found Dead & 0 & 0 & 0 & $1^{\mathrm{d}}$ \\
Nonpregnant (on GD 21) & 5 & 5 & 5 & 1 \\
\hline
\end{tabular}

GD = gestation day.

${ }^{\mathrm{a} D a m}$ removed on GD 19.

bDam removed on GD 20.

'Dam removed on GD 21; dam and offspring were included in maternal and fetal assessments.

${ }^{\mathrm{d}}$ Dam removed on GD 10.

\section{Body Weights and Feed Consumption}

There were no dose-related effects on maternal body weight or body weight gain during gestation in any dose group (Figure 4 and Table 7; Appendix $\mathrm{D}^{52}$ ); however, there was a significant increase (approximately 16\%) in body weight gain in the $500 \mathrm{mg} / \mathrm{kg} / \mathrm{day}$ dams relative to the vehicle control group between GD 6 and GD 21 (Table 7).

Mean feed consumption values were similar between vehicle control and dosed dams (Table 8). The $1,000 \mathrm{mg} / \mathrm{kg}$ pregnant dam euthanized moribund on GD 21 exhibited decreased feed consumption between GDs 15 and 21. 


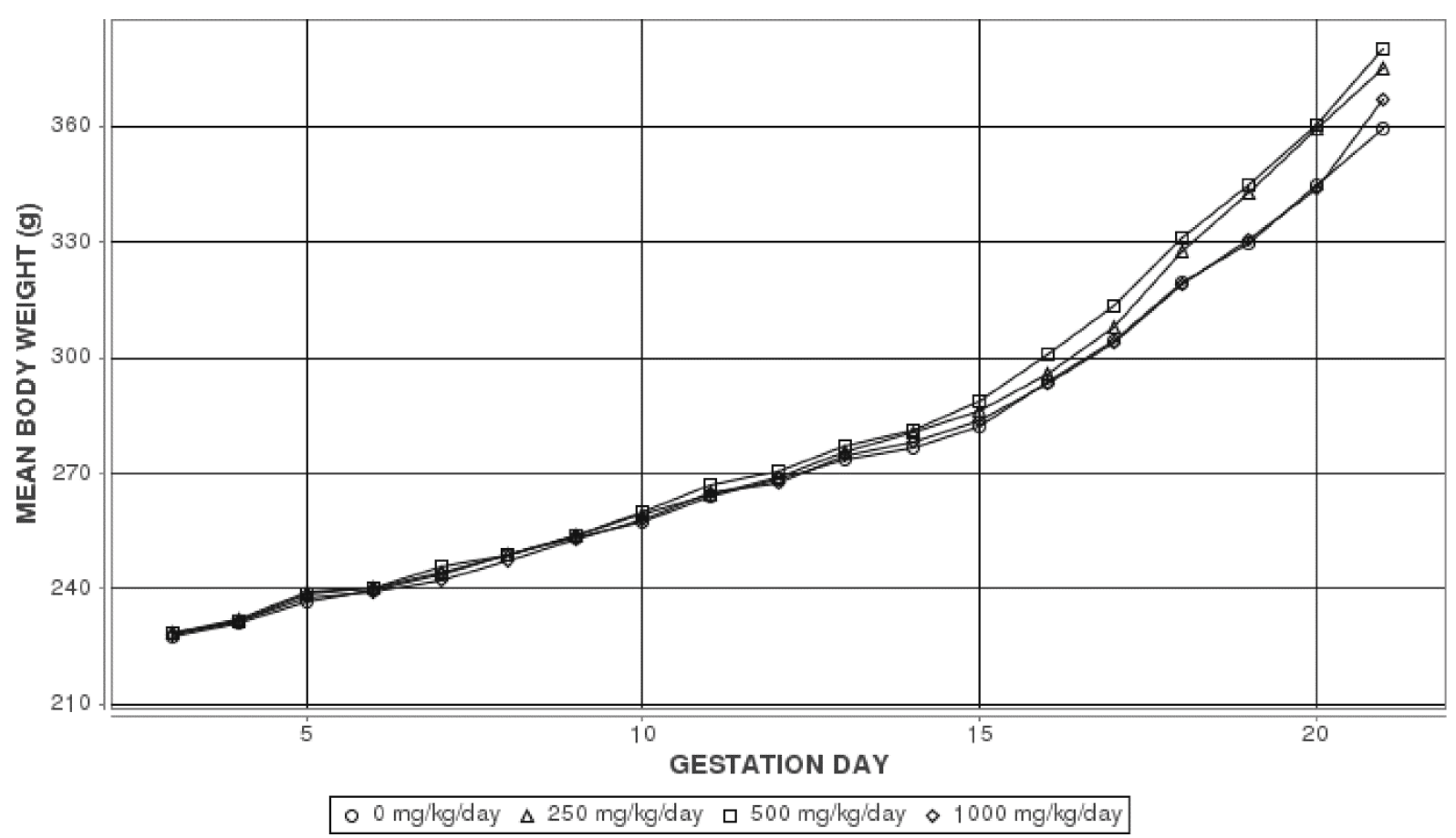

Figure 4. Maternal Growth Curves for Pregnant Rats Administered Dimethylaminoethanol Bitartrate by Gavage in the Prenatal Developmental Toxicity Study

Information for statistical significance in maternal weights is provided in Table 7 and Appendix D. ${ }^{52}$

Table 7. Summary of Maternal Body Weight Gains of Rats in the Prenatal Developmental Toxicity Gavage Study of Dimethylaminoethanol Bitartrate ${ }^{a}$

\begin{tabular}{ccccc}
\hline $\begin{array}{c}\text { Gestation Day } \\
\text { Interval }\end{array}$ & $\mathbf{0 ~} \mathbf{~ m g} / \mathbf{k g}$ & $\mathbf{2 5 0} \mathbf{~ m g} / \mathbf{k g}$ & $\mathbf{5 0 0} \mathbf{~} \mathbf{~ g} / \mathbf{k g}$ & $\mathbf{1 , 0 0 0} \mathbf{~ m g} / \mathbf{k g}$ \\
\hline $6-21$ & $120.5 \pm 7.5(19)$ & $135.2 \pm 4.7(20)$ & $140.0 \pm 4.2^{*}(20)$ & $127.7 \pm 5.8(21)$ \\
$3-6$ & $11.8 \pm 0.9(20)$ & $11.3 \pm 0.9(20)$ & $11.6 \pm 1.2(20)$ & $11.1 \pm 0.8(24)$ \\
$6-9$ & $13.6 \pm 0.6(20)$ & $14.1 \pm 1.0(20)$ & $13.7 \pm 0.9(20)$ & $13.3 \pm 1.1(24)$ \\
$9-12$ & $15.2 \pm 0.8(20)$ & $15.0 \pm 0.9(20)$ & $16.4 \pm 1.0(20)$ & $14.8 \pm 0.9(23)$ \\
$12-15$ & $13.6 \pm 1.9(20)$ & $17.2 \pm 2.3(20)$ & $18.1 \pm 1.3(20)$ & $15.6 \pm 2.1(23)$ \\
$15-18$ & $37.7 \pm 3.5(20)$ & $41.2 \pm 1.9(20)$ & $42.8 \pm 1.5(20)$ & $35.4 \pm 4.7(23)$ \\
$18-21$ & $41.6 \pm 3.1(19)$ & $47.8 \pm 2.3(20)$ & $49.0 \pm 2.1(20)$ & $43.2 \pm 2.1(21)$ \\
\hline
\end{tabular}

Statistical analysis performed by the Jonckheere test found no statistically significant trend.

*Statistically significant $(\mathrm{p} \leq 0.05$ ) pairwise comparison by the Williams or Dunnett test.

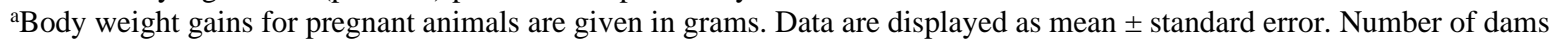
weighed is given in parentheses. 
Table 8. Summary of Maternal Feed Consumption of Rats in the Prenatal Developmental Toxicity Study of Dimethylaminoethanol Bitartrate ${ }^{a}$

\begin{tabular}{|c|c|c|c|c|}
\hline $\begin{array}{c}\text { Gestation Day } \\
\text { Interval }\end{array}$ & $0 \mathrm{mg} / \mathrm{kg}$ & $250 \mathrm{mg} / \mathrm{kg}$ & $500 \mathrm{mg} / \mathrm{kg}$ & $1,000 \mathrm{mg} / \mathrm{kg}$ \\
\hline $6-21$ & $21.2 \pm 0.4$ (19) & $21.6 \pm 0.4(20)$ & $22.0 \pm 0.3(20)$ & $21.5 \pm 0.4(22)$ \\
\hline $6-9$ & $19.9 \pm 0.3(20)$ & $20.0 \pm 0.3(20)$ & $19.6 \pm 0.4(20)$ & $19.1 \pm 0.5$ \\
\hline $9-12$ & $20.5 \pm 0.3(20)$ & $20.9 \pm 0.3(20)$ & $20.6 \pm 0.3(20)$ & $20.7 \pm 0.3$ \\
\hline $12-15$ & $20.3 \pm 0.6$ (19) & $21.2 \pm 0.5(20)$ & $21.5 \pm 0.4(20)$ & $21.0 \pm 0.4(23)$ \\
\hline $15-18$ & $23.1 \pm 0.4^{*}(20)$ & $22.7 \pm 0.7$ (20) & $24.5 \pm 0.4(20)$ & $23.7 \pm 0.8(23)$ \\
\hline $18-21$ & $22.1 \pm 0.5$ (19) & $23.4 \pm 0.6(20)$ & $23.8 \pm 0.5(20)$ & $22.6 \pm 1.1(22)$ \\
\hline
\end{tabular}

Statistical analysis performed by the Shirley or Dunn test found no statistically different pairwise comparisons.

*Statistically significant $(\mathrm{p} \leq 0.05)$ trend (by the Jonckheere test).

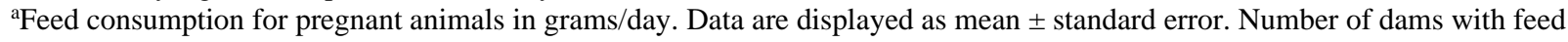
consumption measured is given in parentheses.

\section{Maternal and Litter Observations}

There were no dose-related gross observations noted at necropsy (Appendix $\mathrm{D}^{52}$ ). There was a significant positive trend in mean absolute liver weight (2.5\%, 3.3\%, and $7.2 \%$ in the 250, 500, and $1,000 \mathrm{mg} / \mathrm{kg}$ groups respectively); however, these weights were only marginally greater than the vehicle control weight, and the relative liver weights were similar across all groups (Table 9). Therefore, this trend was not deemed treatment related. The $1,000 \mathrm{mg} / \mathrm{kg}$ pregnant dam euthanized moribund on GD 21 had the smallest recorded liver weight (8.81 g) of any animal in the study; mean absolute liver weights for all dose groups ranged from 13.96 to $14.96 \mathrm{~g}$.

There were no effects on pregnancy status or litter size following administration of dimethylaminoethanol bitartrate (Table 10). The mean number of corpora lutea and implantations for all dose groups were also similar to the vehicle control group. The 1,000 mg/kg pregnant dam euthanized moribund on GD 21 had 11 dead fetuses and one early resorption, which accounted for the apparent increase in percent postimplantation loss; this was not representative of the dose group. That result, therefore, was considered spurious and unrelated to treatment. There were no treatment-related effects on the number of live fetuses per litter, live male fetuses per litter, or live female fetuses per litter. Fetal body weights (male and female, or separate) were similar across all treatment groups.

Table 9. Summary of Maternal Liver Weights of Rats in the Prenatal Developmental Toxicity Study of Dimethylaminoethanol Bitartrate ${ }^{a}$

\begin{tabular}{lcccc}
\hline & $\mathbf{0 ~} \mathbf{~ g} / \mathbf{k g}$ & $\mathbf{2 5 0} \mathbf{~} \mathbf{g} / \mathbf{k g}$ & $\mathbf{5 0 0} \mathbf{~} \mathbf{g} / \mathbf{k g}$ & $\mathbf{1 , 0 0 0} \mathbf{~} \mathbf{~ g} / \mathbf{k g}$ \\
\hline $\mathbf{n}$ & $\mathbf{1 9}$ & $\mathbf{2 0}$ & $\mathbf{2 0}$ & $\mathbf{2 1}$ \\
\hline Terminal Body Wt. & $359.6 \pm 8.8$ & $375.2 \pm 5.3$ & $380.3 \pm 5.1$ & $367.1 \pm 6.5$ \\
Absolute & $13.96 \pm 0.37^{*}$ & $14.31 \pm 0.34$ & $14.42 \pm 0.36$ & $14.96 \pm 0.25$ \\
$\quad$ Relative & $38.91 \pm 0.66$ & $38.10 \pm 0.64$ & $37.89 \pm 0.75$ & $41.00 \pm 1.01$ \\
\hline
\end{tabular}

Statistical analysis performed by the Williams or Dunnett tests found no statistically significant pairwise comparison.

* Significant trend $(\mathrm{p} \leq 0.05)$ by the Jonckheere test.

aLiver weights (absolute weights) and body weights are given in grams; liver-weight-to-body-weight ratios (relative weights) are given as mg organ weight/g body weight. Data are displayed as mean \pm standard error. 
Table 10. Summary of Uterine Content Data of Rats in the Prenatal Developmental Toxicity Study of Dimethylaminoethanol Bitartrate

\begin{tabular}{|c|c|c|c|c|}
\hline & $0 \mathrm{mg} / \mathrm{kg}$ & $250 \mathrm{mg} / \mathrm{kg}$ & $500 \mathrm{mg} / \mathrm{kg}$ & $1,000 \mathrm{mg} / \mathrm{kg}$ \\
\hline \multicolumn{5}{|l|}{ Pregnancy Summary } \\
\hline Mated females & 25 & 25 & 25 & 25 \\
\hline Pregnant females & 20 & 20 & 20 & 24 \\
\hline Pregnant females examined on GD $21^{\mathrm{a}}$ & 19 & 20 & 20 & $22^{\mathrm{b}}$ \\
\hline Corpora lutea per female ${ }^{c}$ & $15.74 \pm 0.57(19)$ & $15.85 \pm 0.45(20)$ & $16.70 \pm 0.73(20)$ & $15.86 \pm 0.64(22)$ \\
\hline Implantations per female ${ }^{c}$ & $11.47 \pm 1.11(19)$ & $13.75 \pm 0.54(20)$ & $13.50 \pm 0.60(20)$ & $12.45 \pm 0.87(22)$ \\
\hline Percent postimplantation loss ${ }^{\mathrm{c}}$ & $5.05 \pm 1.57(19)$ & $3.80 \pm 1.53(20)$ & $3.45 \pm 1.10(20)$ & $11.17 \pm 5.56(22)$ \\
\hline Total resorptions per litter ${ }^{\mathrm{C}}$ & $0.47 \pm 0.12(19)$ & $0.50 \pm 0.20(20)$ & $0.50 \pm 0.17(20)$ & $0.64 \pm 0.26(22)$ \\
\hline Early resorptions per litter ${ }^{\mathrm{C}}$ & $0.47 \pm 0.12(19)$ & $0.50 \pm 0.20(20)$ & $0.50 \pm 0.17(20)$ & $0.64 \pm 0.26(22)$ \\
\hline Late resorptions per litter ${ }^{c}$ & $0.00 \pm 0.00(19)$ & $0.00 \pm 0.00(20)$ & $0.00 \pm 0.00(20)$ & $0.00 \pm 0.00(22)$ \\
\hline Dead fetuses per litter ${ }^{\mathrm{C}}$ & $0.00 \pm 0.00(19)$ & $0.00 \pm 0.00(20)$ & $0.00 \pm 0.00(20)$ & $0.50 \pm 0.50(22)$ \\
\hline Number of early resorptions ${ }^{\mathrm{d}}$ & 9 & 10 & 10 & 14 \\
\hline Number of late resorptions & 0 & 0 & 0 & 0 \\
\hline Number of whole litter resorptions & 0 & 0 & 0 & 0 \\
\hline Number of dead fetuses ${ }^{\mathrm{e}}$ & 0 & 0 & 0 & 11 \\
\hline \multicolumn{5}{|l|}{ Live Fetuses $^{c}$} \\
\hline Number of live fetuses & 209 & 265 & 260 & 249 \\
\hline Live fetuses per litter & $11.00 \pm 1.12(19)$ & $13.25 \pm 0.60(20)$ & $13.00 \pm 0.56(20)$ & $11.32 \pm 1.07(22)$ \\
\hline Live male fetuses per litter & $5.21 \pm 0.68(19)$ & $6.10 \pm 0.55(20)$ & $6.10 \pm 0.55(20)$ & $5.77 \pm 0.67(22)$ \\
\hline Live female fetuses per litter & $5.79 \pm 0.69(19)$ & $7.15 \pm 0.50(20)$ & $6.90 \pm 0.48(20)$ & $5.55 \pm 0.60(22)$ \\
\hline Percent live male fetuses per litter & $47.53 \pm 5.21(19)$ & $44.76 \pm 3.98(20)$ & $46.61 \pm 3.23(20)$ & $50.42 \pm 4.39(21)$ \\
\hline \multicolumn{5}{|l|}{ Fetal Weight $(g)^{\mathrm{f}}$} \\
\hline Fetal body weight per litter & $5.38 \pm 0.15(19)$ & $5.26 \pm 0.05(20)$ & $5.33 \pm 0.06(20)$ & $5.40 \pm 0.09(21)$ \\
\hline Male fetal weight per litter & $5.44 \pm 0.16(18)$ & $5.37 \pm 0.05(19)$ & $5.50 \pm 0.06(20)$ & $5.51 \pm 0.09(20)$ \\
\hline Female fetal weight per litter & $5.15 \pm 0.12(18)$ & $5.14 \pm 0.06(20)$ & $5.18 \pm 0.07(20)$ & $5.21 \pm 0.08(20)$ \\
\hline \multicolumn{5}{|l|}{ Gravid Uterine Weight (g) ${ }^{g}$} \\
\hline Gravid uterine weight & $80.18 \pm 7.36(19)$ & $95.85 \pm 3.93(20)$ & $96.17 \pm 3.82(20)$ & $85.25 \pm 6.38(22)$ \\
\hline Terminal body weight & $359.6 \pm 8.8(19)$ & $375.2 \pm 5.3(20)$ & $380.3 \pm 5.1(20)$ & $361.4 \pm 8.5(22)$ \\
\hline Adjusted body weight & $279.42 \pm 3.68(19)$ & $279.34 \pm 3.77(20)$ & $284.12 \pm 2.90(20)$ & $276.17 \pm 4.59(22)$ \\
\hline \multicolumn{5}{|c|}{$\begin{array}{l}\text { Values are reported per litter as mean } \pm \text { standard error (n) and do not include nonpregnant animals or those that did not survive to } \\
\text { the end of the study. No statistically significant trends or pairwise differences from the control group were found. } \\
\text { astatistical analysis performed by the Cochran-Armitage (trend) and Fisher exact (pairwise) tests. } \\
\text { bThe dam euthanized moribund on GD } 21 \text { was included in the uterine content assessment. } \\
\text { 'Statistical analysis on number per female or per litter performed by the Jonckheere's (trend) and Shirley or Dunn (pairwise) } \\
\text { tests. } \\
\text { dNo statistical analyses performed on number of early resorptions. } \\
\text { e'One dam at } 1000 \mathrm{mg} / \mathrm{kg} \text { was euthanized moribund on GD } 21 \text { with } 11 \text { dead fetuses and } 1 \text { early resorption. } \\
\text { fStatistical analysis performed using a mixed-effects linear model with litter as a random effect (trend and pairwise). } \\
\text { 'Statistical analysis performed by the Jonckheere (trend) and Williams or Dunnett (pairwise) tests; } \\
\text { adjusted body weight = terminal body weight minus gravid uterine weight. }\end{array}$} \\
\hline
\end{tabular}




\section{Fetal Findings}

\section{External}

Subcutaneous hemorrhage was observed in fetuses from all exposure groups with a higher incidence in the $1,000 \mathrm{mg} / \mathrm{kg}$ group; however, three of the five affected fetuses in the $1,000 \mathrm{mg} / \mathrm{kg}$ group were from the same dam (Table 11; Appendix $\mathrm{D}^{52}$ ), and the incidences were low and not significantly increased. Malformations observed in the vehicle control and exposed groups were limited to a single incidence each of meningocele, omphalocele, and bent right hind limb and to sporadic incidences of bent tail.

Table 11. Summary of Selected Fetal External Findings in the Prenatal Developmental Toxicity Study of Dimethylaminoethanol Bitartrate

\begin{tabular}{lcccc}
\hline & $\mathbf{0 ~} \mathbf{~} \mathbf{g} / \mathbf{k g}$ & $\mathbf{2 5 0} \mathbf{~} \mathbf{~ g} / \mathbf{k g}$ & $\mathbf{5 0 0} \mathbf{~} \mathbf{~ g} / \mathbf{k g}$ & $\mathbf{1 , 0 0 0 ~} \mathbf{~} \mathbf{g} / \mathbf{k g}$ \\
\hline Total Number of Fetuses & 209 & 265 & 260 & 260 \\
\hline Number of Fetuses Examined & 209 & 265 & 260 & 260 \\
Number of Litters Examined & 19 & 20 & 20 & 22 \\
\hline
\end{tabular}

Body: General

Body, subcutaneous hemorrhage - [GF]

$\begin{array}{lcccc}\text { Fetuses } & 1(0.48) & 2(0.75) & 1(0.38) & 5(1.92) \\ \text { Litters } & 1(5.26) & 2(10.00) & 1(5.00) & 3(13.64)\end{array}$

Extremities

Limb, hind, right, bent - [M]

$\begin{array}{lcccc}\text { Fetuses } & 0(0.0) & 0(0.0) & 0(0.0) & 1(0.38) \\ \text { Litters } & 0(0.00) & 0(0.00) & 0(0.00) & 1(4.55) \\ \text { Tail, bent }-[\mathrm{M}] & & & & \\ \text { Fetuses } & 0(0.0) & 1(0.38) & 1(0.38) & 2(0.77) \\ \text { Litters } & 0(0.00) & 1(5.00) & 1(5.00) & 1(4.55)\end{array}$

Head

Head, meningocele $-[\mathrm{M}]$

Fetuses

Litters

Trunk

General, omphalocele - [M]

Fetuses

$0(0.0)$

$1(0.38)$

$0(0.0)$

$0(0.0)$

Litters

$0(0.00)$
$0(0.0)$

$0(0.0)$

$0(0.0)$

$0(0.00)$

$0(0.00)$

$0(0.00)$

Upper row denotes number of affected fetuses (\%), and lower row the number of affected litters (\%).

Statistical analysis for litter data and for fetal data (without litter effect) performed by the Cochran-Armitage (trend) and the Fisher exact (pairwise) tests found no statistically significant trend or pairwise comparison, respectively.

Statistical analysis of fetuses with litter-based adjustments performed by mixed-effects logistic regression found no statistically significant trend or pairwise comparison.

$[\mathrm{GF}]$ = gross finding; $[\mathrm{M}]=$ malformation . 


\section{Visceral}

There were single incidences of malformations in the heart of vehicle control and exposed groups that included large right atrium, thick bilateral ventricular wall, and ventricular septal defect (Table 12; Appendix $\mathrm{D}^{52}$ ). Misshapen aortic valve, a malformation, was observed in all exposure groups at singular or low incidences. Visceral malformations in the major vessels of control and exposed groups were limited to single incidences of absent aortic arch, atresia of the innominate artery, and dilated pulmonary artery/trunk. Visceral variations occurred predominantly in the vessels and included absent or short innominate arteries, which are a common background variation; these were noted in both the vehicle control and exposed groups. The incidence of absent innominate artery in the 1,000 mg/kg group was significantly higher than in the control group; however, innominate artery variations are a common finding noted in approximately $5 \%$ of control rat fetuses. ${ }^{75}$

Table 12. Summary of Selected Fetal Visceral Findings in the Prenatal Developmental Toxicity Study of Dimethylaminoethanol Bitartrate

\begin{tabular}{|c|c|c|c|c|}
\hline & $0 \mathrm{mg} / \mathrm{kg}$ & $250 \mathrm{mg} / \mathrm{kg}$ & $500 \mathrm{mg} / \mathrm{kg}$ & $1,000 \mathrm{mg} / \mathrm{kg}$ \\
\hline Total Number of Fetuses & 209 & 265 & 260 & 260 \\
\hline Number of Fetuses Examined & 209 & 265 & 260 & 260 \\
\hline Number of Litters Examined & 19 & 20 & 20 & 22 \\
\hline \multicolumn{5}{|l|}{ Heart } \\
\hline \multicolumn{5}{|l|}{ Aortic valve, misshapen - [M] } \\
\hline Fetuses & $2(0.96)$ & $1(0.38)$ & $3(1.15)$ & $1(0.38)$ \\
\hline Litters & $2(10.53)$ & $1(5.00)$ & $3(15.00)$ & $1(4.55)$ \\
\hline \multicolumn{5}{|l|}{ Atrium, right, large $-[\mathrm{M}]$} \\
\hline Fetuses & $0(0.0)$ & $0(0.0)$ & $0(0.0)$ & $1(0.38)$ \\
\hline Litters & $0(0.00)$ & $0(0.00)$ & $0(0.00)$ & $1(4.55)$ \\
\hline \multicolumn{5}{|c|}{ Ventricle, bilateral, thick wall - [M] } \\
\hline Fetuses & $1(0.48)$ & $0(0.0)$ & $0(0.0)$ & $0(0.0)$ \\
\hline Litters & $1(5.26)$ & $0(0.00)$ & $0(0.00)$ & $0(0.00)$ \\
\hline \multicolumn{5}{|c|}{ Ventricle, bilateral, ventricular septum defect - [M] } \\
\hline Fetuses & $1(0.48)$ & $0(0.0)$ & $0(0.0)$ & $0(0.0)$ \\
\hline Litters & $1(5.26)$ & $0(0.00)$ & $0(0.00)$ & $0(0.00)$ \\
\hline \multicolumn{5}{|l|}{ Major Vessels } \\
\hline \multicolumn{5}{|l|}{ Aortic arch, absent $-[\mathrm{M}]$} \\
\hline Fetuses & $0(0.0)$ & $0(0.0)$ & $1(0.38)$ & $0(0.0)$ \\
\hline Litters & $0(0.00)$ & $0(0.00)$ & $1(5.00)$ & $0(0.00)$ \\
\hline \multicolumn{5}{|c|}{ Innominate artery, atresia $-[\mathrm{M}]$} \\
\hline Fetuses & $0(0.0)$ & $0(0.0)$ & $0(0.0)$ & $1(0.38)$ \\
\hline Litters & $0(0.00)$ & $0(0.00)$ & $0(0.00)$ & $1(4.55)$ \\
\hline Innominate artery, absent -[ & & & & \\
\hline
\end{tabular}




\begin{tabular}{lcccc}
\hline & $\mathbf{0 ~} \mathbf{~ g} / \mathbf{k g}$ & $\mathbf{2 5 0} \mathbf{~} \mathbf{g} / \mathbf{k g}$ & $\mathbf{5 0 0} \mathbf{~} \mathbf{g} / \mathbf{k g}$ & $\mathbf{1 , 0 0 0} \mathbf{~} \mathbf{g} / \mathbf{k g}$ \\
\hline Fetuses & $3(1.44)^{* * \#}$ & $4(1.51)$ & $6(2.31)$ & $12(4.62)^{* \#}$ \\
Litters & $3(15.79)^{*}$ & $4(20.00)$ & $4(20.00)$ & $10(45.45)^{*}$ \\
Innominate artery, short - [V] & & & & \\
Fetuses & $6(2.87)$ & $7(2.64)$ & $8(3.08)$ & $5(1.92)$ \\
Litters & $4(21.05)$ & $7(35.00)$ & $6(30.00)$ & $4(18.18)$ \\
Pulmonary artery/trunk, dilated - $[\mathrm{M}]$ & & & & \\
Fetuses & $1(0.48)$ & $0(0.0)$ & $0(0.0)$ & $0(0.0)$ \\
Litters & $1(5.26)$ & $0(0.00)$ & $0(0.00)$ & $0(0.00)$ \\
\hline
\end{tabular}

Upper row denotes number of affected fetuses (\%), and lower row the number of affected litters (\%).

Statistical analysis for litter data and for fetal data (without litter effects) performed by the Cochran-Armitage (trend) and the

Fisher exact (pairwise) tests. Statistical analysis of fetuses with litter-based adjustments performed by mixed-effects logistic regression.

*Statistically significant $(\mathrm{p} \leq 0.05)$ trend (denoted in vehicle control column) or pairwise comparison (denoted in dose group column).

$* * \mathrm{p} \leq 0.01$

\#Statistically significant $(\mathrm{p} \leq 0.05)$ trend (denoted in vehicle control column) or pairwise comparison (denoted in dose group column) in litter-based analysis of fetuses

$\# \mathrm{p} \leq 0.01$.

$[\mathrm{M}]=$ malformation; $[\mathrm{V}]=$ variation .

${ }^{a}$ Historical incidence for control groups in prenatal developmental toxicity gavage studies: fetuses 27/1,326 (2.0\%), range

1.4-2.8\%; litters 22/104 (21.2\%), range 15.8-27.8\%.

\section{Head}

There were no exposure-related effects of dimethylaminoethanol bitartrate administration on the incidence of fetal head, specifically brain, abnormalities (Appendix $\mathrm{D}^{52}$ ).

\section{Skeletal}

Skeletal malformations and variations occurred predominantly in the ribs of fetuses from all exposure groups (Table 13; Appendix $\mathrm{D}^{52}$ ). Single or low incidences of nodulated costal cartilage (sixth, eighth, and ninth), a variation, were observed in vehicle control, $500 \mathrm{mg} / \mathrm{kg}$, and $1,000 \mathrm{mg} / \mathrm{kg}$ groups. There was a negative trend in the incidences of total (sum of left, right, and bilateral) and full thoracolumbar ribs (malformation), whereas a significant increase in the incidence of left, bilateral, and total short thoracolumbar ribs (variation) was observed in the $1,000 \mathrm{mg} / \mathrm{kg}$ group compared to the control group, along with a significant positive trend.

There was a significant increase in the number of supernumerary sites, or extra bones, in the skull (around the frontonasal suture) in 1,000 mg/kg fetuses relative to the control group (Table 13; Appendix $\mathrm{D}^{52}$ ) as well as a significant positive trend across all groups. 
Table 13. Summary of Selected Fetal Skeletal Findings in the Prenatal Developmental Toxicity Study of Dimethylaminoethanol Bitartrate

\begin{tabular}{|c|c|c|c|c|}
\hline & 0 mg/kg & $250 \mathrm{mg} / \mathrm{kg}$ & $500 \mathrm{mg} / \mathrm{kg}$ & $1,000 \mathrm{mg} / \mathrm{kg}$ \\
\hline Total Number of Fetuses & 209 & 265 & 260 & 260 \\
\hline Number of Fetuses Examined & 209 & 264 & 260 & 260 \\
\hline Number of Litters Examined & 19 & 20 & 20 & 22 \\
\hline \multicolumn{5}{|l|}{ Ribs } \\
\hline \multicolumn{5}{|c|}{ Costal cartilage, 6th right, nodulated - [V] } \\
\hline Fetuses & $1(0.48)$ & $0(0.0)$ & $0(0.0)$ & $2(0.77)$ \\
\hline Litters & $1(5.26)$ & $0(0.00)$ & $0(0.00)$ & $2(9.09)$ \\
\hline \multicolumn{5}{|c|}{ Costal cartilage, 8th right, nodulated - [V] } \\
\hline Fetuses & $0(0.0)$ & $0(0.0)$ & $1(0.38)$ & $0(0.0)$ \\
\hline Litters & $0(0.00)$ & $0(0.00)$ & $1(5.00)$ & $0(0.00)$ \\
\hline \multicolumn{5}{|c|}{ Costal cartilage, 9th right, nodulated - [V] } \\
\hline Fetuses & $1(0.48)$ & $0(0.0)$ & $0(0.0)$ & $0(0.0)$ \\
\hline Litters & $1(5.26)$ & $0(0.00)$ & $0(0.00)$ & $0(0.00)$ \\
\hline \multicolumn{5}{|l|}{ Supernumerary Rib } \\
\hline \multicolumn{5}{|l|}{ Thoracolumbar, left, full - [M] } \\
\hline Fetuses & $3(1.44)^{*}$ & $1(0.38)$ & $0(0.0)$ & $0(0.0)$ \\
\hline Litters & $3(15.79)^{*}$ & $1(5.00)$ & $0(0.00)$ & $0(0.00)$ \\
\hline \multicolumn{5}{|c|}{ Thoracolumbar, right, full - [M] } \\
\hline Fetuses & $3(1.44)$ & $2(0.76)$ & $1(0.38)$ & $1(0.38)$ \\
\hline Litters & 3 (15.79) & $2(10.00)$ & $1(5.00)$ & $1(4.55)$ \\
\hline \multicolumn{5}{|c|}{ Thoracolumbar, bilateral, full - [M] } \\
\hline Fetuses & $1(0.48)$ & $0(0.0)$ & $0(0.0)$ & $0(0.0)$ \\
\hline Litters & $1(5.26)$ & $0(0.00)$ & $0(0.00)$ & $0(0.00)$ \\
\hline \multicolumn{5}{|c|}{ Thoracolumbar, full, total - [M] } \\
\hline Fetuses & $7(3.35)^{* * \# \#}$ & $3(1.14)$ & $1(0.38)^{* \#}$ & $1(0.38)^{* \#}$ \\
\hline Litters & $6(31.58)^{*}$ & $3(15.00)$ & $1(5.00)^{*}$ & $1(4.55)^{*}$ \\
\hline \multicolumn{5}{|c|}{ Thoracolumbar, left, short - [V] } \\
\hline Fetuses & $23(11.0)^{* \#}$ & $32(12.12)$ & $26(10.0)$ & $45(17.31)^{* \#}$ \\
\hline Litters & 14 (73.68) & 17 (85.00) & $16(80.00)$ & 17 (77.27) \\
\hline \multicolumn{5}{|c|}{ Thoracolumbar, right, short - [V] } \\
\hline Fetuses & $16(7.66)$ & $13(4.92)$ & $9(3.46)^{* \#}$ & $16(6.15)$ \\
\hline Litters & $10(52.63)$ & $10(50.00)$ & $8(40.00)$ & $10(45.45)$ \\
\hline \multicolumn{5}{|c|}{ Thoracolumbar, bilateral, short - [V] } \\
\hline Fetuses & $17(8.13)^{* * \# \#}$ & $11(4.17)$ & $24(9.23)$ & 39 (15.0)* \\
\hline
\end{tabular}




\begin{tabular}{|c|c|c|c|c|}
\hline & $0 \mathrm{mg} / \mathrm{kg}$ & $250 \mathrm{mg} / \mathrm{kg}$ & $500 \mathrm{mg} / \mathrm{kg}$ & $1,000 \mathrm{mg} / \mathrm{kg}$ \\
\hline Litters & $8(42.11)^{*}$ & $7(35.00)$ & $11(55.00)$ & $16(72.73)^{*}$ \\
\hline \multicolumn{5}{|c|}{ Thoracolumbar, short, total $-[\mathrm{V}]^{\mathrm{a}}$} \\
\hline Fetuses & $56(26.79) * * \# \#$ & $56(21.21)$ & 59 (22.69) & $100(38.46)^{* * \#}$ \\
\hline Litters & 17 (89.47) & $18(90.00)$ & $18(90.00)$ & 19 (86.36) \\
\hline \multicolumn{5}{|l|}{ Skeletal: Skull } \\
\hline Number of Fetuses Examined & 100 & 128 & 126 & 128 \\
\hline Number of Litters Examined & 18 & 20 & 20 & 20 \\
\hline \multicolumn{5}{|l|}{ Skull } \\
\hline \multicolumn{5}{|c|}{ General, isolated ossification site - [V] } \\
\hline Fetuses & $1(1.0)$ & $5(3.91)$ & $3(2.38)$ & $3(2.34)$ \\
\hline Litters & $1(5.56)$ & $5(25.00)$ & $2(10.00)$ & $2(10.00)$ \\
\hline \multicolumn{5}{|c|}{ General, supernumerary site - [V] ${ }^{\mathrm{b}}$} \\
\hline Fetuses & $1(1.0)^{* * \# \#}$ & $3(2.34)$ & $2(1.59)$ & $13(10.16)^{* * \#}$ \\
\hline Litters & $1(5.56)^{* *}$ & $3(15.00)$ & $2(10.00)$ & $10(50.00)^{* *}$ \\
\hline
\end{tabular}

Upper row denotes number of affected fetuses (\%) and lower row the number of affected litters (\%).

Statistical analysis for litter data and for fetal data (without litter effects) performed by the Cochran-Armitage (trend) and the Fisher exact (pairwise) tests. Statistical analysis of fetuses with litter-based adjustments performed by mixed-effects logistic regression.

*Statistically significant $(\mathrm{p} \leq 0.05)$ trend (denoted in vehicle control column) or pairwise comparison (denoted in dose group column).

$* * \mathrm{p} \leq 0.01$.

\#Statistically significant $(\mathrm{p} \leq 0.05)$ trend (denoted in vehicle control column) or pairwise comparison (denoted in dose group column) in litter-based analysis of fetuses

${ }^{\# \#} \mathrm{p} \leq 0.01$.

$[\mathrm{V}]=$ variation; $[\mathrm{M}]=$ malformation .

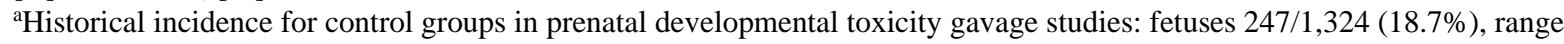
9.9-26.8\%; litters 83/104 (79.8\%), range 66.7-91.3\%.

${ }^{\mathrm{b}}$ Historical incidence for control groups in prenatal developmental toxicity gavage studies: fetuses 11/637 (1.73\%), range 0.70-2.94\%; litters 7/102 (6.86\%), range 4.35-11.11\%. 


\section{Discussion}

Dimethylaminoethanol is a close structural analog of choline ( $N, N, N$-trimethylaminoethanol), an essential nutrient. Dimethylaminoethanol supplies the brain with choline, where it is acetylated to form acetylcholine. ${ }^{10}$ Choline is required for many biological processes, including nervous system development, and choline deficiency has been associated with neural tube defects (NTDs) in both rodents and humans. ${ }^{25 ; 26 ; 30-32}$ Human exposure to dimethylaminoethanol can occur in occupational settings (e.g., spray painting, beverage can lacquering); ${ }^{8}$ however, the primary exposure pathway in the U.S. population is consumption of dimethylaminoethanol as a dietary supplement. Dietary supplements containing dimethylaminoethanol bitartrate, a salt of dimethylaminoethanol, are marketed to improve memory and general cognitive function due to the ability of ingested dimethylaminoethanol to increase levels of acetylcholine in the brain. Dimethylaminoethanol bitartrate supplements are also purported to treat symptoms of attention deficit hyperactivity disorder (ADHD) in children.

There are indications in the literature on experiments in rodents that exposure to dimethylaminoethanol can induce developmental and reproductive toxicity, including decreases in viable implants, litter size, and pup survival and increases in fetal skeletal variations. ${ }^{27-29}$ Due to the potential for widespread human exposure and concerns for use by pregnant women and children, the NTP conducted prenatal developmental toxicity studies in rats to assess the effects of oral dimethylaminoethanol bitartrate administration on pregnant females and on fetal development.

There were no indications of maternal or fetal toxicity in the dose range-finding study following exposure to $0,250,500$, or $1,000 \mathrm{mg} / \mathrm{kg} /$ day dimethylaminoethanol bitartrate. As no maternal toxicity was observed in the dose range-finding study, identical doses of 250, 500, and $1,000 \mathrm{mg} / \mathrm{kg} /$ day dimethylaminoethanol bitartrate were chosen for the prenatal developmental toxicity study. Dimethylaminoethanol bitartrate was well tolerated in the prenatal developmental toxicity study, allowing for a complete evaluation of embryo-fetal development following exposure. There were no significant effects on maternal survival, body weight, or food consumption. One dam in the $1,000 \mathrm{mg} / \mathrm{kg}$ group was euthanized moribund (GD 21), and one other was found dead (GD 10, gavage accident), but these deaths were not considered doserelated. Marginal increases in liver weights were observed, and similar results have been reported in the literature with dimethylaminoethanol (45 to $890 \mathrm{mg} / \mathrm{kg}$ ) in the diet for 90 days causing increased liver weights with no associated histopathologic changes. ${ }^{76}$ The marginal increases in liver weight observed in this study were not considered to be toxicologically significant.

Exposure to dimethylaminoethanol bitartrate did not affect any pregnancy or litter parameters. The dam administered $1,000 \mathrm{mg} / \mathrm{kg}$ dimethylaminoethanol bitartrate and euthanized moribund on GD 21 had 11 dead fetuses and one early resorption. Including the data for that one female resulted in a higher calculated postimplantation loss that was unlikely to be exposure related or representative of the entire dose group. Fetal body weight, a sensitive indicator of embryo-fetal toxicity, was unaffected in all exposure groups in the dose range-finding and prenatal developmental toxicity studies. 
There were minimal significant findings of increased incidences of variations in fetal morphology, which included absent innominate artery, short thoracolumbar ribs (short supernumerary ribs), and supernumerary sites in the skull. Absent innominate artery was noted in some fetuses in all groups, including the control group, but occurred at a slightly higher incidence, $4.6 \%$ of fetuses and $45.5 \%$ of litters, in dams administered dimethylaminoethanol bitartrate at $1,000 \mathrm{mg} / \mathrm{kg} / \mathrm{day}$. Those incidences were considered potentially exposure related, because the percentage of affected fetuses and litters were outside the NTP historical control ranges (1.37-2.82\% fetuses; $15.8-27.8 \%$ litters). Innominate artery variations have been reported in the literature, however, in approximately $5 \%$ of control rat fetuses. ${ }^{75}$ Short supernumerary ribs occurred in $86-90 \%$ of litters across all groups, but the fetal incidence was significantly higher, by $12 \%$, in the $1,000 \mathrm{mg} / \mathrm{kg}$ fetuses (38.5\%) relative to the vehicle control group (26.8\%). This increase was considered exposure related, because the percentage of affected fetuses was outside the NTP historical control range (9.90-26.79\% for fetuses); however, this did not correspond to an increase in full thoracolumbar ribs (a malformation), and this is also a common background variation in the Sprague Dawley rat strain used in this study. The manifestation of short supernumerary ribs is short-lived, as this particular variation is considered reversible during postnatal development. ${ }^{77-79}$ The incidence of supernumerary sites in the skull was significantly increased in 1,000 mg/kg fetuses (approximately 10\%) relative to the vehicle control group (1\%) and outside of the NTP historical control range (0.70-2.94\% for fetuses). This increase, therefore, was considered to be treatment-related; however, the toxicological significance of this finding is unclear. There are minimal available animal data evaluating whether these supernumerary sites cause biological consequences later in life or resolve. In clinical research, these findings are commonly used as diagnostic markers suggestive of certain syndromes and genetic disorders such as craniosynostosis and osteogenesis imperfecta. ${ }^{80}$

When examined individually, the noted effects are likely common variations (absent innominate artery), reversible (supernumerary ribs), or of uncertain biological significance (supernumerary sites in the skull). However, the increased incidence of a cardiovascular finding and extra ossification sites in two separate locations could be considered an indication of altered development in exposed fetuses, particularly because the incidences are outside of the NTP historical control range and occurred in the absence of decreased fetal weight and maternal toxicity. Skull and rib development occur via two different skeletal developmental pathways, endochondral ossification (ribs) and intramembranous ossification (skull). ${ }^{81}$ During endochondral ossification, a cartilage template is gradually replaced with bone via osteoblasts that secrete extracellular bone matrix which undergoes mineralization to form bone. Subsequent growth requires remodeling by bone-resorbing osteoclasts followed by deposition of new bone matrix by osteoblasts. Intramembranous ossification, on the other hand, occurs in the absence of cartilage template and involves condensation of mesenchymal stem cells (osteoblast precursors) at sites of future skull bones. These precursor cells differentiate to become osteoblasts which secrete extracellular bone matrix that undergoes mineralization to form ossified bone. Both pathways require functioning osteoblasts and osteoclasts. Although differential gene expression patterns are required for each of these developmental pathways, there are genes common to both pathways (i.e., Runx2). ${ }^{81}$ The data in this Developmental and Reproductive Toxicity Technical Report suggest that dimethylaminoethanol bitartrate exposure might affect multiple skeletal development pathways; however, the observed rib and skull findings are of unclear biological significance. 


\section{Conclusions}

Under the conditions of this prenatal study, there was equivocal evidence of developmental toxicity of dimethylaminoethanol bitartrate in Hsd:Sprague Dawley ${ }^{\circledR} \mathrm{SD}^{\circledR}$ rats attributable to increased incidences of absent innominate artery, short thoracolumbar ribs, and supernumerary sites in the skull in the absence of overt maternal toxicity. 


\section{References}

1. The Merck index. 14th ed. Whitehouse Station, NJ: Merck and Company, Inc; 2006. p. 480.

2. Sigma Aldrich. Safety data sheet: 2-dimethylaminoethanol (+)-bitartrate salt. 2014. http://www.sigmaaldrich.com [Accessed: December 1, 2016]

3. Hazardous Substances Data Bank (HSDB). 2-Dimethylaminoethanol. CASRN: 108-01-0. Bethesda, MD: National Library of Medicine; 2015. HSDB No. 1329. https://toxnet.nlm.nih.gov/cgi-bin/sis/search/a?dbs+hsdb:@term+@DOCNO+1329 [Profile updated: October 19, 2015]

4. U.S. Environmental Protection Agency (USEPA). Toxic Substances Control Act (TSCA) Inventory Update Rule (IUR). 2016. https://www.epa.gov/chemical-data-reporting/2016chemical-data-reporting-results [Accessed: June 22, 2017]

5. Organisation for Economic Co-operation and Development (OECD). The 2004 OECD list of high production volume chemicals. Paris, France: OECD Environment Directorate, Environment, Health and Safety Division; 2004.

6. U.S. Environmental Protection Agency (USEPA). Chemical Data Reporting (CDR) database. 2011. https://chemview.epa.gov/chemview [Accessed: January 16, 2018]

7. Organisation for Economic Co-operation and Development (OECD). Screening information data set: N,N-Dimethylamino-2-ethanol. Processed by International Register of Potentially Toxic Chemicals. New York, NY and Geneva, Switzerland: A contribution to the United Nations, International Programme on Chemical Safety; 1996.

8. Pitts JN, Jr., Winer AM, Carter WPL. Chemical consequences of air quality standards and of control implementation programs. Riverside, CA: University of California, Statewide Air Pollution Research Center; 1981. Report No. ARB-R-80/131, NTIS Order No. PB81-137697.

9. National Toxicology Report (NTP). Dimethylethanolamine (DMAE) [108-01-0] and selected salts and esters. Review of toxicological literature (update). Research Triangle Park, NC: U.S. Department of Health and Human Services, National Institutes of Health, National Toxicology Program; 2002.

https://ntp.niehs.nih.gov/ntp/htdocs/chem_background/exsumpdf/dmae_update_110002_508.pdf [Accessed: June 22, 2017]

10. De Silva L. Biochemical mechanisms and management of choreiform movement disorders. Drugs. 1977; 14(4):300-310. http://dx.doi.org/10.2165/00003495-197714040-00005

11. Rothe J, Cordelair H, Wehman C. New catalysts for low VOC in flexible slabstock foam. J Cell Plast. 2001; 37(3):207-220. http://dx.doi.org/10.1106/X6BV-73PB-6FQC-KCRN

12. Stenbäck F, Weisburger JH, Williams GM. Effect of lifetime, administration of dimethylaminoethanol on longevity, aging changes, and cryptogenic neoplasms in $\mathrm{C} 3 \mathrm{H}$ mice. Mech Ageing Dev. 1988; 42(2):129-138. http://dx.doi.org/10.1016/0047-6374(88)90068-1 
13. Deanol. In: Hendler SS, Rorvik D, editors. PDR for Nutritional Supplements. Montvale, NJ: Thomson Healthcare; 2001. p. 123-124.

14. Source Naturals ${ }^{\circledR}$. Dimethylaminoethanol bitartrate (DMAE). 2017. http://www.sourcenaturals.com/products/GP1101 [Accessed: June 22, 2017]

15. Nature's Plus. Pedi-active (phosphatidylserion, DMAE complex). 2017. http://naturesplus.com/products/productdetail.php?productNumber=3000 [Accessed: June 22, 2017]

16. Source Naturals®. Attentive Child (TM). 2017. http://www.sourcenaturals.com/products/GP1028 [Accessed: June 22, 2017]

17. Dormard Y, Levron JC, Benakis A. Pharmacokinetic study of maleate acid of 2-(N, Ndimethylaminoethanol-14C1)-cyclohexylpropionate (cyprodenate) and of $\mathrm{N}, \mathrm{N}$ dimethylaminoethanol-14C1 in animals. Arzneimittelforschung. 1975; 25(2):194-201.

18. Zahniser N, Chou D, Hanin I. Is 2-dimethylaminoethanol (deanol) indeed a precursor of brain acetylcholine? A gas chromatographic evaluation. J Pharmacol Exp Ther. 1977; 200(3):545-559.

19. Ceder G, Schuberth J. 2-Dimethylaminoethanol (deaner) in body fluids. J Pharm Pharmacol. 1977; 29(1):373-374. http://dx.doi.org/10.1111/j.2042-7158.1977.tb11341.x

20. Shipkowski KA, Sanders JM, McDonald JD, Garner CE, Doyle-Eisele M, Wegerski CJ, Waidyanatha S. Comparative disposition of dimethylaminoethanol and choline in rats and mice following oral or intravenous administration. Toxicol Appl Pharmacol. 2019; 378:114592. http://dx.doi.org/10.1016/j.taap.2019.05.011

21. Schlenk DK. Dimethylaminoethanol In: Buhler DR, Reed DJ, editors. Ethel Browning's Toxicity and Metabolism of Industrial Solvents. 2nd ed. New York, NY: Elsevier Science Publishers; 1990. p. 417-422.

22. Miyazaki H, Nambu K, Minaki Y, Hashimoto M, Nakamura K. Comparative studies on the metabolism of $\beta$-dimethylaminoethanol in the mouse brain and liver following administration of $\beta$-dimethyl-aminoethanol and its p-chlorophenoxyacetate, meclofenoxate. Chem Pharm Bull. 1976; 24(4):763-769. http://dx.doi.org/10.1248/cpb.24.763

23. Jope RS, Jenden DJ. Dimethylaminoethanol (deanol) metabolism in rat brain and its effect on acetylcholine synthesis. J Pharmacol Exp Ther. 1979; 211(3):472-479.

24. Beard RR, Noe JT. Aliphatic and alicyclic amines In: Clayton GD, Clayton FE, editors. Patty's Industrial Hygiene and Toxicology. 3rd ed. New York, NY: John Wiley \& Sons, Inc; 1981. p. 3135-3173.

25. Fisher MC, Zeisel SH, Mar MH, Sadler TW. Inhibitors of choline uptake and metabolism cause developmental abnormalities in neurulating mouse embryos. Teratology. 2001; 64(2):114122. http://dx.doi.org/10.1002/tera.1053 
26. Fisher MC, Zeisel SH, Mar M-H, Sadler TW. Perturbations in choline metabolism cause neural tube defects in mouse embryos in vitro. FASEB J. 2002; 16(6):619-621.

http://dx.doi.org/10.1096/fj.01-0564fje

27. Zahniser NR, Katyal SL, Shih TM, Hanin I, Moossy J, Martinez AJ, Lombardi B. Effects of $\mathrm{N}$-methylaminoethanol, and N,N-dimethylaminoethanol in the diet of pregnant rats on neonatal rat brain cholinergic and phospholipid profile. J Neurochem. 1978; 30(6):1245-1252.

http://dx.doi.org/10.1111/j.1471-4159.1978.tb10452.x

28. Leung HW, Tyl RW, Ballantyne B, Klonne DR. Developmental toxicity study in Fischer 344 rats by whole-body exposure to N, N-dimethylethanolamine vapor. J Appl Toxicol. 1996; 16(6):533-538. http://dx.doi.org/10.1002/(SICI)1099-1263(199611)16:6<533::AIDJAT391>3.0.CO;2-B

29. Tyl RW, Homan ER, Klonne DR, Pritts IM, Fowler EH, Fisher LC, France KA, Rebick TA, Beskitt JL, Ballantyne B. Developmental toxicity evaluation of inhaled N,Ndimethylethanolamine (DMEA) in Fischer 344 rats. Toxicologist. 1987; 7:173.

30. Shaw GM, Carmichael SL, Yang W, Selvin S, Schaffer DM. Periconceptional dietary intake of choline and betaine and neural tube defects in offspring. Am J Epidemiol. 2004; 160(2):102109. http://dx.doi.org/10.1093/aje/kwh187

31. Shaw GM, Finnell RH, Blom HJ, Carmichael SL, Vollset SE, Yang W, Ueland PM. Choline and risk of neural tube defects in a folate-fortified population. Epidemiology. 2009:714-719. http://dx.doi.org/10.1097/EDE.0b013e3181ac9fe7

32. Mills JL, Fan R, Brody LC, Liu A, Ueland PM, Wang Y, Kirke PN, Shane B, Molloy AM. Maternal choline concentrations during pregnancy and choline-related genetic variants as risk factors for neural tube defects. Am J Clin Nutr. 2014; 100(4):1069-1074.

http://dx.doi.org/10.3945/ajcn.113.079319

33. Hartung R, Cornish HH. Cholinesterase inhibition in the acute toxicity of alkyl-substituted 2aminoethanols. Toxicol Appl Pharmacol. 1968; 12(3):486-494. http://dx.doi.org/10.1016/0041$\underline{008 X(68) 90155-5}$

34. Union Carbide. Initial submission: N,N-dimethylethanolamine: Acute toxicity and primary irritancy studies (project report) with cover sheet and letter dated 05/05/92. U.S. Environmental Protection Agency (USEPA), Toxic Substances Control Act (TSCA) Section 8ECP Test Submission; 1986. Doc. No. 88-920002183. Fiche No. OTS0536318.

35. Klonne DR, Dodd DE, Pritts IM, Nachreiner DJ, Fowler EH, Troup CM, Homan ER, Ballantyne B. Dimethylethanolamine: Acute, 2-week, and 13-week inhalation toxicity studies in rats. Fundam Appl Toxicol. 1987; 9(3):512-521. http://dx.doi.org/10.1016/0272-0590(87)90033$\underline{9}$

36. Murray MP, Cummins JE. Mutagenic activity of epoxy embedding reagents employed in electron microscopy. Environ Mutagen. 1979; 1(4):307-313.

http://dx.doi.org/10.1002/em.2860010402 
37. Union Carbide. Dimethylethanolamine (DMEA). Salmonella/microsomes (Ames) bacterial mutagenicity assay. Westmoreland, PA: Bushy Run Research Center; 1987. Project Report 5085.

38. Union Carbide. Dimethylethanolamine (DMEA). In vitro genotoxicity studies: CHO/HGPRT gene mutation test and sister chromatid exchange assay. Westmoreland, PA: Bushy Run Research Center; 1988. Project Report 50-130.

39. Zeiger E, Anderson B, Haworth S, Lawlor T, Mortelmans K, Speck W. Salmonella mutagenicity tests: III. Results from the testing of 255 chemicals. Environ Mutagen. 1987; 9(S9 S9):61-109.

40. Leung H-W, Ballantyne B. Evaluation of the genotoxic potential of alkylalkanolamines. Mutat Res/Genet Toxicol Environ Mutagen. 1997; 393(1-2):7-15. http://dx.doi.org/10.1016/S1383-5718(97)00104-6

41. Ingredients index: Deanol. In: Gosselin RE, Smith RP, Hodge HC, editors. Clinical Toxicology of Commercial Products. 5th ed. Baltimore, MD: Wilkens and Wilkens Company; 1984. p. 240.

42. Mehta D, Mehta S, Mathew P. Failure of deanol in treating tardive dyskinesia. Am J Psychiatry. 1976; 133(12):1467-1467. http://dx.doi.org/10.1176/ajp.133.12.1467a

43. Nesse RM, Carroll BJ. Cholinergic side-effects associated with deanol. Lancet. 1976; 2:5051. http://dx.doi.org/10.1016/S0140-6736(76)93016-6

44. Soares KVS, McGrath JJ. The treatment of tardive dyskinesia: A systematic review and meta-analysis. Schizophr Res. 1999; 39(1):1-16. http://dx.doi.org/10.1016/S0920$\underline{\text { 9964(99)00021-3 }}$

45. Tammenmaa I, McGrath J, Sailas EES, Soares-Weiser K. Cholinergic medication for neuroleptic-induced tardive dyskinesia. Cochrane Database Syst Rev. 2002; 3:1-33.

46. Chernoff N, Setzer RW, Miller DB, Rosen MB, Rogers JM. Effects of chemically induced maternal toxicity on prenatal development in the rat. Teratology. 1990; 42(6):651-658. http://dx.doi.org/10.1002/tera.1420420610

47. U.S. Environmental Protection Agency (USEPA). Guidelines for developmental toxicity risk assessment. Washington, DC: U.S. Environmental Protection Agency, Risk Assessment Forum; 1991. EPA Document No. EPA/600/FR-91/001.

48. Tyl RW. Commentary on the role of maternal toxicity on developmental toxicity. Birth Defects Res B: Dev Reprod Toxicol. 2012; 95(3):262-266. http://dx.doi.org/10.1002/bdrb.21015

49. Organisation for Economic Co-operation and Development (OECD). OECD guideline for the testing of chemicals: Prenatal developmental toxicity study. Paris, France: Organisation for Economic Cooperation and Development; 2001. OECD 414.

50. Makris SL, Solomon HM, Clark R, Shiota K, Barbellion S, Buschmann J, Ema M, Fujiwara M, Grote K, Hazelden KP. Terminology of developmental abnormalities in common laboratory 
mammals (version 2). Congenital anomalies. 2009; 49(3):123-246.

http://dx.doi.org/10.1111/j.1741-4520.2009.00239.x

51. National Institute of Standards and Technology (NIST). Mass spectral library: Wiley Registry, 8th ed. Revision D06.00, version G1035B, entry 78256. New York, NY: Wiley and Sons, Inc; 2005.

52. National Toxicology Program (NTP). DART-04: Growth and clinical finding tables (I), pathology tables (PA), developmental and reproductive tables (R) from NTP developmental and reproductive toxicity studies. Research Triangle Park, NC. 2019.

http://dx.doi.org/10.22427/NTP-DATA-DART-04

53. Suckow MA, Weisbroth SH, Franklin CL. The laboratory rat. 2nd ed. Amsterdam, Netherlands: Elsevier; 2006.

54. Hayes AW, Kruger CL. Hayes' principles and methods of toxicology. 6th ed. New York, NY: CRC Press; 2014. p. 1670-1674.

55. Salewski E. Färbemethode zum makroskopischen nachweis von implantationsstellen am uterus der ratte. Naunyn-Schmiedeberg's Arch Pharmacol. 1964; 247(4):367. http://dx.doi.org/10.1007/BF02308461

56. Tyl RW, Marr MC. Developmental toxicity texting - methodology. Developmental and Reproductive Toxicology. 2nd ed. New York, NY: Taylor and Francis Group; 2006. p. 201-261.

57. Staples RE. Detection of visceral alterations in mammalian fetuses. Teratology. 1974; 9:A37A38.

58. Stuckhardt JL, Poppe SM. Fresh visceral examination of rat and rabbit fetuses used in teratogenicity testing. Teratog Carcinog Mutagen. 1984; 4(2):181-188.

http://dx.doi.org/10.1002/tcm.1770040203

59. Thompson RF. Basic neuroanatomy. Foundations of Physiological Psychology. New York, NY: Harper and Row Publishers; 1967. p. 79-82.

60. Marr MC, Price CJ, Myers CB, Morrissey RE. Developmental stages of the CDR(SpragueDawley) rat skeleton after maternal exposure to ethylene glycol. Teratology. 1992; 46(2):169181. http://dx.doi.org/10.1002/tera.1420460210

61. Dunnett CW. A multiple comparison procedure for comparing several treatments with a control. J Am Stat Assoc. 1955; 50(272):1096-1121. http://dx.doi.org/10.1080/01621459.1955.10501294

62. Williams DA. A test for differences between treatment means when several dose levels are compared with a zero dose control. Biometrics. 1971; 27:103-117.

http://dx.doi.org/10.2307/2528930

63. Williams DA. The comparison of several dose levels with a zero dose control. Biometrics. 1972; 28:519-531. http://dx.doi.org/10.2307/2556164 
64. Shirley E. A non-parametric equivalent of Williams' test for contrasting increasing dose levels of a treatment. Biometrics. 1977:386-389. http://dx.doi.org/10.2307/2529789

65. Williams DA. A note on Shirley's nonparametric test for comparing several dose levels with a zero-dose control. Biometrics. 1986; 42:183-186. http://dx.doi.org/10.2307/2531254

66. Dunn OJ. Multiple comparisons using rank sums. Technometrics. 1964; 6(3):241-252. http://dx.doi.org/10.1080/00401706.1964.10490181

67. Jonckheere AR. A distribution-free k-sample test against ordered alternatives. Biometrika. 1954; 41(1/2):133-145. http://dx.doi.org/10.2307/2333011

68. Dixon WJ, Massey FJ, Jr. Introduction to statistical analysis. 2nd ed. New York, NY: McGraw-Hill Book Company, Inc; 1957. p. 276-278, 412.

69. Hsu JC. The factor analytic approach to simultaneous inference in the general linear model. J Comput Graph Stat. 1992; 1(2):151-168.

70. Armitage P. Tests for linear trends in proportions and frequencies. Biometrics. 1955; 11(3):375-386. http://dx.doi.org/10.2307/3001775

71. Gart JJ, Chu KC, Tarone RE. Statistical issues in interpretation of chronic bioassay tests for carcinogenicity. J Natl Cancer Inst. 1979; 62(4):957-974.

72. Zorrilla EP. Multiparous species present problems (and possibilities) to developmentalists. Dev Psychobiol. 1997; 30(2):141-150. http://dx.doi.org/10.1002/(SICI)10982302(199703)30:2<141::AID-DEV5>3.0.CO;2-Q

73. Pendergast JF, Gange SJ, Lindstrom MJ. Correlated binary data In: Encyclopedia of Biostatistics. Hoboken, NJ: John Wiley \& Sons, Ltd; 2005. http://dx.doi.org/10.1002/0470011815.b2a10018

74. Li B, Lingsma HF, Steyerberg EW, Lesaffre E. Logistic random effects regression models: A comparison of statistical packages for binary and ordinal outcomes. BMC Med Res Methodol. 2011; 11:77. http://dx.doi.org/10.1186/1471-2288-11-77

75. Scott WJ, Jr., Resnick E, Hummler H, Clozel J-P, Bürgin H. Cardiovascular alterations in rat fetuses exposed to calcium channel blockers. Reprod Toxicol. 1997; 11(2-3):207-214. http://dx.doi.org/10.1016/S0890-6238(97)00008-7

76. Huntsman Corporation. Technical bulletin: N,N-dimethylethanolamine (DMEA). Houston, TX; 2007.

77. Wickramaratne GA. The post-natal fate of supernumerary ribs in rat teratogenicity studies. J Appl Toxicol. 1988; 8(2):91-94. http://dx.doi.org/10.1002/jat.2550080205

78. Foulon O, Jaussely C, Repetto M, Urtizberea M, Blacker AM. Postnatal evolution of supernumerary ribs in rats after a single administration of sodium salicylate. J Appl Toxicol. 2000; 20(3):205-209. http://dx.doi.org/10.1002/(SICI)1099-1263(200005/06)20:3<205::AIDJAT635>3.0.CO;2-G 
79. Chernoff N, Rogers JM. Supernumerary ribs in developmental toxicity bioassays and in human populations: Incidence and biological significance. J Toxicol Environ Health. 2004; 7(6):437-449. http://dx.doi.org/10.1080/10937400490512447

80. Bellary SS, Steinberg A, Mirzayan N, Shirak M, Tubbs RS, Cohen-Gadol AA, Loukas M. Wormian bones: A review. Clin Anat. 2013; 26(8):922-927. http://dx.doi.org/10.1002/ca.22262

81. Lefebvre V, Bhattaram P. Vertebrate skeletogenesis. Curr Top Dev Biol. 2010; 90:291-317. http://dx.doi.org/10.1016/S0070-2153(10)90008-2

82. Clares B, Ruiz MA, Morales ME, Tamayo JA, Lara VG. Structural characterization and stability of dimethylaminoethanol and dimethylaminoethanol bitartrate for possible use in cosmetic firming. J Cosmet Sci. 2010; 61(4):269-278. http://dx.doi.org/10.1111/j.14682494.2010.00620_1.X

83. SDBSweb. SDBS No. 3992. 2019. http://sdbs.riodb.aist.go.jp/sdbs/cgi-bin/directframetop.cgi?lang=eng [Accessed: January 18, 2019]

84. U.S. Environmental Protection Agency (USEPA). Dimethylaminoethanol. USEPA Chemistry Dashboard. 2018.

https://comptox.epa.gov/dashboard/dsstoxdb/results?search=dimethylaminoethanol\#properties [Accessed: October 1, 2018] 


\section{Appendix A. Chemical Characterization and Dose Formulation Studies}

\section{Table of Contents}

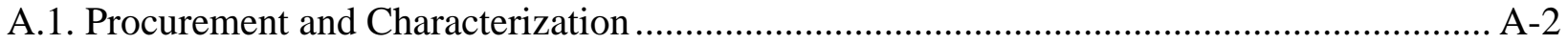

A.2. Preparation and Analysis of Dose Formulations...................................................... A-3

\section{Tables}

Table A-1. Gas Chromatography Systems Used in the Gavage Studies of

Dimethylaminoethanol Bitartrate

Table A-2. Preparation and Storage of Dose Formulations in the Gavage Studies of

Dimethylaminoethanol Bitartrate in Rats

Table A-3. Results of Analyses of Dose Formulations Administered to Female Rats in the Dose Range-finding Gavage Study of Dimethylaminoethanol Bitartrate.

Table A-4. Results of Analyses of Dose Formulations Administered to Female Rats in the Prenatal Developmental Toxicity Gavage Study of Dimethylaminoethanol Bitartrate.....

\section{Figures}

Figure A-1. Fourier Transform Infrared Absorption Spectrum of Dimethylaminoethanol Bitartrate.

Figure A-2. Proton Nuclear Magnetic Resonance Spectrum of Dimethylaminoethanol Bitartrate.

Figure A-3. Carbon-13 Nuclear Magnetic Resonance Spectrum of Dimethylaminoethanol Bitartrate 


\section{A.1. Procurement and Characterization}

\section{A.1.1. Dimethylaminoethanol Bitartrate}

Dimethylaminoethanol bitartrate was obtained from Bayville Chemical Supply Company, Inc. (Deer Park, NY) in one lot (159AK) that was used in the dose range-finding and prenatal developmental toxicity studies. Identity, purity, and stability analyses were conducted by the analytical chemistry laboratory at RTI International (Research Triangle Park, NC) for the study laboratory at Southern Research (Birmingham, AL). Reports on analyses performed in support of the dimethylaminoethanol bitartrate studies are on file at the National Institute of Environmental Health Sciences.

Lot 159AK of the chemical, a white crystalline powder, was identified as dimethylaminoethanol bitartrate using Fourier transform infrared (FTIR) and proton and carbon-13 nuclear magnetic resonance (NMR) spectroscopy. The exact mass for dimethylaminoethanol and tartaric acid was determined using ultra high-performance liquid chromatography (UHPLC) with time-of-flight mass spectrometry (TOF-MS) detection. In addition, the melting point of the bulk chemical was determined. All spectra were consistent with the structure and literature spectra ${ }^{82 ; 83}$ of dimethylaminoethanol bitartrate. UHPLC/TOF-MS results measured values within $3.9 \mathrm{ppm}$ or less of the theoretical mass values for dimethylaminoethanol and tartaric acid. The melting point ${ }^{84}$ was in good agreement with literature values. Representative FTIR and proton and carbon-13 NMR spectra are presented in Figure A-1, Figure A-2 and Figure A-3, respectively.

The moisture content of lot 159AK was measured by a desorption type Karl Fischer analysis and by thermogravimetric analysis (TGA); these procedures were conducted by Robertson Microlit Laboratory (Ledgewood, NJ). The purity of lot 159AK was determined by Galbraith Laboratories, Inc. (Knoxville, TN) using elemental analyses and by the analytical chemistry laboratory initially using UHPLC/TOF-MS with a hydrophilic interaction liquid chromatography (HILIC) gradient in the positive mode for dimethylaminoethanol and the negative mode for tartaric acid and subsequently using gas chromatography (GC) with MS detection. The UHPLC/TOF-MS system included a 1290 Infinity chromatograph with TOF-MS detection (Agilent, Santa Clara, CA) and a Waters Acquity ${ }^{\circledR}$ UPLC BEH Amide $(2.1 \mathrm{~mm} \times 50 \mathrm{~mm}$, $1.7 \mu \mathrm{M}$ particle size) column (Waters Corporation, Milford, MA). The mobile phases consisted of (A) $10 \mathrm{mM}$ ammonium acetate (pH 6.8) and (B) acetonitrile, programmed with a HILIC gradient of $5 \%$ A for 2 minutes, then to $95 \%$ A in 5 minutes, held for 0.5 minutes, reversed to $5 \% \mathrm{~A}$ in 2 minutes, and then held at $5 \% \mathrm{~A}$ for 2.5 minutes; the flow rate was $0.5 \mathrm{~mL} / \mathrm{minute}$. Assays for volatile organic impurities in the bulk chemical were conducted by the analytical chemistry laboratory using two GC systems with flame ionization detection (FID).

The Karl Fischer desorption analysis indicated approximately 12\% water and TGA results indicated an estimated maximum water value not greater than 3.5\%, calculated from the mass lost in the temperature range matching the boiling point of water. Elemental analyses for carbon, hydrogen, nitrogen, and oxygen were consistent with the structural composition of dimethylaminoethanol bitartrate and theoretical values. UHPLC/TOF-MS indicated one major peak accounting for greater than $99.9 \%$ of the total peak area relative to either the dimethylaminoethanol or tartaric acid peak. GC/MS using system A (Table A-1) indicated one major peak accounting for $100 \%$ of the total peak area; the spectrum was consistent with a library reference spectrum. ${ }^{51} \mathrm{~A}$ residual solvent screening assay using GC/FID by system B 
tentatively identified the presence of ethanol, chloroform, pyridine, and $N, N$-dimethylformamide. A second quantitative analysis using GC/FID by system $\mathrm{C}$ confirmed only the presence of one residual solvent, ethanol at $0.325 \%$; the other analytes were not quantified above their corresponding limits of quantitation ( 0.05 to $0.1 \%)$. The overall purity of lot $159 \mathrm{AK}$ was determined to be $96 \%$ or greater.

Stability studies of lot 159AK were conducted using the HILIC gradient UHPLC/TOF-MS system described above for the bulk chemical purity assessment. Results indicated that both dimethylaminoethanol and the counterion tartaric acid were stable in the bulk chemical for at least 14 days when stored in amber glass vials sealed with Teflon ${ }^{\circledR}$-lined caps at temperatures up to $60^{\circ} \mathrm{C}$. To ensure stability, the bulk chemical was stored at room temperature in sealed glass bottles. Reanalyses of the bulk chemical were performed prior to the dose range-finding study and after the prenatal developmental toxicity study using FTIR spectroscopy (dose range-finding study only) and GC/FID by system D—no degradation of the bulk chemical was detected.

\section{A.1.2. Sterile Water for Irrigation, USP}

The sterile water vehicle was obtained from Baxter Healthcare Corporation (Cleveland, MS) in two lots (G105999 and G110783). Lot G10599 was used in the dose range-finding study, and lot G110783 was used in the prenatal developmental toxicity study.

\section{A.2. Preparation and Analysis of Dose Formulations}

The dose formulations were prepared once for each study by mixing dimethylaminoethanol bitartrate with sterile water to give the required concentrations (Table A-2). The dose formulations were stored at room temperature in sealed amber glass bottles for up to 42 days.

The analytical chemistry laboratory performed syringeability studies of a $300 \mathrm{mg} / \mathrm{mL}$ formulation using a 22-gauge gavage needle and syringe and stability studies of a $10 \mathrm{mg} / \mathrm{mL}$ formulation using GC/FID by system D (Table A-1). Syringeability was confirmed and stability was confirmed for at least 42 days for dimethylaminoethanol for dose formulations stored in sealed clear glass bottles both at refrigerated and room temperatures and for 3 hours under simulated animal room conditions.

Additional stability studies of formulations of dimethylaminoethanol bitartrate in sterile water were performed to monitor the relative stability of the tartaric acid counterion and the $\mathrm{pH}$ of the formulations. Two formulations ( 25.0 and $22.5 \mathrm{mg} / \mathrm{mL}$ ) of dimethylaminoethanol bitartrate in sterile water were prepared for direct comparison to standards of tartaric acid at concentrations equivalent to those present in the formulations. After diluting into the range of a validated analytical method, a $300 \mathrm{mg} / \mathrm{mL}$ formulation was also analyzed using HPLC. The HPLC system included a Waters Alliance 2695 instrument (Waters Corporation) with a SIELC Primesep ${ }^{\mathrm{TM}} \mathrm{D}$ $150 \mathrm{~mm} \times 4.6 \mathrm{~mm}, 5 \mu \mathrm{M}$ particle size column (SIELC Technologies, Wheeling, IL). The mobile phases were: (A) deionized water (adjusted to $\mathrm{pH} 2.2$ with $\mathrm{H}_{3} \mathrm{PO}_{4}$ ), (B) acetonitrile, and (C) $100 \mathrm{mM} \mathrm{NaH}_{2} \mathrm{PO}_{4}$ in deionized water (adjusted to $\mathrm{pH} 2.7$ with $\mathrm{H}_{3} \mathrm{PO}_{4}$ ). The isocratic gradient was $30 \% \mathrm{~A}, 10 \% \mathrm{~B}$, and $60 \% \mathrm{C}$; ultraviolet detection was performed at $210 \mathrm{~nm}$; and flow rate was $1.0 \mathrm{~mL} /$ minute. Formulations were determined to have a stable tartaric acid concentration for at least 42 days. The $\mathrm{pH}$ of the formulations across the concentration range 2.5 to $300 \mathrm{mg} / \mathrm{mL}$ was between 3.4 and 3.6; based on analysis of the $10 \mathrm{mg} / \mathrm{mL}$ formulation, the $\mathrm{pH}$ of the 
formulation did not change over the period of 42 days when stored at either refrigerated or room temperatures.

RTI conducted periodic analyses of the dose formulations of dimethylaminoethanol bitartrate using GC/FID by system D. During the dose range-finding study, the dose formulations were analyzed once; all three of the dose formulations were within $10 \%$ of the target concentrations (Table A-3). Animal room samples of these dose formulations were also analyzed, and all three were within $10 \%$ of the target concentrations. During the prenatal developmental toxicity study, the dose formulations were analyzed once; all three dose formulations analyzed were used and all three animal room samples were within $10 \%$ of the target concentrations (Table A-4).

Table A-1. Gas Chromatography Systems Used in the Gavage Studies of Dimethylaminoethanol Bitartrate $^{\mathrm{a}}$

\begin{tabular}{|c|c|c|c|}
\hline Detection System & Column & Carrier Gas & Oven Temperature Program \\
\hline \multicolumn{4}{|l|}{ System A } \\
\hline $\begin{array}{l}\text { Mass Spectrometry with } \\
\text { Electron Impact Ionization } \\
\text { (35 to } 100 \mathrm{amu} \text { ) }\end{array}$ & $\begin{array}{l}\mathrm{DB}^{\mathrm{TM}}-\mathrm{WAX}, \\
30 \mathrm{~m} \times 0.32 \mathrm{~mm}, 0.5 \mu \mathrm{M} \\
\text { film (J\&W Scientific, } \\
\text { Folsom, CA) }\end{array}$ & Helium at $\sim 1.5 \mathrm{~mL} /$ minute & $\begin{array}{l}60^{\circ} \mathrm{C} \text { for } 4 \text { minutes, then } \\
\text { increased by } 20^{\circ} \mathrm{C} / \text { minute to } \\
240^{\circ} \mathrm{C} \text {, held for } 2 \text { minutes }\end{array}$ \\
\hline \multicolumn{4}{|l|}{ System B } \\
\hline Flame Ionization & $\begin{array}{l}\mathrm{DB}^{\mathrm{TM}}-624, \\
30 \mathrm{~m} \times 0.53 \mathrm{~mm}, 3.0 \mu \mathrm{M} \\
\text { film (J\&W Scientific) }\end{array}$ & Helium at $\sim 4.5 \mathrm{~mL} /$ minute & $\begin{array}{l}40^{\circ} \mathrm{C} \text { for } 20 \text { minutes, then } \\
\text { increased by } 20^{\circ} \mathrm{C} / \text { minute to } \\
240^{\circ} \mathrm{C} \text {, held for } 20 \text { minutes }\end{array}$ \\
\hline \multicolumn{4}{|l|}{ System C } \\
\hline Flame Ionization & $\begin{array}{l}\text { Rt }^{\circledR}-200,30 \mathrm{~m} \times 0.53 \mathrm{~mm}, \\
3.0 \mu \mathrm{M} \text { film thickness) } \\
\text { (Restek, Bellefonte, PA) }\end{array}$ & Helium at $\sim 4.5 \mathrm{~mL} /$ minute & $\begin{array}{l}40^{\circ} \mathrm{C} \text { for } 20 \text { minutes, then } \\
\text { increased by } 20^{\circ} \mathrm{C} / \text { minute to } \\
240^{\circ} \mathrm{C} \text {, held for } 20 \text { minutes }\end{array}$ \\
\hline \multicolumn{4}{|l|}{ System D } \\
\hline Flame Ionization & $\begin{array}{l}\mathrm{DB}^{\mathrm{TM}}-\mathrm{WAX}, \\
29 \mathrm{~m} \times 0.53 \mathrm{~mm}, 1.0 \mu \mathrm{M} \\
\text { film (J\&W Scientific) }\end{array}$ & Helium at $\sim 5 \mathrm{~mL} /$ minute & $\begin{array}{l}80^{\circ} \mathrm{C} \text { for } 1 \text { minute, then } \\
\text { increased by } 10^{\circ} \mathrm{C} / \text { minute to } \\
150^{\circ} \mathrm{C} \text {, held for } 7 \text { or } 12 \text { minutes }\end{array}$ \\
\hline
\end{tabular}

${ }^{\mathrm{a}}$ The gas chromatographs and mass spectrometer were manufactured by Agilent Technologies, Inc. (Santa Clara, CA). 
Table A-2. Preparation and Storage of Dose Formulations in the Gavage Studies of Dimethylaminoethanol Bitartrate in Rats

Dose Range-finding and Prenatal Developmental Toxicity Studies

\section{Preparation}

The dose formulations were prepared by weighing the appropriate amount of dimethylaminoethanol bitartrate into a small glass beaker, transferring the test article into a calibrated glass bottle with sterile water rinses, diluting to final volume with sterile water, and stirring for approximately 15 minutes. The dose formulations were prepared once for each study.

\section{Chemical Lot Number}

159AK

\section{Maximum Storage Time}

42 days

\section{Storage Conditions}

Stored in sealed amber glass bottles at room temperature

Study Laboratory

Southern Research (Birmingham, AL)

Table A-3. Results of Analyses of Dose Formulations Administered to Female Rats in the Dose Range-finding Gavage Study of Dimethylaminoethanol Bitartrate

\begin{tabular}{lcccc}
\hline Date Prepared & Date Analyzed & $\begin{array}{c}\text { Target } \\
\text { Concentration } \\
\text { (mg/mL) }\end{array}$ & $\begin{array}{c}\text { Determined } \\
\text { Concentration } \\
\text { (mg/mL) }\end{array}$ & $\begin{array}{c}\text { Difference from } \\
\text { Target (\%) }\end{array}$ \\
\hline January 27, 2014 & January 28-29, 2014 & 50 & 50.9 & +2 \\
& & 100 & 103 & +3 \\
& February 28, 2014b & 200 & 203 & +2 \\
& & 50 & 50.0 & 0 \\
& & 100 & 99.1 & -1 \\
\hline
\end{tabular}

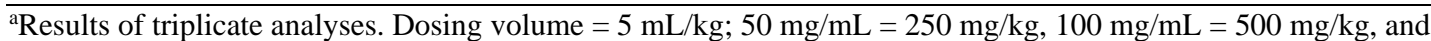
$200 \mathrm{mg} / \mathrm{mL}=1,000 \mathrm{mg} / \mathrm{kg}$.

bAnimal room samples. 
Table A-4. Results of Analyses of Dose Formulations Administered to Female Rats in the Prenatal Developmental Toxicity Gavage Study of Dimethylaminoethanol Bitartrate

\begin{tabular}{lcccc}
\hline Date Prepared & Date Analyzed & $\begin{array}{c}\text { Target Concentration } \\
\text { (mg/mL) }\end{array}$ & $\begin{array}{c}\text { Determined } \\
\text { Concentration } \\
(\mathbf{m g} / \mathbf{m L})\end{array}$ & $\begin{array}{c}\text { Difference from } \\
\text { Target (\%) }\end{array}$ \\
\hline March 31, 2014 & April 2-4, 2014 & 50 & 53.6 & +7 \\
April 4, 2014 & & 100 & 106 & +6 \\
& \multirow{2}{*}{ May 9, 2014 } & 200 & 220 & +10 \\
& & 50 & 52.3 & +5 \\
& & 100 & 104 & +4 \\
\hline
\end{tabular}

${ }^{\mathrm{a}}$ Results of triplicate analyses. Dosing volume $=5 \mathrm{~mL} / \mathrm{kg} ; 50 \mathrm{mg} / \mathrm{mL}=250 \mathrm{mg} / \mathrm{kg}, 100 \mathrm{mg} / \mathrm{mL}=500 \mathrm{mg} / \mathrm{kg}$, and $200 \mathrm{mg} / \mathrm{mL}=1,000 \mathrm{mg} / \mathrm{kg}$.

bAnimal room samples.

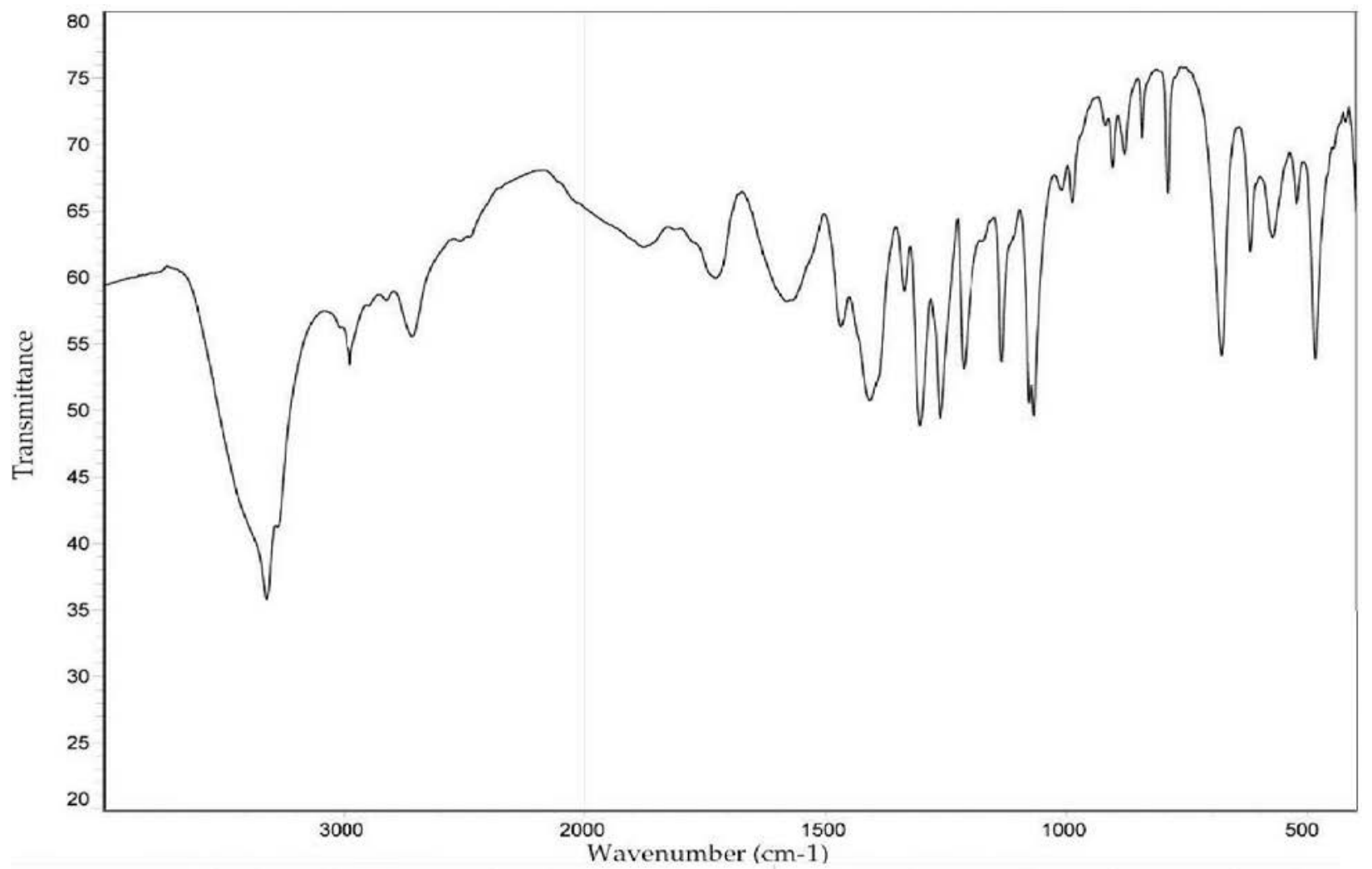

Figure A-1. Fourier Transform Infrared Absorption Spectrum of Dimethylaminoethanol Bitartrate 


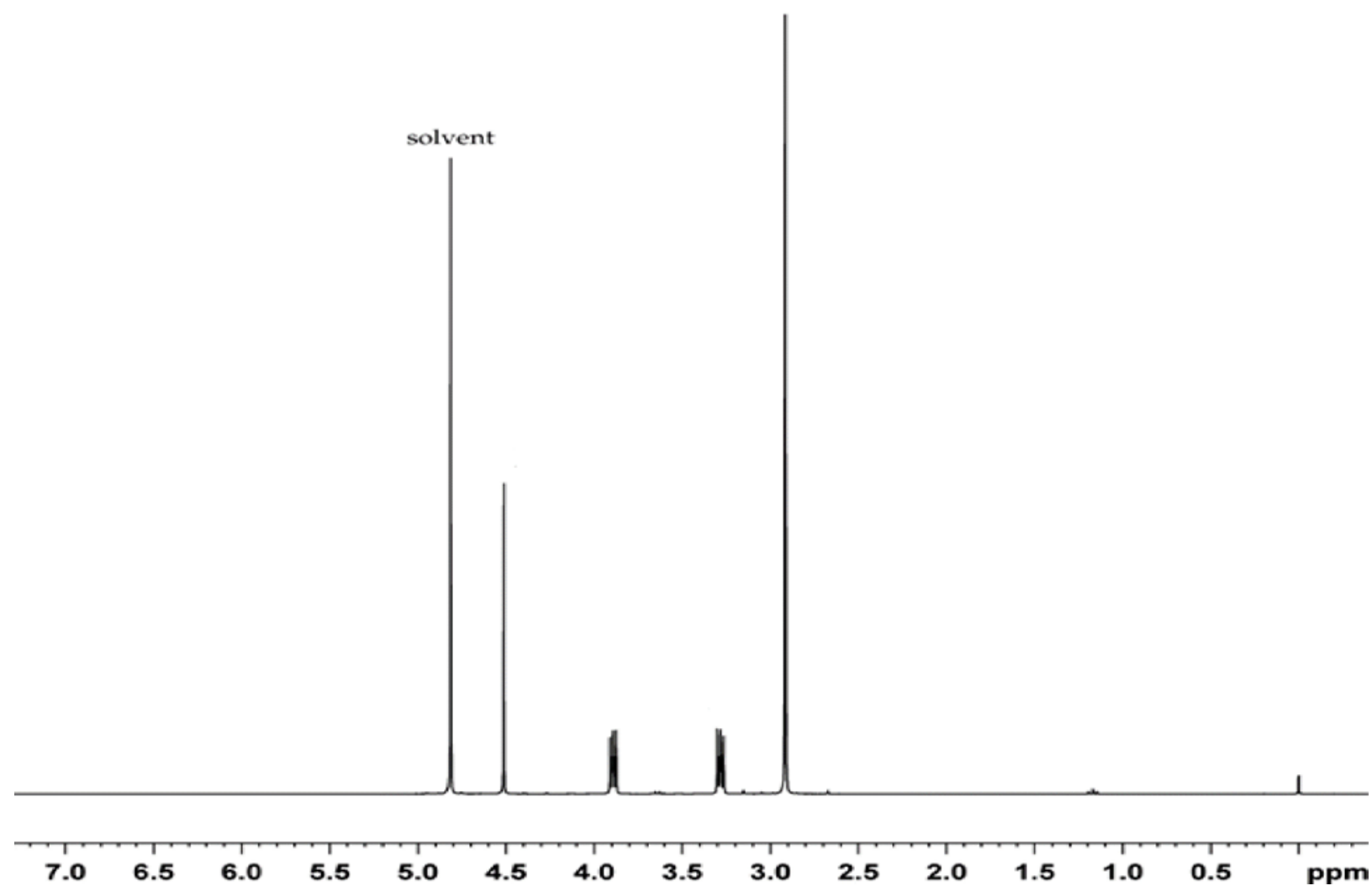

Figure A-2. Proton Nuclear Magnetic Resonance Spectrum of Dimethylaminoethanol Bitartrate 


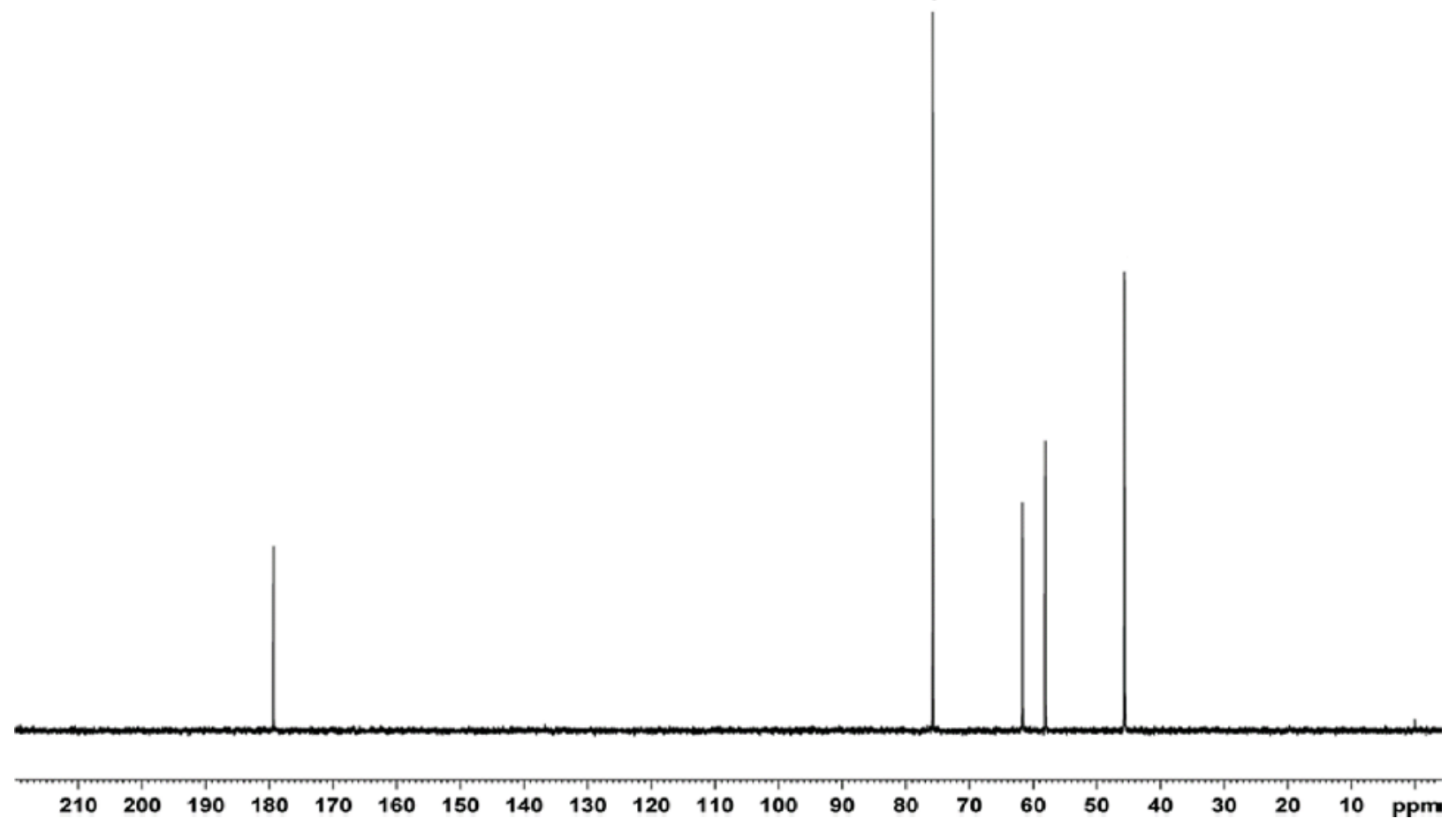

Figure A-3. Carbon-13 Nuclear Magnetic Resonance Spectrum of Dimethylaminoethanol Bitartrate 


\section{Appendix B. Ingredients, Nutrient Composition, and Contaminant Levels in NIH-07 Rat and Mouse Ration}

\section{Tables}

Table B-1. Ingredients of NIH-07 Rat and Mouse Ration

B-2

Table B-2. Vitamins and Minerals in NIH-07 Rat and Mouse Ration .......................................3

Table B-3. Nutrient Composition of NIH-07 Rat and Mouse Ration ..........................................

Table B-4. Contaminant Levels in NIH-07 Rat and Mouse Ration............................................6 
Table B-1. Ingredients of NIH-07 Rat and Mouse Ration

\begin{tabular}{lc}
\hline \multicolumn{1}{c}{ Ingredients } & Percent by Weight \\
\hline Ground \#2 Yellow Shelled Corn & 24.25 \\
Ground Hard Winter Wheat & 23.00 \\
Soybean Meal (49\% protein) & 12.00 \\
Wheat Middlings & 10.00 \\
Fish Meal (60\% protein) & 10.00 \\
Dried Skim Milk & 5.00 \\
Alfalfa Meal (Dehydrated, 17\% Protein) & 4.00 \\
Corn Gluten Meal (60\% Protein) & 3.00 \\
Soy Oil & 2.50 \\
Dried Brewer's Yeast & 2.00 \\
Dry Molasses & 1.50 \\
Dicalcium Phosphate & 1.25 \\
Ground Limestone & 0.50 \\
Salt & 0.50 \\
Vitamin Premix & 0.25 \\
Mineral Premix & 0.15 \\
Choline Chloride (70\% Choline) & 0.10 \\
\hline
\end{tabular}

${ }^{a}$ Wheat middlings as carrier.

${ }^{\mathrm{b} C a l c i u m}$ carbonate as carrier. 
Table B-2. Vitamins and Minerals in NIH-07 Rat and Mouse Ration ${ }^{\mathrm{a}}$

\begin{tabular}{lcl}
\hline & Amount & \multicolumn{1}{c}{ Source } \\
\hline Vitamins & & \\
$\mathrm{A}$ & $5,500,000 \mathrm{IU}$ & Stabilized vitamin A palmitate or acetate \\
$\mathrm{D}_{3}$ & $4,600,000 \mathrm{IU}$ & D-activated animal sterol \\
$\mathrm{K}$ & $2.8 \mathrm{~g}$ & Dimethylpyrimidinol bisulfite \\
$d$ - $\alpha$-Tocopheryl Acetate & $20.0 \mathrm{~g}$ & - \\
Niacin & $30.0 \mathrm{~g}$ & - \\
Folic Acid & $2.2 \mathrm{~g}$ & - \\
$d$-Pantothenic Acid & $18.0 \mathrm{~g}$ & \\
Riboflavin & $3.4 \mathrm{~g}$ & \\
Thiamine & $10.0 \mathrm{~g}$ & Thiamine mononitrate \\
$\mathrm{B}_{12}$ & $45,400.0 \mathrm{Hg}$ & \\
Pyridoxine & $5.9 \mathrm{~g}$ & Pyridoxine hydrochloride \\
Biotin & $140.0 \mathrm{mg}$ & $d$-Biotin \\
\hline Minerals & & \\
Iron & $120.0 \mathrm{~g}$ & Iron sulfate \\
Manganese & $60.0 \mathrm{~g}$ & Manganous oxide \\
Zinc & $16.0 \mathrm{~g}$ & Zinc oxide \\
Copper & $4.0 \mathrm{~g}$ & Copper sulfate \\
Iodine & $1.4 \mathrm{~g}$ & Calcium iodate \\
Cobalt & $0.4 \mathrm{~g}$ & Cobalt carbonate \\
\hline Per &
\end{tabular}

${ }^{\mathrm{a} e r}$ ton $(2,000 \mathrm{lb}$.) of finished product. 
Table B-3. Nutrient Composition of NIH-07 Rat and Mouse Ration

\begin{tabular}{|c|c|c|c|}
\hline Nutrient & $\begin{array}{c}\text { Mean } \pm \text { Standard } \\
\text { Deviation }\end{array}$ & Range & Number of Samples \\
\hline Protein (\% by Weight) & $23.25 \pm 0.636$ & $22.8-23.7$ & 2 \\
\hline Crude Fat (\% by Weight) & $5.75 \pm 0.071$ & $5.7-5.8$ & 2 \\
\hline Crude Fiber (\% by Weight) & $3.325 \pm 0.092$ & $3.26-3.39$ & 2 \\
\hline Ash (\% by Weight) & $6.36 \pm 0.240$ & $6.19-6.53$ & 2 \\
\hline \multicolumn{4}{|c|}{ Amino Acids (\% of Total Diet) } \\
\hline Arginine & $1.375 \pm 0.065$ & $1.30-1.49$ & 8 \\
\hline Cysteine & $0.321 \pm 0.035$ & $0.274-0.372$ & 8 \\
\hline Glycine & $1.145 \pm 0.077$ & $1.06-1.31$ & 8 \\
\hline Histidine & $0.516 \pm 0.023$ & $0.497-0.553$ & 8 \\
\hline Isoleucine & $0.982 \pm 0.025$ & $0.952-1.03$ & 8 \\
\hline Leucine & $1.996 \pm 0.054$ & $1.93-2.08$ & 8 \\
\hline Lysine & $1.261 \pm 0.032$ & $1.22-1.32$ & 8 \\
\hline Methionine & $0.487 \pm 0.015$ & $0.468-0.515$ & 8 \\
\hline Phenylalanine & $1.091 \pm 0.020$ & $1.07-1.12$ & 8 \\
\hline Threonine & $0.919 \pm 0.032$ & $0.883-0.961$ & 8 \\
\hline Tryptophan & $0.280 \pm 0.022$ & $0.266-0.326$ & 8 \\
\hline Tyrosine & $0.855 \pm 0.039$ & $0.785-0.894$ & 8 \\
\hline Valine & $1.134 \pm 0.0245$ & $1.11-1.17$ & 8 \\
\hline \multicolumn{4}{|c|}{ Essential Fatty Acids (\% of Total Diet) } \\
\hline Linoleic & $2.33 \pm 0.211$ & $2.04-2.59$ & 8 \\
\hline Linolenic & $0.25 \pm 0.028$ & $0.217-0.296$ & 8 \\
\hline \multicolumn{4}{|l|}{ Vitamins } \\
\hline Vitamin A (IU/kg) & $5,950 \pm 66.5$ & $5,480-6,420$ & 2 \\
\hline$\alpha$-Tocopherol (ppm) & $48.07 \pm 4.38$ & $40.3-52.73$ & 8 \\
\hline Thiamine (ppm) ${ }^{\mathrm{b}}$ & $11.3 \pm 1.13$ & $10.5-12.1$ & 2 \\
\hline Riboflavin (ppm) & $14.3 \pm 3.58$ & $10.0-19.8$ & 8 \\
\hline Niacin (ppm) & $99.4 \pm 9.10$ & $87.0-112$ & 8 \\
\hline Pantothenic Acid (ppm) & $45.6 \pm 3.13$ & $40.4-51.1$ & 8 \\
\hline Pyridoxine (ppm) $)^{\mathrm{b}}$ & $12.33 \pm 2.25$ & $9.63-15.6$ & 8 \\
\hline Folic Acid (ppm) & $2.47 \pm 0.550$ & $1.68-3.09$ & 8 \\
\hline Biotin (ppm) & $0.342 \pm 0.125$ & $0.25-0.64$ & 8 \\
\hline Vitamin B12 (ppb) & $50.21 \pm 7.47$ & $41.8-61.6$ & 8 \\
\hline Choline (ppm) $)^{\mathrm{b}}$ & $1,776 \pm 197$ & $1,570-2,200$ & 8 \\
\hline
\end{tabular}


Dimethylaminoethanol Bitartrate, NTP DART 04

\begin{tabular}{lccc}
\hline \multicolumn{1}{c}{ Nutrient } & $\begin{array}{c}\text { Mean } \pm \text { Standard } \\
\text { Deviation }\end{array}$ & Range & Number of Samples \\
\hline Minerals & $1.190 \pm 0.028$ & & 2 \\
Calcium (\%) & $0.978 \pm 0.046$ & $1.17-1.21$ & 2 \\
Phosphorus (\%) & $0.829 \pm 0.036$ & $0.945-1.01$ & 8 \\
Potassium (\%) & $0.625 \pm 0.102$ & $0.77-0.88$ & 8 \\
Chloride (\%) & $0.368 \pm 0.047$ & $0.441-0.8$ & 8 \\
Sodium (\%) & $0.183 \pm 0.009$ & $0.318-0.469$ & 8 \\
Magnesium (\%) & $376.3 \pm 52.5$ & $0.170-0.194$ & 8 \\
Iron (ppm) & $91.03 \pm 7.93$ & $276-455$ & 8 \\
Manganese (ppm) & $64.07 \pm 11.32$ & $80.7-104$ & 8 \\
Zinc (ppm) & $14.11 \pm 2.91$ & $52.4-89.2$ & 8 \\
Copper (ppm) & $1.71 \pm 0.886$ & $11.9-21.1$ & 8 \\
Iodine (ppm) & $3.96 \pm 0.033$ & $0.54-3.45$ & 8 \\
Chromium (ppm) & $0.53 \pm 0.293$ & $3.91-4.00$ & 8 \\
Cobalt (ppm) & & $0.01-0.963$ & \\
\hline aFrom formulation. & & & 8 \\
\hline
\end{tabular}

aFrom formulation.

${ }^{\mathrm{b}}$ As hydrochloride (thiamine and pyridoxine) or chloride (choline). 
Table B-4. Contaminant Levels in NIH-07 Rat and Mouse Ration ${ }^{\mathrm{a}}$

\begin{tabular}{|c|c|c|c|}
\hline & Mean \pm Standard Deviation ${ }^{b}$ & Range & Number of Samples \\
\hline \multicolumn{4}{|l|}{ Contaminants } \\
\hline Arsenic (ppm) & $0.368 \pm 0.038$ & $0.341-0.395$ & 2 \\
\hline Cadmium (ppm) & $0.097 \pm 0.010$ & $0.09-0.104$ & 2 \\
\hline Lead (ppm) & $0.074 \pm 0.003$ & $0.072-0.076$ & 2 \\
\hline Mercury (ppm) & $<0.02$ & - & 2 \\
\hline Selenium (ppm) & $0.519 \pm 0.092$ & $0.454-0.584$ & 2 \\
\hline Aflatoxins (ppb) & $<5.00$ & - & 2 \\
\hline Nitrate Nitrogen $(\mathrm{ppm})^{\mathrm{c}}$ & $25.05 \pm 3.041$ & $22.9-27.2$ & 2 \\
\hline Nitrite Nitrogen $(\mathrm{ppm})^{\mathrm{c}}$ & $<0.61$ & - & 2 \\
\hline BHA $(\mathrm{ppm})^{\mathrm{d}}$ & $<1.0$ & - & 2 \\
\hline BHT (ppm) $)^{\mathrm{d}}$ & $<1.0$ & - & 2 \\
\hline Aerobic Plate Count (CFU/g) & 10 & - & 2 \\
\hline Coliform (MPN/g) & 3.0 & - & 2 \\
\hline Escherichia coli (MPN/g) & $<3$ & - & 2 \\
\hline Salmonella (MPN/g) & Negative & - & 2 \\
\hline Total Nitrosoamines (ppb) ${ }^{\mathrm{e}}$ & $5.1 \pm 7.1$ & $0-10.1$ & 2 \\
\hline$N$-Nitrosodimethylamine (ppb) ${ }^{\mathrm{e}}$ & $1.2 \pm 1.6$ & $0-2.3$ & 2 \\
\hline$N$-Nitrosopyrrolidine (ppb) ${ }^{\mathrm{e}}$ & $3.9 \pm 5.5$ & $0-7.8$ & 2 \\
\hline \multicolumn{4}{|l|}{ Pesticides (ppm) } \\
\hline$\alpha$-BHC & $<0.01$ & - & 2 \\
\hline$\beta$-BHC & $<0.02$ & - & 2 \\
\hline$\gamma$-BHC & $<0.01$ & - & 2 \\
\hline$\delta$-BHC & $<0.01$ & - & 2 \\
\hline Heptachlor & $<0.01$ & - & 2 \\
\hline Aldrin & $<0.01$ & - & 2 \\
\hline Heptachlor Epoxide & $<0.01$ & - & 2 \\
\hline DDE & $<0.01$ & - & 2 \\
\hline DDD & $<0.01$ & - & 2 \\
\hline DDT & $<0.01$ & - & 2 \\
\hline HCB & $<0.01$ & - & 2 \\
\hline Mirex & $<0.01$ & - & 2 \\
\hline Methoxychlor & $<0.05$ & - & 2 \\
\hline Dieldrin & $<0.01$ & - & 2 \\
\hline Endrin & $<0.01$ & - & 2 \\
\hline Telodrin & $<0.01$ & - & 2 \\
\hline
\end{tabular}




\section{Dimethylaminoethanol Bitartrate, NTP DART 04}

\begin{tabular}{lccc}
\hline & Mean \pm Standard Deviation & Range & Number of Samples \\
\hline Chlordane & $<0.05$ & - & 2 \\
Toxaphene & $<0.10$ & - & 2 \\
Estimated PCBs & $<0.20$ & - & 2 \\
Ronnel & $<0.01$ & - & 2 \\
Ethion & $<0.02$ & - & 2 \\
Trithion & $<0.05$ & - & 2 \\
Diazinon & $<0.10$ & - & 2 \\
Methyl Chlorpyrifos & $0.051 \pm 0.02$ & - & 2 \\
Methyl Parathion & $<0.02$ & - & 2 \\
Ethyl Parathion & $<0.02$ & $0.02-0.024$ & 2 \\
Malathion & $0.022 \pm 0.003$ & - & 2 \\
Endosulfan I & $<0.01$ & - & 2 \\
Endosulfan II & $<0.01$ & - & 2 \\
Endosulfan Sulfate & $<0.03$ & 2 \\
\hline
\end{tabular}

BHA = butylated hydroxyanisole; BHT = butylated hydroxytoluene; CFU = colony-forming units; MPN = most probable number; BHC = hexachlorocyclohexane or benzene hexachloride; DDE = dichlorodiphenyldichloroethylene;

DDD = dichlorodiphenyldichloroethane; DDT = dichlorodiphenyltrichloroethane; HCB = hexachlorobenzene;

PCB = polychlorinated biphenyl.

${ }^{a}$ All samples were irradiated.

${ }^{\mathrm{b}}$ For values less than the limit of detection, the detection limit is given as the mean.

'Sources of contamination: alfalfa, grains, and fish meal.

${ }^{\mathrm{d} S}$ Sources of contamination: soy oil and fish meal.

${ }^{\mathrm{e}} \mathrm{All}$ values were corrected for percent recovery. 


\section{Appendix C. Summary of Peer Review Panel Comments}

\section{Table of Contents}

C.1. Attendees

.C-2

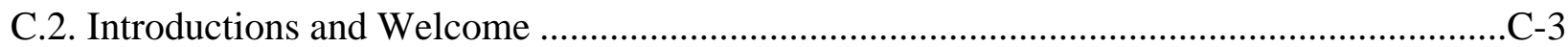

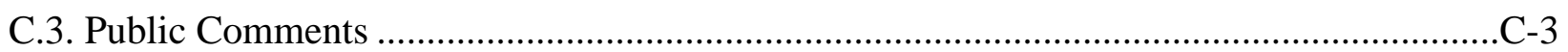

C.4. Background and Charge to the Panel ..............................................................................

C.5. Prenatal Developmental Toxicity Studies of Tris(chloropropyl) Phosphate ......................C-4

C.6. Prenatal Developmental Toxicity Studies of 4-Methylcyclohexanemethanol ......................-6

C.7. Prenatal Developmental Toxicity Studies of Vinpocetine ..............................................10

C.8. Prenatal Developmental Toxicity Studies of Dimethylaminoethanol Bitartrate................C-13

C.9. Closing Remarks on the Draft Reports .........................................................................14

C.10. Approval of the Peer Review Report by the Chair of the Peer Review Panel .................C-15 


\section{C.1. Attendees}

\section{Peer Review Panel}

Chair: George Daston, The Procter and Gamble Company

Cheryl Broussard, Centers for Disease Control and Prevention

Alan Hoberman, Charles River Laboratories Preclinical Services

Linda Roberts, NapaTox Consulting LLC

Mary Alice Smith, University of Georgia

Kimberley Treinen, Sunovion Pharmaceuticals Inc.

National Toxicology Program Board of Scientific Counselors Liaison

Donald Stump, Charles River Laboratories International

\section{National Institute of Environmental Health Sciences Staff}

Brian Berridge

Chad Blystone

Bradley Collins

Michelle Cora

Helen Cunny

Shawn Harris

Michelle Hooth

Angela King-Herbert

Elizabeth Maull, Designated Federal Official

Barry McIntyre

Georgia Roberts

Kristen Ryan

Sheena Scruggs

Keith Shockley

Matthew Stout

Vicki Sutherland

Nigel Walker 
AtLee Watson

Mary Wolfe

Other Federal Agency Staff

Gonçalo Gamboa, FDA

\section{Contract Support Staff}

Susan Blaine, ICF

Dave Burch, ICF

Lindsey Green, ICF

Ernie Hood, Bridport Services

Steve McCaw, Image Associates

Blake Riley, ICF

Samantha Snow, ICF

\section{C.2. Introductions and Welcome}

The National Toxicology Program (NTP) convened a peer review panel for the draft NTP Developmental and Reproductive Toxicity Technical Reports on the Prenatal Development Studies of Tris(chloropropyl) Phosphate, 4-Methylcyclohexanemethanol, Vinpocetine, and Dimethylaminoethanol Bitartrate on July 31, 2019, in Conference Room F193, Rall Building, National Institute for Environmental Health Sciences (NIEHS), Research Triangle Park, North Carolina (or via webcast).

- Dr. George Daston, panel chair, called the meeting to order at 8:30 a.m., welcomed everyone to the meeting, asked all attendees to introduce themselves, and reviewed the format for the peer review meeting for the panel and audience.

- Dr. Elizabeth Maull read the conflict of interest policy statement and briefed the attendees on meeting logistics.

- Dr. Donald Stump attended as the liaison to the NTP Board of Scientific Counselors.

\section{C.3. Public Comments}

Dr. Daston noted that no written public comments or requests for oral public comments on the draft technical reports had been received.

\section{C.4. Background and Charge to the Panel}

Dr. Chad Blystone gave a brief presentation on NTP draft technical reports, including information about the levels of evidence for developmental toxicity. He also described the 
Developmental and Reproductive Toxicity (DART) historical controls and the charge to the panel for the individual peer reviews:

- Review and evaluate the scientific and technical elements of each study and its presentation.

- Determine whether each study's experimental design, conduct, and findings support NTP's conclusions regarding the developmental toxicity of the substances tested.

\section{C.5. Prenatal Developmental Toxicity Studies of Tris(chloropropyl) Phosphate}

\section{C.5.1. Presentation and Clarifying Questions}

Dr. Kristen Ryan summarized the studies and conclusions reported in the draft NTP Developmental and Reproductive Toxicity Technical Report on the Prenatal Development Studies of Tris(chloropropyl) Phosphate (CASRN 13674-84-5) in Sprague Dawley (Hsd:Sprague Dawley ${ }^{\circledR} S D^{\circledR}$ ) Rats (Gavage Studies).

Tris(chloropropyl) phosphate (TCPP) is a flame retardant found in a variety of commercial and consumer products. It is ubiquitous but not bioaccumulative in the environment. Exposure can occur via dermal, oral, or inhalation routes. TCPP is a mixture constituted primarily of four isomers; the research focus is often on the primary isomer due to its abundance. The test article used for the NTP studies contained all four isomers. The goal of this study was to characterize the effects of TCPP exposure on pregnant rats and developing fetuses.

The dose range-finding study was conducted in 11 time-mated female rats using doses of 0, 300, 650 , and $1,000 \mathrm{mg} / \mathrm{kg} / \mathrm{day}$, administered via gavage. Adverse signs at $1,000 \mathrm{mg} / \mathrm{kg} / \mathrm{day}$ occurred throughout gestation. These results informed the use in the main study of doses of $0,162.5,325$, and $650 \mathrm{mg} / \mathrm{kg} /$ day in 25 time-mated female rats per group. An additional 25 control dams were added to this study to supplement historical control data for maternal and fetal findings. The main study findings revealed:

- No maternal treatment-related effects on mortality or body weights during gestation

o Clinical observations were of low incidence and limited to the $650 \mathrm{mg} / \mathrm{kg} /$ day group

o At $650 \mathrm{mg} / \mathrm{kg} / \mathrm{day}$, absolute and relative liver weights were increased approximately $26 \%$

- No treatment-related effects on uterine or litter parameters, such as implantations, litter size, live fetuses per litter, or fetal weight

- Fetal skeletal malformations of limited toxicological relevance (e.g., lumbar rudimentary ribs) or those that occurred as single or sporadic incidence

Under the conditions of this prenatal study, NTP's draft conclusion was:

- No evidence of developmental toxicity of TCPP in Hsd:Sprague Dawley rats administered $162.5,325$, or $650 \mathrm{mg} / \mathrm{kg} /$ day in the absence of overt maternal toxicity

There were no clarifying questions or comments about the presentation. 


\section{C.5.2. Peer Review Comments and Panel Discussion}

\section{C.5.2.1. First Reviewer - Dr. Cheryl Broussard}

Dr. Broussard indicated that the study was clearly described, well conducted, and the conclusions followed logically from the presented findings. She agreed with NTP's draft conclusions. Dr. Broussard then recommended adding language explaining the rationale for limiting soft tissue examination to only $50 \%$ of the heads. She also requested that NTP clarify more specifically where the audit procedures and findings were located to aid in transparency. The comments regarding soft tissue allocations and audit procedures applied to all reports. Finally, Dr. Broussard questioned why blood was not collected from the dams for clinical pathology.

- Dr. Ryan noted that the allocation for fetal exams was based on the study guidelines, with every other fetus allocated for head examination. She agreed that NTP could consider adding more information on fetal exam allocations and the use and location of the audit procedures and findings, which are archived electronically, to the reports.

- Dr. Ryan stated that blood chemistry was not typically required in this type of study. Furthermore, these endpoints were not identified in the literature as a primary concern for TCPP exposure.

\section{C.5.2.2. Second Reviewer - Dr. Alan Hoberman}

Dr. Hoberman stated that the study was well conducted, and he did not disagree with the conclusion. However, he noted that the only individual data presented in the reports were fetal data and that the public would benefit from having access to all individual animal data. This comment applied to all reports. The presence or absence of deviations should be included in the report. The historical control data lacked information on postimplantation loss percentages as well as other fetal information. The report failed to comment on an earlier study by Kawasaki (1982) that noted an increase in cervical ribs. Although Dr. Hoberman understood the use of two control groups, he noted that inclusion of group variations would have been informative. He also noted that this class of compound is known to produce enlarged livers, which may be considered an adaptive change rather than maternal toxicity. Because NTP referenced the changes in liver weights, the authors must have considered that the change in weight represented some sort of system perturbation. He recommended adding some discussion detailing why the enlarged liver was not considered as maternal toxicity.

In response to Dr. Hoberman's comments, Dr. Ryan indicated:

- NTP would consider adding language to the report specifying the location of the individual animal data.

- Deviations are listed in the good laboratory practices report. NTP would consider adding a line to the main report such as "no other deviations were noted."

- NTP is currently evaluating the historical control data and will be adding information (i.e., fetal and uterine parameters) to the database. Postimplantation loss observed in this study was limited to a single litter and was not considered an exposure-related finding.

- NTP evaluates cervical ribs as part of the fetal examinations. Although an increase in cervical ribs had been observed in the Kawasaki study, they were not seen in the NTP 
study, and, therefore, not populated in the historical control database. This information could be added.

- $\quad$ She reviewed the cross-reference data from dams to fetuses from the two control groups prior to the data being pooled and found that there were comparable findings in both control groups.

- NTP chose to report that no developmental toxicity was observed in the absence of overt maternal toxicity in this study and indicated that NTP would consider adding language to clarify the issues related to enlarged liver in the discussion.

\section{C.5.3. Vote on NTP Conclusion}

Dr. Daston called for a motion from the panel to approve the conclusion as written. Dr. Hoberman so moved and Dr. Kimberley Treinen seconded the motion. The panel voted unanimously (5 yes, 0 no, 0 abstentions) to approve the conclusion as written.

\section{C.6. Prenatal Developmental Toxicity Studies of 4-Methylcyclohexanemethanol}

\section{C.6.1. Presentation and Clarifying Questions}

Dr. AtLee Watson summarized the studies and conclusions reported in the draft NTP Developmental and Reproductive Toxicity Technical Report on the Prenatal Development Studies of 4-Methylcyclohexanemethanol (CASRN 34885-03-5) in Sprague Dawley (Hsd:Sprague Dawley ${ }^{\circledR} S D^{\circledR}$ ) Rats (Gavage Studies).

4-Methylcyclohexanemethanol (MCHM) was the chemical involved in the 2014 Elk River Chemical Spill in West Virginia. An estimated 10,000 gallons of crude MCHM leaked into the river, contaminated the municipal water supply, and likely led to human exposure. This prenatal developmental toxicity study resulted from concern for women of childbearing potential and developing embryos/fetuses, and provided an opportunity to evaluate the adequacy of the 1 part per million advisory level set forth by the Centers for Disease Control and Prevention (CDC) and the Agency for Toxic Substances and Disease Registry (ATSDR) for MCHM in drinking water.

The dose range-finding study tested doses of $0,150,300,600$, and $900 \mathrm{mg} / \mathrm{kg} / \mathrm{day}$ in groups of 10 time-mated female rats each and examined maternal and fetal endpoints. In this study, exposure to 600 and $900 \mathrm{mg} / \mathrm{kg} /$ day resulted in dose-related mortality and clinical observations of toxicity. These results informed the selection of doses of $0,50,100,200$, and $400 \mathrm{mg} / \mathrm{kg} / \mathrm{day}$ for the main study in 25 time-mated female rats per group. Main study findings included:

- Reduced maternal serum total protein and globulin at doses $\geq 100 \mathrm{mg} / \mathrm{kg} / \mathrm{day}$

- Fetal findings at $400 \mathrm{mg} / \mathrm{kg} /$ day:

o Decreased fetal body weights (15\%) and gravid uterine weight (18\%) compared with controls

o Increased incidences of malformations of the axial skeleton

o Misshapen adrenal glands (malformation)

- No exposure-related fetal findings at doses $\leq 200 \mathrm{mg} / \mathrm{kg} /$ day 
Under the conditions of this prenatal study, NTP's draft conclusion was:

- Clear evidence of developmental toxicity of MCHM in Hsd:Sprague Dawley rats at $400 \mathrm{mg} / \mathrm{kg} /$ day in the absence of overt maternal toxicity based on findings of:

o Reduced fetal weight

o Malformations of the axial skeleton

o Malformations of the adrenal glands

As a follow-up to the presentation, panelists had the following clarifying questions and discussion:

\section{Topic - Malformation of the adrenal glands}

- Dr. Linda Roberts asked for a description of the criteria for classifying the adrenal glands as misshapen.

- Dr. Hoberman asked if histopathology is routinely performed when necrotic masses are observed on adrenal glands. Although this finding appeared in three fetuses from different litters, the genealogy of the litters was unknown, which may play a role in the occurrence rate. Responding to a question posed by Dr. Roberts, Dr. Hoberman stated he could not recall ever seeing a misshapen adrenal with a necrotic mass. Dr. Sutherland agreed that it was an unusual finding.

o Dr. Watson indicated that the misshapen adrenal designation was attributed to the presence of a necrotic mass on the adrenal glands.

o Dr. Watson stated that while histopathology could inform whether the occurrence of a necrotic mass on the adrenal gland represents a permanent change or would alter postnatal or subsequent development, guideline prenatal developmental toxicity studies do not routinely call for it.

\section{Topic - Clinical chemistry endpoints}

- Dr. Daston inquired if the clinical chemistry findings on glucose, triglycerides, and blood urea nitrogen levels were also observed in other subchronic MCHM studies or if the changes in the clinical chemistry endpoints were specific to the pregnancy in the rat.

o Dr. Watson noted that there was a decrease in some of the red blood cells in the repeat dose oral gavage study that was conducted by the Eastman Chemical Company. He indicated that Eastman Chemical Company did not observe the same glucose findings.

\section{Topic - Potential MCHM review article}

- Dr. Daston noted that NTP played a significant role in quickly developing information on MCHM and wondered if there will be a larger synthesis of information based on this and other recently conducted studies. He added that there would be interest in these types of summary reports from people who were exposed and who had made health decisions based on what the scientific community conveyed to them. The current report format may be difficult for the general public to understand given the dry and science-based conclusions they contain. 
o Dr. Watson indicated that NTP's website currently has summary findings, but the development of a report summarizing all MCHM-related NTP studies would be addressed in subsequent NTP discussions.

o Dr. Blystone noted that prior communications to the stakeholders were less dry and more informal.

\section{C.6.2. Peer Review Comments and Panel Discussion}

\section{C.6.2.1. First Reviewer - Dr. Mary Alice Smith}

Dr. Smith indicated that the study was designed and conducted according to accepted DART guidelines. She stated that the findings in the study, including reduced fetal weight, adrenal malformations, and increased malformations of the axial skeleton, support the conclusion of clear evidence of developmental toxicity of MCHM in the fetuses from dams exposed to $400 \mathrm{mg} / \mathrm{kg} /$ day. Dr. Smith recommended adding historical normal pregnant rat clinical chemistry ranges (as reported for human studies) to the report, which would help interpret the exposurerelated data. Adding to this comment, Dr. Daston asked if some of the qualitative statements on clinical chemistry endpoints found in the report might be expanded on to put this type of data in context. Dr. Smith recommended that the report clearly state that the dose-related changes are significantly different from the controls based on a dose-related trend or a pairwise comparison effect and to include this type of information in the conclusion statements. Finally, she requested inclusion of a 2018 human epidemiology study investigating the possible association of adverse birth defects with exposure to crude MCHM from the spill site.

- Dr. Michelle Cora, NTP Clinical Pathologist, responding to the clinical chemistry questions, noted that currently NTP does not have historical control data for pregnant rats. She added that reporting values from the study's controls are preferred over those of historical controls due to the number of uncontrolled variables (i.e., animal diet, conditions of the study, type of machine the samples were run on) that influence historical control data. She added that the range for clinical chemistry data indicated in these reports is typically the standard error. Expansion beyond qualitative statements would not be feasible.

- Dr. Watson agreed that inclusion of dose-related response in the fetal body weight conclusion would improve the comprehension of the data but was concerned that it could overcomplicate the conclusion statement. He indicated that NTP would consider implementing this recommendation if it could be done in a concise manner.

- Dr. Watson indicated that he would incorporate the 2018 study, which found no adverse birth outcomes following the spill, in the report's discussion.

\section{C.6.2.2. Second Reviewer - Dr. Cheryl Broussard}

Dr. Broussard found the study design clearly described and well conducted, and that the conclusions followed logically from the presented findings. She agreed with the draft conclusion of clear evidence of developmental toxicity. She suggested adding the rationale for why approximately $50 \%$ of the heads were examined for soft tissue alterations, as well as being more transparent about where to find the audit procedures and findings. She wondered whether the Sentinel Animal Program described in some of the other reports was relevant here also. 
- Dr. Watson replied:

o NTP would add the rationale to the methodology section of the report.

o Given the short duration of these studies, a Sentinel Animal Program is not required. The dams received by the lab underwent a full evaluation by the staff animal veterinarian before they were cleared to be included in the study. That information is included in the report.

\section{C.6.2.3. Third Reviewer - Dr. Linda Roberts}

Dr. Roberts indicated that the studies were conducted properly and agreed, with a single caveat, with the NTP conclusion. She was not as confident with a classification of "clear evidence" versus "some or equivocal" evidence based on the absence of statistical significance in misshapen adrenal glands in the historical controls. The strongest evidence for developmental toxicity was the reduction in fetal body weight. To clarify Dr. Roberts' comments, Dr. Daston asked her to confirm that she thought there was clear evidence that MCHM causes developmental effects based on fetal weight and skeletal malformations, but not changes in adrenal malformation. Dr. Roberts confirmed that this was a correct interpretation of her thoughts.

Dr. Roberts also expressed appreciation that the fetal no-observed-effect level (NOEL) was included in the report and noted that the maternal NOEL of $50 \mathrm{mg} / \mathrm{kg} /$ day was based on the clinical chemistry endpoints. She stated that although there was statistical significance in these endpoints, she was less confident that there was biological significance.

- Dr. Watson agreed that additional information discriminating between structural malformations and alterations that might affect postnatal development would be useful to help understand the significance of the effect. It was difficult to confirm whether there was a pairwise significant difference in the highest dose group for this finding due to the very low incidences. Dr. Watson noted that NTP takes litter incidence into account. The fact that the findings occurred in three single fetuses from three separate litters support the conclusion that the adrenal malformation was a treatment-related effect.

\section{C.6.2.4. Panel Discussion}

Dr. Kimberley Treinen questioned the choice of reporting NOEL for maternal toxicity rather than the no-observed-adverse-effect level (NOAEL). She mentioned that the entire call was characterized as being "in the absence of overt maternal toxicity," by which she assumes to be a NOAEL. Dr. Treinen also recommended adding a line to the summary table correcting for uterine weight. She noted that the study reported high nonpregnancy rates, along with a high rate of misshapen aortic valves. She would like to have seen a lower background rate, given concern about cardiovascular malformations in the controls. The relatively large increase in the axial skeletal malformations with limited variations in other endpoints was an unusual finding. Dr. Treinen recommended that further elaboration is needed in the report to describe the misshapen adrenal glands, perhaps by providing images, given that this is an unusual finding. Dr. Daston agreed that this issue needs more attention in the report. 
- Dr. Watson indicated that NTP avoided distinguishing between adverse and nonadverse effects. Using the NOEL designation avoided some of the close calls that would have been generated by using NOAEL.

- $\quad$ Dr. Vicki Sutherland noted:

o NTP would consider adding language to the tables as recommended.

o At the time of the study, there was a concern about successful pregnancy rates, which has since improved with increased training, suggesting this was not a strain-related effect. NTP uses the same strain across all its studies.

o NTP will consider directing the lab to follow up with histopathology in the future if this finding is present. NTP will also ascertain if this finding is specific to this strain of rat.

Dr. Daston noted that the significant decrease in dam body weight with a significant increase in food consumption was a remarkable finding that, combined with the findings on blood glucose, suggests something interesting going on beyond general maternal toxicity-something that may yield an indication of a mechanism of action. The phenomenon deserved more treatment in the report.

- Dr. Watson said that data from a MCHM toxicogenomics study suggested that fatty acid metabolism may be involved as a mechanism of action. He indicated that NTP would add a discussion to the report.

- Dr. Cora remarked that although she thought the change in blood glucose levels was real, the rats would not be considered hypoglycemic, and the mild decrease is seen with some frequency. She said the triglycerides were affected by what the dams were eating and when they had last ingested food.

\section{C.6.3. Vote on NTP Conclusion}

Dr. Daston called for a motion to accept the conclusion as written, understanding that there would be information added to the report on the adrenal malformations. Dr. Roberts said she would prefer that the reference to adrenal gland malformations be removed from the conclusion. Dr. Smith moved to accept the conclusion as written and Dr. Broussard seconded. The panel passed the motion (4 yes, 1 no, 0 abstentions). Dr. Roberts voted no, citing her discomfort with including the adrenal malformations as the reason for her vote.

\section{C.7. Prenatal Developmental Toxicity Studies of Vinpocetine}

\section{C.7.1. Presentation and Clarifying Questions}

Dr. Sutherland summarized the studies and conclusions reported in the draft NTP Developmental and Reproductive Toxicity Technical Report on the Prenatal Development Studies of Vinpocetine (CASRN 42971-09-5) in Sprague Dawley (Hsd:Sprague Dawley ${ }^{\circledR} S D^{\circledR}$ ) Rats and New Zealand White (Hra:NZW SPF) Rabbits (Gavage Studies).

Vinpocetine is marketed as a dietary supplement for cognitive enhancement. It is also a semisynthetic/synthetic pharmaceutical agent for treatment of cerebrovascular and cognitive disorders. NTP chose to study vinpocetine due to concerns of consumer exposure through dietary 
supplement use, signals of developmental toxicity in the literature, and lack of adequate toxicity data.

The rat dose range-finding study used doses of $0,20,40,80,160$, or $320 \mathrm{mg} / \mathrm{kg} /$ day via gavage, with 10 time-mated female rats per group. A dose-related decrease in maternal body weight correlated with fetal loss at the higher two doses in this study. These results informed the selection of doses of $0,5,20$, and $60 \mathrm{mg} / \mathrm{kg} /$ day for the main study in 25 time-mated female rats per group. Findings from the main study included:

- Dose-related increase in the incidence of vaginal discharge (20 and $60 \mathrm{mg} / \mathrm{kg} / \mathrm{day}$ )

- Decreased maternal body weight

- Exposure-related increases in postimplantation loss (83\% at $60 \mathrm{mg} / \mathrm{kg} /$ day)

- Fetal examination findings such as:

o Increased incidences of fetuses with ventral septal defect (malformation)

o Increased incidences of incomplete ossification of the thoracic centra (variation) and full thoracolumbar ribs (malformation)

The above findings provided sufficient concern to examine the effects of vinpocetine in a second species, the rabbit. The dosages chosen for the rabbit study were $0,25,75,150$, and $300 \mathrm{mg} / \mathrm{kg} /$ day, administered via gavage to eight time-mated female animals per group. The main rabbit study findings revealed:

- Decreased maternal body weight gains at 150 and $300 \mathrm{mg} / \mathrm{kg} / \mathrm{day}$

- Exposure-related effect on embryo-fetal survival at $300 \mathrm{mg} / \mathrm{kg} / \mathrm{day}$

Data from the rabbit study supported the findings observed in the rat dose range-finding study and rat prenatal developmental toxicity studies.

Under the conditions of the rat prenatal study, NTP's draft conclusion was:

- Clear evidence of developmental toxicity of vinpocetine in Hsd:Sprague Dawley rats in the absence of overt maternal toxicity based on findings of:

o Increased postimplantation loss

o Increased incidences of ventricular septum defects

o Increased incidences of thoracolumbar ribs (full)

o Increased incidences of incomplete ossification of the thoracic centrum

As a follow-up to the presentation, participants had the following clarifying question and discussion:

\section{Topic - No-observed-effect levels}

- Dr. Roberts noted that the study did not include NOEL values and asked whether that was intentional.

o Dr. Sutherland responded that NTP had internal discussion about the language; if the panel feels that NOELs should be included in all the reports, the team will consider modifying the text. 


\section{C.7.2. Peer Review Comments and Panel Discussion}

\section{C.7.2.1. First Reviewer - Dr. Alan Hoberman}

Dr. Hoberman expressed appreciation to NTP for completing the study of this dietary supplement, approved performing the studies in both the rat and rabbit, and overall agreed with the conclusion. He recommended that individual animal data be made available for this report and all other studies and thought that including the onset and duration for clinical signs, such as vaginal discharge, could be informative. Recognizing that the studies were hazard assessments and not risk assessments, Dr. Hoberman also thought it would be beneficial to report how the animal doses in the study compared with human doses.

Dr. Sutherland responded:

- The individual data are available online and indicated that NTP would consider how to make access more apparent in the reports.

- The vaginal discharge data did not directly correlate with embryonic loss.

- NTP considered risk assessment information outside the scope of this report.

\section{C.7.2.2. Second Reviewer - Dr. Linda Roberts}

Dr. Roberts commented that the study was well conducted and appreciated that a second species was included. She said that the body weight gain seen did not meet the criteria for overt maternal toxicity. She agreed with the clear evidence conclusion as written.

\section{C.7.2.3. Third Reviewer - Dr. Kimberley Treinen}

Dr. Treinen recommended that an additional line be added to the summary table with corrected numbers for maternal body weight. She noted that there was a comment made in the rabbit study that food consumption might have contributed to the body weight decrement, but it appeared that it was more attributable to the decrease in implants.

In response to Dr. Treinen's comments, Dr. Sutherland indicated:

- NTP would consider adding corrected body weight in the text and tables if that would add clarity.

- The food consumption was not directly correlated to embryonic loss.

\section{C.7.2.4. Other Comments}

Dr. Gonçalo Gamboa, FDA, thanked NTP for keeping the FDA apprised as to the results. He noted that FDA released a statement cautioning women of childbearing ages from consuming this chemical. He appreciated the good communication.

\section{C.7.3. Vote on NTP Conclusion}

Dr. Daston asked for a motion and second from the panel to approve the conclusion as written. Dr. Roberts so moved and Dr. Hoberman seconded the motion. The panel voted unanimously (5 yes, 0 no, 0 abstentions) to approve the conclusion as written. 


\section{C.8. Prenatal Developmental Toxicity Studies of Dimethylaminoethanol Bitartrate}

\section{C.8.1. Presentation and Clarifying Questions}

Dr. Sutherland summarized the studies and conclusions reported in the draft NTP Developmental and Reproductive Toxicity Technical Report on the Prenatal Development Studies of Dimethylaminoethanol Bitartrate (CASRN 5988-51-2) in Sprague Dawley (Hsd:Sprague Dawley ${ }^{\circledR} S{ }^{\circledR}$ ) Rats (Gavage Studies).

Dimethylaminoethanol bitartrate (DMAE) is a close structural analog of the essential nutrient choline. It is marketed as a dietary supplement to improve memory and general cognitive function. NTP chose to study DMAE because of its potential for widespread human exposure through its use in industrial and consumer products and limited evidence from the literature that it may be a teratogen and reproductive toxicant.

The dose range-finding study used doses of $0,250,500$, and $1,000 \mathrm{mg} / \mathrm{kg} /$ day via gavage, with 10 time-mated female rats per group. No maternal or fetal toxicity were present at the doses used in the range-finding study. The same doses were employed in the main study, which used 25 time-mated female rats per group. Findings from the main study revealed:

- No treatment-related effects on mortality, body weights, or feed consumption o Effects were sporadic or without a dose response

- No effects on uterine or litter parameters such as implantations, litter size, live fetuses per litter, or fetal weight

- Fetal examination findings of:

o Increased incidence of short thoracolumbar ribs (a variation) at the $1,000 \mathrm{mg} / \mathrm{kg} /$ day dose

o Increased incidence in the number of supernumerary sites, or ossification sites, in the skull at the $1,000 \mathrm{mg} / \mathrm{kg} / \mathrm{day}$ dose

Under the conditions of this prenatal study, NTP's draft conclusion was:

- Equivocal evidence of developmental toxicity of DMAE in Hsd:Sprague Dawley rats in the absence of overt maternal toxicity based on increased incidences of:

o Short thoracolumbar ribs

o Supernumerary sites in the skull

There were no clarifying questions or comments about the presentation.

\section{C.8.2. Peer Review Comments and Panel Discussion}

\section{C.8.2.1. First Reviewer - Dr. Kimberley Treinen}

Dr. Treinen commented that the study was well conducted and met the standard for this type of study. She wondered why the absent innominate artery in the high dose group was not considered a finding, even though it was statistically different from controls and was present across multiple litters. When combined with short innominate arteries, it potentially looked like a 
dose-related effect. Dr. Hoberman commented that the absent innominate artery is a very common variation. However, he added that it and other similar variations do seem to indicate a perturbation in the system and should be investigated.

Dr. Treinen recommended breaking down the historical controls rather than lumping them together.

Dr. Sutherland noted that the absent innominate artery is an extremely common finding and therefore was not included as a potential toxicity endpoint.

\section{C.8.2.2. Second Reviewer - Dr. Mary Alice Smith}

Dr. Smith thought that the maternal death in the $1,000 \mathrm{mg} / \mathrm{kg} /$ day dose group raised a question and recommended adding more historical control data in the report. She remarked that there was not a lot of evidence for dose-related outcomes in this study. In addition, Dr. Smith cautioned against concluding that there were no brain effects and recommended qualifying the statement by indicating that there were no lesions noted in the brain because functional outcomes were not evaluated. Dr. Smith said that it should be made clear that there were no structural changes in the brain.

Dr. Sutherland responded to Dr. Smith:

- More historical control data would be helpful.

- NTP only looked for structural changes in the brain. NTP will ensure that it is clear that there were no structural changes in the brain in the revised report.

- Individual data tables were available, but NTP needs to consider how to make them easier to access.

- The primary report focused on bringing forward positive findings; therefore, negative findings were not highlighted. She mentioned that this distinction would be clarified in the report.

\section{C.8.2.3. Panel Discussion}

Dr. Roberts indicated that the innominate artery finding should have received more attention in the report. Dr. Sutherland asked if she was suggesting more detail in the discussion or an addition to the conclusion. Dr. Roberts responded both.

\section{C.8.3. Vote on NTP Conclusion}

Dr. Daston proposed adding a third bullet to the draft NTP conclusion to read "increased incidence of absent innominate artery." He called for a motion to add the bullet to the NTP conclusion. Dr. Treinen so moved and Dr. Smith seconded. Dr. Daston called for a vote on the conclusion, including the addition. The panel voted unanimously ( 5 yes, 0 no, 0 abstentions) to approve the conclusion with the addition.

\section{C.9. Closing Remarks on the Draft Reports}

Dr. Daston welcomed additional panel comments on the overall organization of the reports. Dr. Hoberman suggested clarifying the definition of the term "natural death" used throughout the reports. 
Dr. Sutherland noted that they would revise the term to "found dead" in the reports.

Dr. Treinen recommended that litter data, as well as individual data, be added to the reports or compiled as a stand-alone report to assist with understanding the rate of resorptions and other important fetal findings. Dr. Hoberman added that it was standard to have that type of information in a toxicology report.

Dr. Blystone remarked that NTP could explore adding some of the selected endpoints in an appendix.

Dr. Roberts appreciated having the pharmacokinetic information in the report along with its relevance to humans. She added that the value of including the NOEL eliminates the possibility of other researchers calculating their own NOEL based on the data in the report.

Closing the meeting, Dr. Maull thanked all the peer review panelists.

Dr. Daston added his thanks to NTP staff and the panel members for their efforts.

Dr. Daston adjourned the meeting at 11:22 a.m. EDT on July 31, 2019.

\section{C.10. Approval of the Peer Review Report by the Chair of the Peer Review Panel}

This peer review report has been read and approved by the chair of the July 31, 2019, Peer Review of the Draft NTP Developmental and Reproductive Toxicity Technical Reports on the Prenatal Development Studies of Tris(chloropropyl) Phosphate, 4-Methylcyclohexanemethanol, Vinpocetine, and Dimethylaminoethanol Bitartrate.

George Daston, Ph.D.

Peer Review Panel Chair

Date: July 31, 2019 


\section{Appendix D. Supplemental Files}

The following supplemental files are available at https://dx.doi.org/10.22427/NTP-DATADART-04.

\section{D.1. Prenatal Developmental Toxicity Dose Range-finding Study - Rats}

I01 - Animal Removal Summary

I03 - Growth Curve

I04 - Mean Body Weights and Survival

I04G - Mean Body Weight Gain

I05 - Clinical Observations Summary

I06 - Mean Feed Consumption

PA46 - Gross Pathology Summary

R09 - Uterine Content Summary

R10 - Fetal Defects

R12 - Placental Findings

\section{D.2. Prenatal Developmental Toxicity Dose Range-finding Individual Animal Data - Rats}

Individual Animal Body Weight Data

Individual Animal Clinical Observations Data

Individual Animal Consumption Data

Individual Animal Gross Pathology Data

Individual Animal Removal Reasons

Individual Animal Teratology Dam Data

Individual Animal Teratology Fetal Weight Data

Individual Animal Teratology Implant Findings Data 


\section{D.3. Prenatal Developmental Toxicity Study - Rats}

I01 - Animal Removal Summary

I03 - Growth Curve

I04 - Mean Body Weights and Survival

I04G - Mean Body Weight Gain

I05 - Clinical Observations Summary

I06 - Mean Feed Consumption

PA06 - Organ Weights Summary

PA46 - Gross Pathology Summary

R09 - Uterine Content Summary

R10 - Fetal Defects

R11 - Fetal Defect Summary

R12 - Placental Findings

R13 - Fetal Defect Cross Reference Summary

D.4. Prenatal Developmental Toxicity Individual Animal Data - Rats

Individual Animal Body Weight Data

Individual Animal Clinical Observations Data

Individual Animal Consumption Data

Individual Animal Gross Pathology Data

Individual Animal Organ Weight Data

Individual Animal Removal Reasons

Individual Animal Teratology Dam Data

Individual Animal Teratology Fetal Weight Data

Individual Animal Teratology Implant Findings Data 


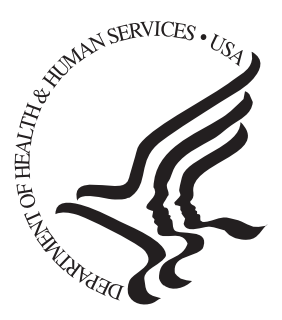

\section{National Toxicology Program}

NTP Central Data Management, MD EC-03

National Institute of Environmental Health Sciences

P.O. Box 12233

Research Triangle Park, NC 27709

http://ntp.niehs.nih.gov 